Old Dominion University

ODU Digital Commons

Engineering Management \& Systems

Engineering Management \& Systems

Engineering Theses \& Dissertations

Engineering

Summer 2013

\title{
The RQ-Tech Methodology: A New Paradigm for Conceptualizing Strategic Enterprise Architectures
}

Christine Ann Hoyland

Old Dominion University

Follow this and additional works at: https://digitalcommons.odu.edu/emse_etds

Part of the Operational Research Commons, and the Systems Engineering Commons

\section{Recommended Citation}

Hoyland, Christine A.. "The RQ-Tech Methodology: A New Paradigm for Conceptualizing Strategic Enterprise Architectures" (2013). Doctor of Philosophy (PhD), Dissertation, Engineering Management \& Systems Engineering, Old Dominion University, DOI: 10.25777/19tt-7g03

https://digitalcommons.odu.edu/emse_etds/87

This Dissertation is brought to you for free and open access by the Engineering Management \& Systems Engineering at ODU Digital Commons. It has been accepted for inclusion in Engineering Management \& Systems Engineering Theses \& Dissertations by an authorized administrator of ODU Digital Commons. For more information, please contact digitalcommons@odu.edu. 
THE RQ-TECH METHODOLOGY: A NEW PARADIGM FOR

CONCEPTUALIZING STRATEGIC ENTERPRISE ARCHITECTURES

$$
\text { by }
$$

Christine Ann Hoyland

B.S.M.E May 1983, California State University at Fresno

M.S.S.E. May 1999, Virginia Polytechnic Institute

A Dissertation Submitted to the Faculty of Old Dominion University in Partial Fulfillment of the Requirements for the Degree of

DOCTOR OF PHILOSOPHY

ENGINEERING MANAGEMENT

OLD DOMINION UNIVERSITY

August 2013

Approved by:

Charles Keating (Director)

Kevin MacG Adams (Member)

Andreas Tolk (Member)

Ređít Únal (Member)

Li Xu (Member) 


\author{
ABSTRACT \\ THE RQ-TECH METHODOLOGY: A NEW PARADIGM FOR \\ CONCEPTUALIZING STRATEGIC ENTERPRISE ARCHITECTURES \\ Christine A. Hoyland \\ Old Dominion University, 2013 \\ Director: Charles Keating, Ph.D.
}

The purpose of this research is to develop and apply a system-theoretic based methodology and corresponding model for Enterprise Architecture development. Enterprise Architectures can assist managers by illustrating the systemic relationships within an organization and the impact changes to the organization could make. Unfortunately, today's modeling practices are proprietary, time-consuming, and generally ineffective as tools for understanding the consequences of strategic-level planning decisions across all levels of the enterprise. This research supports the conclusion that system-specific solutions produce islands of technology and can be prevented by employing better enterprise change planning.

This research combined the practice of Enterprise Architectures with a modern perspective grounded in Systems Theory and the theory regarding the computer science-oriented Semantic Web to present a distinctive methodology for developing models. A review of literature in all three areas provided an illustration of the overlap common to all three domains. It provided support for critical thinking concerning how to enrich the Enterprise Architecture practice. This research was conducted to answer to two primary questions. The first research question investigated the most significant factors to consider when translating authoritative text and rich pictures into semantic models. The second research question qualitatively measured the extent to which models aligned to important organizational guidance are useful for representing 
the organization as a whole.

Reusable Quality Technical Architectures (RQ-Tech) is the methodology developed from this research. It demonstrates that a complex system of systems organization that must creatively respond to a variety of events can be holistically represented using a dynamic model. RQ-Tech techniques provide ways to map and link the multitudes of scope-level authoritative business documents so that together they can effectively represent the nature and essence of the organization as one organic structure. The marriage of authorized enterprise documentation and the Semantic Web produces a model of the holistic enterprise. This model had previously only been experienced at a tacit level by those exceptionally well-trained in the depth and breadth of organizational culture, supporting laws, policies and related publications. This research effort provides the vision that encourages a paradigm shift away from the mechanistic approach toward organizational change to analogy of a socially connected, interdependent enterprise. New horizons for using the common language of the Semantic Web to capture an understanding of the many interactive systems of the enterprise are substantiated. The research concludes with identification of future research themes prompted by this investigation. 


\section{DEDICATION}

This thesis is dedicated to my family; Wendy, Michael, and Shannon, and my best friend, Jeff, for their constant support, love, and understanding throughout this learning process. This is also in memory of my friend, Ed Mellon, who never failed to show interest in my Ph.D. journey even while he was battling cancer. 


\section{ACKNOWLEDGMENTS}

I extend many, many thanks for the untiring efforts of my Ph.D. advisor Dr. Charles Keating, who always inspires me with his enthusiasm for new ideas; my committee members Dr. Andreas Tolk, Dr. Vickie Parsons, and Dr. Li Xu, for their motivation, patience and guidance; and special appreciation to my mentor and long-time friend and teacher, Dr. Kevin MacG. Adams. Please know you all have my highest esteem and unending gratitude 


\section{GLOSSARY}

\begin{tabular}{ll} 
BEA & $\begin{array}{l}\text { Business Enterprise Architecture } \\
\text { CDD }\end{array}$ \\
C4ISR & $\begin{array}{l}\text { Capability definition document } \\
\text { and Reconnaissance }\end{array}$ \\
DARPA & Defense Advanced Research Projects Agency \\
DAML & DARPA Agent Markup Language \\
DAS & Defense Acquisition Systems \\
DoD & Department of Defense \\
DoDAF & DoD Architecture Framework \\
DOC & Department of Commerce \\
DON & Department of the Navy \\
DTIC & Defense Technical Information Center \\
EA & Enterprise Architecture \\
ER & entity-relationship \\
XML & Extensible Markup Language \\
FOAF & Friend of a Friend \\
GAO & Government Accountability Office \\
GERAM & Generalized Enterprise Reference Architecture and Methodology \\
HTML & HyperText Markup Language \\
ICOM & input, controls, output, mechanisms \\
IDEF0 & Integration DEFinition for function modeling \\
IFIP & International Federation of Information Processing \\
IT & information technology \\
\hline
\end{tabular}




\begin{tabular}{|c|c|}
\hline JEL & Joint Electronic Library \\
\hline JFSC & Joint Force Staff College \\
\hline KR & knowledge representation \\
\hline MBSE & Model-based Systems Engineering \\
\hline $\mathrm{MCF}$ & Meta Content Framework \\
\hline MDMP & military decision making process \\
\hline MODAF & Ministry of Defense Architecture Framework \\
\hline NCSoSE & National Centers for SoSE \\
\hline NIST & National Institute of Standards and Technology \\
\hline NECC & Net-enabled Command Capability \\
\hline ODU & Old Dominion University \\
\hline $\mathrm{O}-\mathrm{O}$ & object-oriented \\
\hline OIL & Ontology Inference Layer \\
\hline OMG & Object Management Group \\
\hline OSD & Office of the Secretary of Defense \\
\hline OWL & Web Ontology Language \\
\hline PERA & Purdue Enterprise Reference Architecture \\
\hline RDF & Research Description Framework \\
\hline RDFS & RDF Schema \\
\hline RQ-Tech & Reusable Quality Technical Architecture \\
\hline SADT & Structured Analysis and Design Technique \\
\hline SE & Systems Engineering \\
\hline SME & subject matter expert \\
\hline SOA & Service Oriented Architectures \\
\hline
\end{tabular}




$\begin{array}{ll}\text { SoS } & \text { System of Systems } \\ \text { SoSE } & \text { System of Systems Engineering } \\ \text { SSM } & \text { Soft Systems Methodology } \\ \text { STS } & \text { Socio-technical Systems Theory } \\ \text { UEMO } & \text { Unified Enterprise Modeling Ontology } \\ \text { UML } & \text { Unified Modeling Language } \\ \text { URI } & \text { Uniform Resource Identifier } \\ \text { UST } & \text { Unbounded Systems Thinking } \\ \text { W3C } & \text { World Wide Web Consortium } \\ \text { WBS } & \text { work breakdown structure }\end{array}$


TABLE OF CONTENTS

Page

LIST OF TABLES

xii

LIST OF FIGURES xiii

Chapter

1. PURPOSE AND OBJECTIVES

1.1 INTRODUCTION

1.2 BACKGROUND.

1.3 PURPOSE OF THE RESEARCH.

1.4 DEFICIENCIES IN CURRENT TECHNIQUES...........................................

1.5 PRIMARY RESEARCH QUESTIONS.......................................................... 6

1.6 LIMITATIONS AND DELIMITATIONS................................................. $\quad 8$

1.7 SIGNIFICANT ORIGINAL CONTRIBUTIONS.............................................. 9

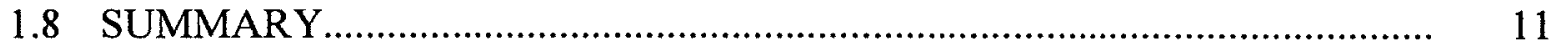

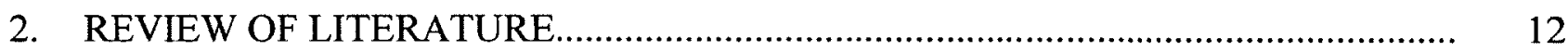

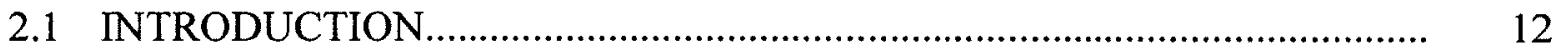

2.2 MAJOR LITERATURE STREAMS ……................................................ 13

2.3 SYSTEMS THEORY ........................................................................... 14

2.4 ENTERPRISE ARCHITECTURES ………………........................................ 29

2.5 SEMANTIC WEB......................................................................................... 42

2.6 SUMMARY OF ENTERPRISE ARCHITECTURE CRITIQUES AND GAPS.

3. RESEARCH DESIGN ....................................................................................... 55

3.1 HIGH-LEVEL RESEARCH DESIGN ....................................................... 55

3.2 SPECIFIC RQ-TECH METHODOLOGY RESEARCH DESIGN.................. 65

3.3 STRATEGIES FOR RIGOROUS RESEARCH DESIGN.............................. 74

3.4 CONSIDERATIONS OF VALIDITY AND RELIABILITY IN RESEARCH DESIGN

3.5 RQ-TECH RESEARCH DESIGN SUMMARY ........................................... $\quad 80$

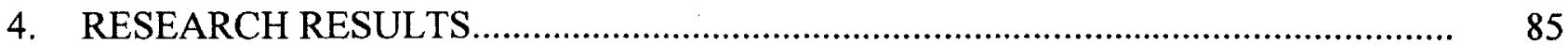

4.1 RESEARCH QUESTION ONE.................................................................. 85

4.2 RESEARCH QUESTION TWO.............................................................. 98

4.3 RESEARCH FINDINGS SUMMARY ....................................................... 112 
5. THEORETICAL CONTRIBUTIONS, IMPLICATIONS, FUTURE INITIATIVES.... 114

$5.1 \quad$ INTRODUCTION................................................................................. 114

5.2 THEORETICAL CONTRIBUTIONS AND IMPLICATIONS........................ 115

5.3 METHODOLOGICAL CONTRIBUTIONS AND IMPLICATIONS............... 123

5.4 CONTRIBUTIONS IN THE FORM OF NEW METHODS AND PRACTICAL APPLICATIONS................................................................ 127

5.5 FUTURE INITIATIVES AND RESEARCH QUESTIONS............................ 133

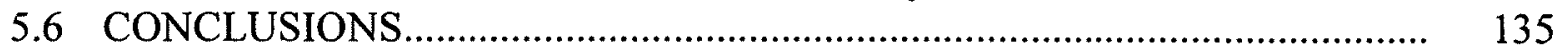

APPENDICES

A. JOINT PUBLICATION STATUS............................................................. 138

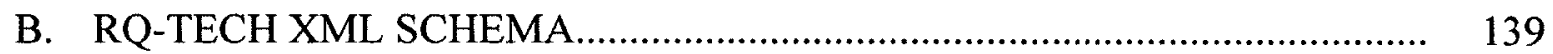

C. METHOD FOR DOCUMENT-PARSING ............................................... 145

D. RQ-TECH SPREADSHEET WORKBOOK SAMPLE .................................... 149

E. RQ-TECH PROTOTYPE (SCREEN SHOTS)............................................. 153

F. LOGISTICS PLANNING SCENARIO....................................................... 157

G. USER FEEDBACK SURVEY ............................................................... 159

H. USER FEEDBACK SURVEY RESULTS ...................................................... 163

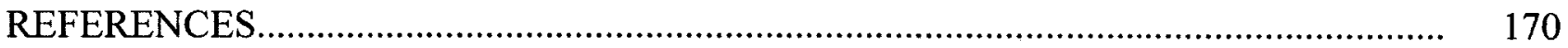

VITAA 


\section{LIST OF TABLES}

Table

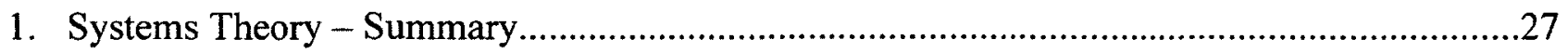

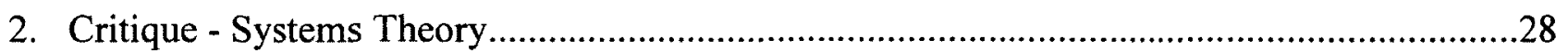

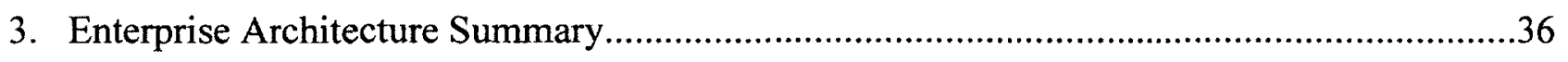

4. Critique - Enterprise Architectures.......................................................................41

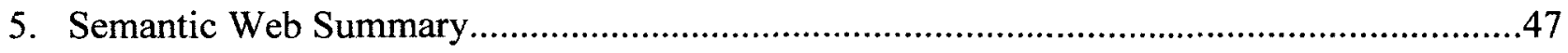

6. Critique - Semantic Web for Developing EAs........................................................51

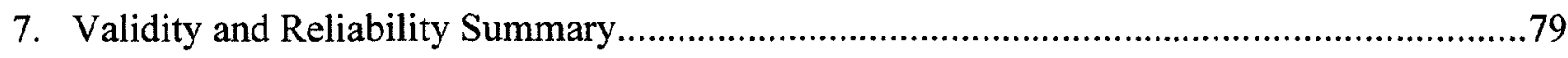

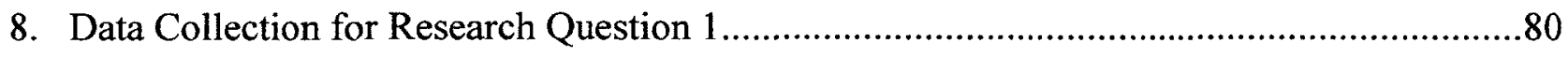

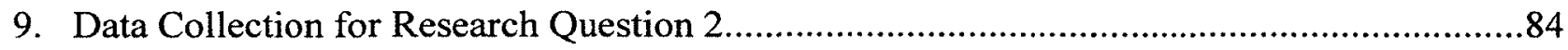

10. Joint Publication 4.0 - Parsing Results.............................................................. 92 


\section{LIST OF FIGURES}

$\begin{array}{ll}\text { Figure } & \text { Page }\end{array}$

1. Gap in Approach to Enterprise Architectures..........................................................

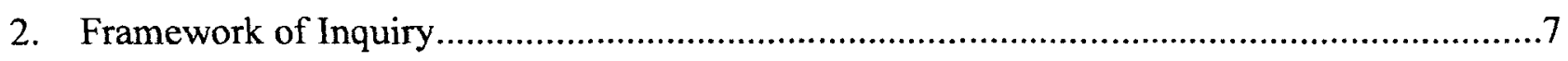

3. Major Research Literature Streams................................................................... 13

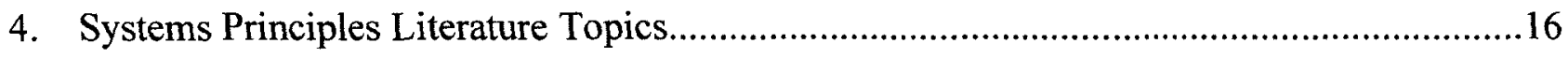

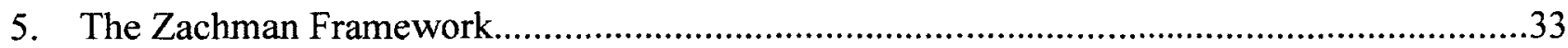

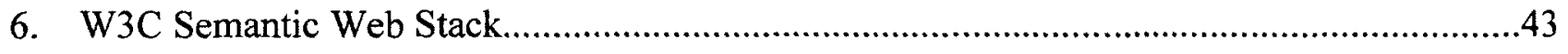

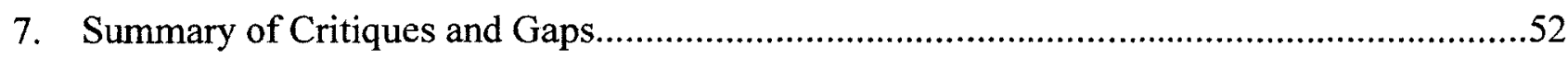

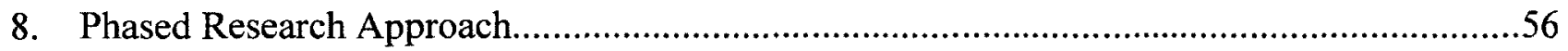

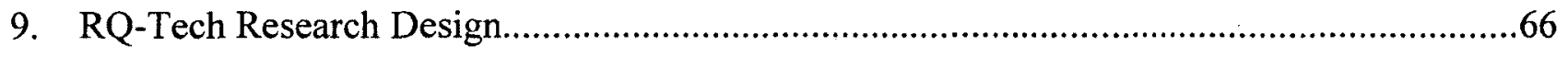

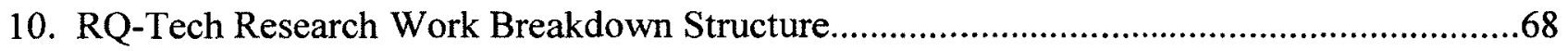

11. RQ-Tech WBS for the Naturalistic Method ...........................................................75

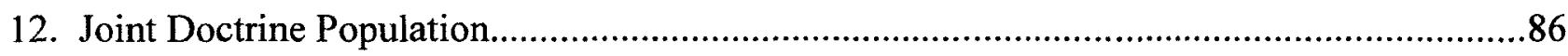

13. JP 4-0 Class Composition Results..................................................................94

14. COCOM JP 4-0 Logistics Communication Profile ................................................96

15. RQ-Tech Organization Representation......................................................... 100

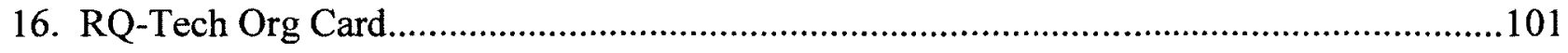

17. RQ-Tech Current Project Sequence ................................................................ 106

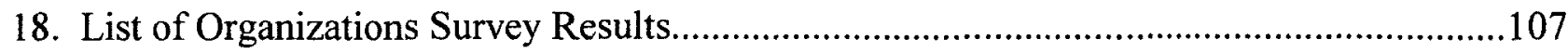

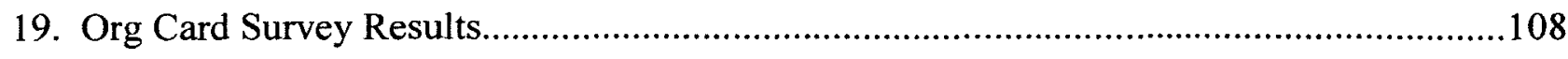

20. Value of RQ-Tech Survey Results............................................................... 109 
Figure

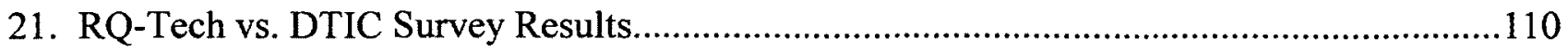

22. RQ-Tech Prototype Recommedation Survey Results................................................110

23. Enterprise Architecture Capability Comparisons..................................................137 


\section{CHAPTER 1 - PURPOSE AND OBJECTIVES}

\section{Introduction}

While technology is changing at an astonishing rate, the practices regarding how technology projects are defined and managed have not changed in a meaningful way since the 1990s. The purpose of this chapter is to identify the context surrounding the use of enterprise architectures (EAs) as the method for managing organizational change, and the issues involved when the practice of EA is applied to organizations that are complex system of systems (SoS) that provide unique and innovative services to their customers. The objectives of this research are defined, and the purpose of the research is allocated to two research questions. Deficiencies in current EA modeling techniques are listed and discussed, and the significance of performing this research is outlined. Limitations and delimitations of the research are detailed and the potential for this research to make theoretical contributions to the EA body of knowledge is summarized.

\section{Background}

Architectures within the U.S Department of Defense (DoD) are created for a number of reasons. From a compliance perspective, the DoD's development of architectures is compelled by law and policy (i.e., Clinger-Cohen Act, Office of Management and Budget (OMB) Circular A-130). From a practical perspective, experience has demonstrated that the management of large organizations employing sophisticated systems and technologies in pursuit of Joint missions demands a structured, repeatable method for evaluating investments and investment alternatives, as well as the ability to effectively implement organizational change, create new systems, and 
deploy new technologies (DoD, 2007). In other words, EAs are the blueprints used to understand and change organizations:

....the rules and standards and systems life cycle information to optimize and maintain the environment which the agency wishes to create and maintain. (OMB, 2000, p. 14)

However, today's Defense Acquisition Systems (DAS) project failure-rate statistics continue to disappoint and frustrate DoD resource sponsors in Congress. The Senate Armed Services Committee chairman, Senator Carl Levin, stated:

Over the last eight years the defense acquisition process has deteriorated dramatically. Ninety-five percent of the Pentagon's major weapons programs are running two years behind schedule and $\$ 300$ billion over budget. (Levin, 2009, p. 1)

Many of the core concepts regarding DoD's EAs were developed in response to the software crisis that was observed between 1965 and 1985 (Gibbs, 1994). Major capabilities of the DoD organization continue to be modeled in the same way as they were in the mid-century. These EAs are regarded as separate functional systems that are assumed to be repetitive, like the activities carried out on a factory assembly line. By law, military systems'as-is architecture views must be constructed to illustrate current processes. However, the modern warfighter's challenges range from peacekeeping duties in Afghanistan, to rescuing hostages from Somali pirates, to distributing aid to earthquake survivors in Haiti, and to post-hurricane clean-up in New Orleans. Some have characterized this as the world of the unexpected, and this work cannot be considered completely routine (Taylor \& Felten, 1993). In addition, the modern warfighter's environment is composed of a plethora of communication technologies including the Global Information Grid (GIG) (OASD, 2007). The standards that govern access to global information are in a state of flux as modern technology initiatives, such as Service Oriented Architectures 
(SOA), promise to transition the DoD to a more intelligent web structure using the Semantic Web (Felhi \& Akaichi, 2012; W3C, 2004a). The root metaphor of industrial automation may no longer be representative of the military user's enterprise. This metaphor also may not appreciate the emergent nature of the context within which the DoD enterprise must exist and contend. It is reasonable to think that the resultant EAs based on this mechanistic image may not be sufficiently useful for characterizing this complex organization's environment and modern organizational challenges.

\section{Purpose of the Research}

The purpose of this research is to develop and apply a system-theoretic based

methodology and corresponding model for EA development. Key elements within this purpose are:

- Systems-theoretic; meaning grounded in the systems principles that comprise an open systems perspective with emphasis on the circular organization of living systems, and their resistance to change (Jackson, 2003).

- Methodology; that is, a framework that embodies nine critical attributes: transportability, theoretical and philosophical grounding, guide to action, significance, consistency, adaptability, neutrality, multiple utility, and rigor (Adams \& Keating, 2011b).

- Models for EA development; meaning they can assist managers, to appreciate the systemic relationships of their business and the impact their decisions can make, and to change their mental models before business improvement can become possible (Jackson, 2003).

This study underscores the notion that a holistic view of the DoD enterprise currently exists only in the volumes of text and rich pictures that make up the Joint doctrine publications that warfighters are trained to execute. However, the corresponding holistic modeling paradigm depicting the essence of these strategic-level documents as useful EA blueprints does not exist today. 


\section{Deficiencies in Current Enterprise Architecture Modeling Techniques}

Both the Zachman Framework (Zachman, 1987) and the Purdue Enterprise Reference Architecture (PERA) frameworks (Williams, Rathwell, \& Li, 2001) were developed to evaluate the many facets of EAs in a modeling-language agnostic fashion. These frameworks are often used to critically assess and rate EA modeling methods and languages. A state-of-the-field literature search found that no product built by major vendors today claims to satisfy either Zachman's or PERA's criteria in order to be designated as capable of the modeling uppermost strategic layer of a large, complex enterprise. Figure 1 illustrates the gap at the conceptual level and how this may affect efforts at the logical level when constructing EAs.

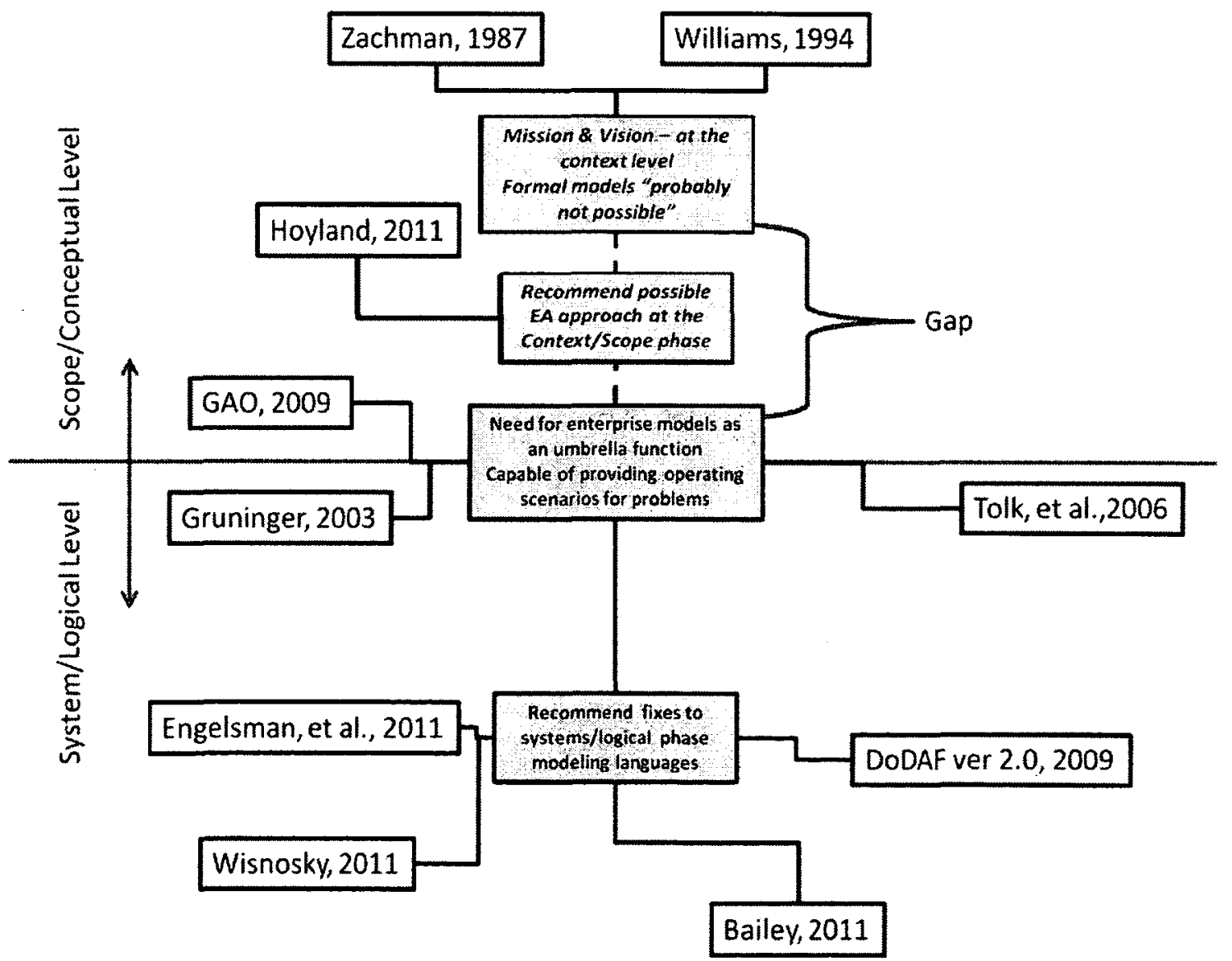

Figure 1: Gap in Approach to Enterprise Architectures 
At the strategic level, the DoD publishes doctrine in an authoritative set of Joint publications and other DoD policy and directives (text), to guide strategic and operational planning. These publications include various templates and diagrams (rich pictures) to convey Joint military organizations and events. Joint doctrine takes precedence over all Service-specific (Army, Navy, Air Force, Marine Corps) doctrine (CJCS, 1996). Therefore it would be logical to posit that if an EA viewpoint at the conceptual level could represent Joint doctrine and associated national scope-level documents, military leadership would be able to critically identify and analyze their capability needs for planning and executing military missions.

Studies (GAO, 2009; Gruninger, 2003; Tolk, 2006;Vernadat, 2002) have identified the need for a flexible configuration of enterprise models as an umbrella function capable of providing operating scenarios for problems. However, most discussions on how these EAs should be revamped to close the gap are instead rigidly focused on improving the state of defining and developing views of technology insertion at the tactical system-level (Bailey, 2011; DoD, 2009; Engelsman, Quartel, Jonkers, \& van Sinderenb, 2010; Wisnosky, 2011). It will be posited in the literature review (Chapter 2) that this mismatch of hierarchical concepts is responsible for incomplete and inaccurate views of strategic requirements from the SoS perspective. As a significant original contribution to the body of knowledge, this research offers an EA approach, namely Reusable Quality Technical Architectures (RQ-Tech), created to close the gap in understanding what is needed to visualize and understand the strategic mission and vision of complex organizations that must function as SoS (Hoyland, 2011).

The concept of the RQ-Tech methodology was sparked by frustrations experienced during the Net-Enabled Command and Control (NECC) project. The RQ-Tech methodology ideas emerged as a way to remedy the difficulties experienced while developing a requirements 
document for new technology that could be used by the Joint forces. NECC was canceled because it did not show significant progress toward completing major DAS milestones. Once the RQ-Tech idea matured to the level where it could be documented, this researcher presented it to supervisors at a Department of the Navy (DON) systems engineering command where she was

employed. The command declined to pursue development of the RQ-Tech methodology claiming inadequate funds for new projects. This researcher continued to develop the idea without DON assistance to the point where it was accepted as a topic for discussion during the Joint Working IEEE/IFIP Conference on Software Architecture, 2009 and European Conference on Software Architecture (Hoyland \& Adams, 2009). The RQ-Tech concept was later described in application documents submitted by this researcher for acceptance to the National Centers for System of Systems Engineering (NCSOSE) graduate-level program at Old Dominion University (ODU).

\section{Primary Research Questions}

The need for an integrated modeling analogy to characterize the construction of EA models at the strategic level prompts the framework of inquiry for this study, as shown in Figure 2. The application of a number of basic systems principles, studied within a structured systemic framework for EAs, provides insight into the root cause for failure to achieve enterprise change management. It has been noted that these failures even occur on DoD acquisition projects that strictly adhere to a systems engineering life cycle approach for managing DoD projects (Kovacic, Sousa-Poza, \& Keating, 2008). 


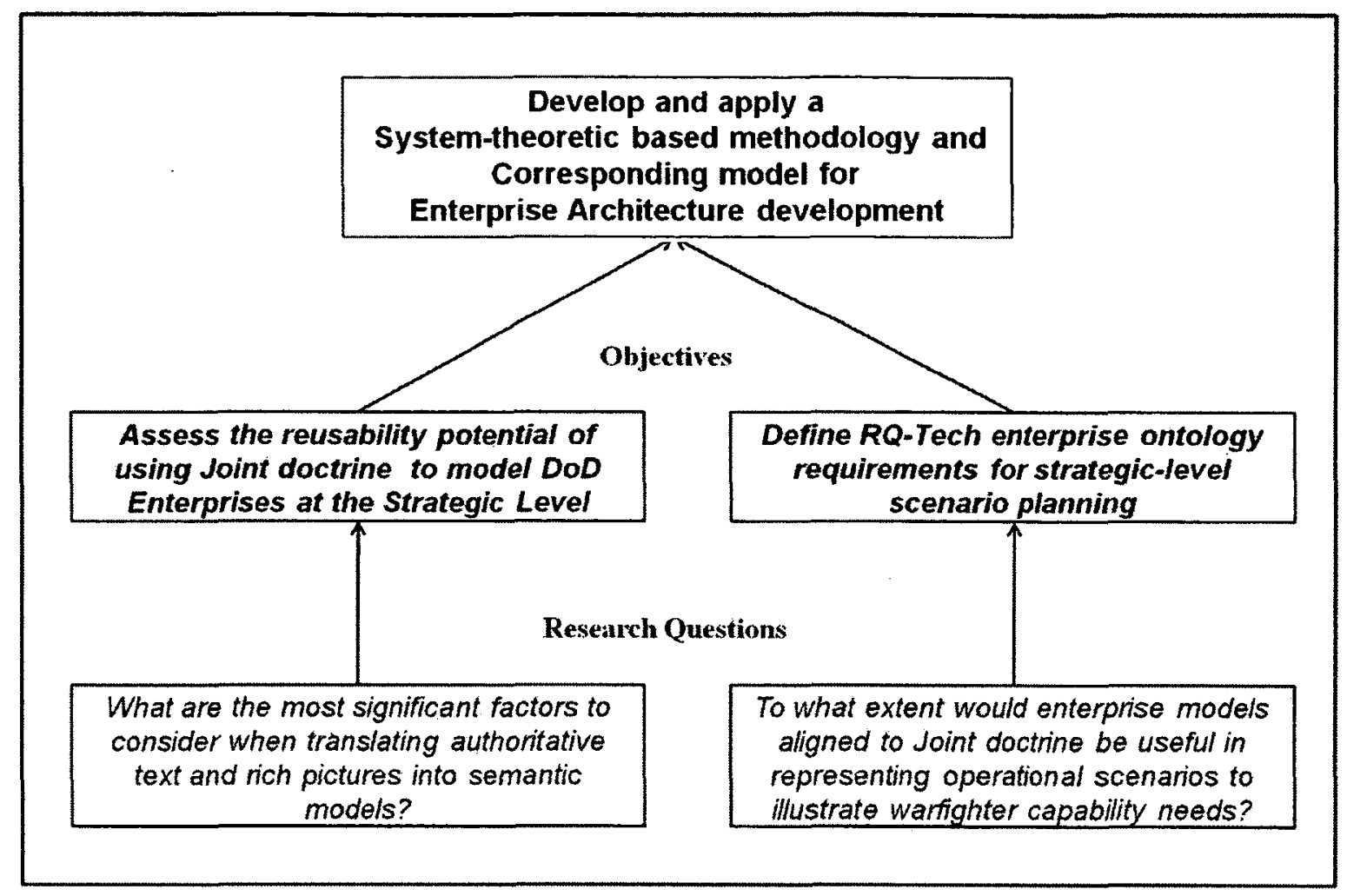

Figure 2: Framework of Inquiry

To address the purpose of this study, the research builds upon the existing foundation of Systems Theory and focuses on answering the first research question:

- What are the most significant factors to consider when translating authoritative text and rich pictures into semantic models?

A unique RQ-Tech ontology developed specifically for this task provides the basis for how samples of Joint doctrine publications are categorized and validated according to the World Wide Web Consortium (W3C) XML (Extensible Markup Language) standards (W3C, 2004c). As developed in Chapter 3, this research uses qualitative methods and the content analysis research methodology to arrive at the objective of this research (Cresswell, 2003; Cresswell \& Plano Clark, 2011; Leedy \& Ormrod, 2001; Patton, 2002), which is to assess the reusability potential of Joint doctrine to model DoD enterprises at the strategic level. 
The second research question asks:

- To what extent are enterprise models aligned to Joint doctrine useful in representing operational scenarios to illustrate warfighter capability needs?

Considering the authoritative nature of Joint doctrine, it appears that if representations (i.e., models) could be constructed from these documents, they would have the potential to be uniformly accepted as descriptive of the decision process followed by members of the enterprise (Pomerol, Brézillon, \& Pasquier, 2002). As described in Chapter 3, this research capitalizes on systems principles as the foundation for a theoretical framework used to construct a research design for investigating a prototype RQ-Tech enterprise methodology. According to qualitative metrics documented in Chapter 4, RQ-Tech is developed as a method for logically and graphically conveying capability gaps uncovered during strategy sessions with leaders preparing for changes to a complex SoS organization.

\section{Limitations and Delimitations}

While there are other organizations that may be described as a complex system of systems, the focus of this research is limited to DoD projects. The Joint Electronic Library (JEL) contains the set of documents known as Joint doctrine. This authoritative set of documents describes how the military services of the United States interact to respond to any crisis, local or worldwide. As such, this set of guidelines represents a whole complex organization that describes itself as composed of unique military Services. Other complex organizations, for example, local governments, or healthcare facilities, are organized and regulated in different ways. While this research may be extended to these other organizations in the future, for the purpose of this research, the boundary limitation is restricted to Joint doctrine, and therefore results are limited to Joint doctrine applications. 
While the RQ-Tech methodology utilizes components of the Semantic Web, this research is not intent on developing computer applications beyond the prototype stage of sophistication. This research endeavors to illustrate how current Semantic Web technology may be utilized. While current technology is available that could automate several of the functions described by this document, developing these functions is beyond the scope of this research.

\section{Significant Original Contributions}

Systems Theory-based thinking offers ways to frame complex SoS problems. An effective problem-solving solution for complex system issues requires an approach capable of addressing the uncertain, dynamic behavior inherent in complex problems (Keating, Peterson, \& Rabadi, 2003). This research exploits systems principles as rungs on the philosophical ladder used to heighten Systems Theory concerning EAs. Specific applicable principles include holism, emergence, complementarity, framing, hierarchy, self-organization, requisite parsimony, satisficing and sub-optimization. This study shows that aspects of the disciplined, but hard systems methodologies of systems engineering and the Semantic Web can be augmented with tenets from Soft Systems Methodology, Socio-technical Systems Theory, and Unbounded Systems Theory concerned with human organizations and their need for flexibility and adaptability. RQ-Tech is a methodology that enables increased understanding of complex systems through use of Semantic Web standards. It was developed for modeling the essence of the strategic, conceptual and doctrinal layer of the organization and by revealing a comprehensive array of decision alternatives in an easily understandable view, all while specifically hyperlinked to its provenance in doctrine. RQ-Tech builds on the mature W3C standard for Friend-of-a-friend (FOAF) (Graves, Constabaris, \& Brickley, 2007) that has been 
recognized as a formal yet light-weight, Semantic Web ontology. When the RQ-Tech extension of the FOAF ontology is applied to a sample of Joint doctrine, the model of a diverse and creative organization begins to takes shape. In addition, once the relational data and organizational concepts that are written in Joint doctrine are organized using the RQ-Tech methodology, this data remains available for reuse and recombination in an infinite number of illustrations of organizational problems, best practices, or better options for the future. Using the RQ-Tech model to build a scenario provides the answer to the second research question concerning the potential usefulness of this research.

RQ-Tech provides a top-down approach for understanding complex human organizations and the context of their problems, and offers both a methodology and a new tool set for evaluating problem situations in complex organizations. RQ-Tech EAs contribute to the conceptual understanding of strategic business objectives and essential information flow for hard-to-conceptualize complex enterprise organizations that must provide creative and innovative services. The RQ-Tech methodology succeeds at this while also demonstrating mandatory compliance with regulatory and procedural authoritative guidance regarding EAs.

This research offers a simple yet effective way to link doctrine and technology. When doctrine is modeled as a reusable framework, it provides value as a dynamic and meaningful way for Combatant Commanders to articulate their needs to acquisition project sponsors and engineers. Instead of building new EAs for each DAS project, the RQ-Tech methodology jumpstarts projects by offering the framework of the whole digital Joint doctrine library as the scaffolding for portraying the context around problems that affect warfighters as they work to carry out their missions. Linkages to connected organizations and their doctrinal requirements 
will be visible such that the environment surrounding the SoS-based problems can be holistically evaluated as potential solutions are offered and analyzed.

Developed and tested using XML, RQ-Tech defines the methodology for constructing open, reusable EAs that once built, will have the ability to interoperate with other Semantic Web-capable hierarchical constructs. As such, there is a real potential for RQ-Tech to be regarded as an extension of standard technology models without requiring further translation.

\section{Summary}

This chapter conveys the purpose, objectives and research questions of this study. It also provides a preview of how these topics and goals have been presented in published works by various researchers in the literature review chapter. This chapter briefly acknowledges the methods of research used indicating that analysis was conducted using accepted qualitative methods. While the original contributions of this research have been suggested here, a more thorough analysis of the theoretical contributions to the existing body of knowledge concerning organizational EAs will be provided in the concluding chapter. 


\section{CHAPTER 2 - REVIEW OF LITERATURE}

\section{Introduction}

This chapter discusses aspects of the research purpose through a review of literature. The literature schema shows themes in the major areas of Systems Theory, Enterprise Architectures (EAs), and the Semantic Web that are pertinent to the study of modern organizational EAs. These themes are presented, synthesized, critiqued and summarized. State-of-the-art findings are presented and gaps in literature are noted.

The purpose of this section is to utilize literature to contribute to a more complete understanding of how organizations approach change, present their requirements for change in the form of EAs, and manage the portion of their investment portfolios allocated to acquiring new technology and making changes to the enterprise. This research makes use of three major areas integrally linked to EAs:

- Systems Theory: The framework of Systems Theory is supported by a number of laws and principles (Adams, 2011). The literature explaining systems principles, including the central, context, goal and design principles; is used in this study as a lens for characterizing large, complex enterprises composed of multiple SoS.

- EAs: The Zachman Framework (Zachman, 2011) continues to be regarded as a lexicon for understanding all types of structural static and dynamic EA models of organizations without offering prejudice regarding how these architectures are built. The language of this framework is used to define and organize a discussion of approaches to developing EAs.

- Semantic Web: Systems practitioners regard a variety of different methodologies, based on various paradigms, as useful interventions to try to resolve the problem situation (Jackson, 2003). The trend toward developing unique EA methods, tools and techniques using the layered technology architecture of Web standards are synthesized, critiqued and examined for systemic thinking gaps. 


\section{Major Literature Streams}

Figure 3 shows the three research streams arranged in a Venn diagram (Lewis, 1918). A literature review of trends in these areas reveals that there is a specific set of information in each major area that supports the other two. In this fashion Systems Theory, which is predicated on philosophy and theory, is shown to support Semantic Web methodologies in areas that are applicable to the practice of EAs. The over-lap that is common to all three constructs is the set of research that sustains the associated arguments and discoveries offered in this research.

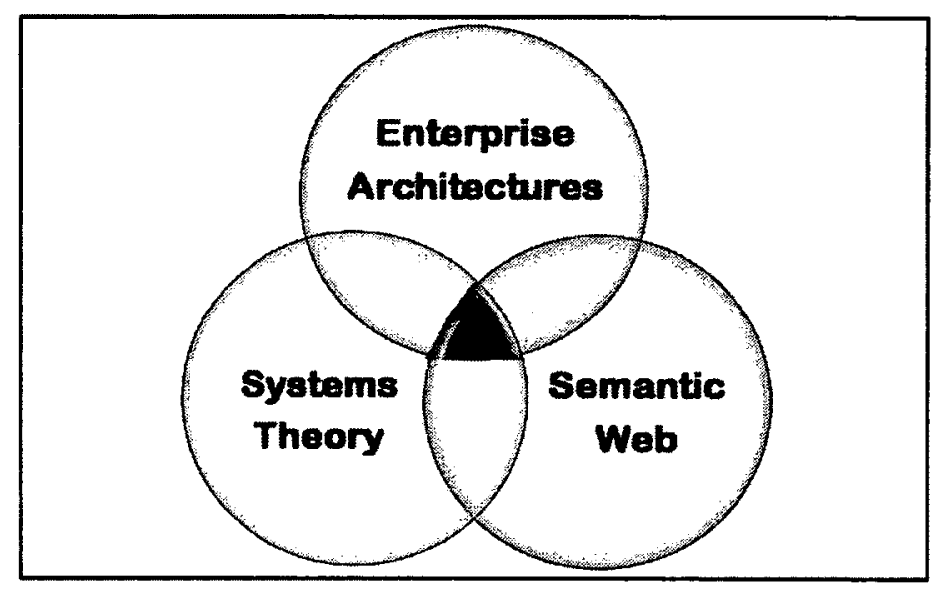

Figure 3: Major Research Literature Streams

Systems Theory has been expressed as a set of seven interrelated axioms with 42 support propositions, or systems principles (Adams, 2012; Adams, Hester, Bradley, Meyers, \& Keating, 2014). This literature also references various systems-oriented frameworks that have their roots in the sub-set of the systems literature, and appear to recommend theories or methodologies that offer increased insight into the problems under investigation. These systems principles and associated systems-oriented frameworks form a foundation for understanding and analyzing approaches to EAs and long-held assumptions regarding EA development and use.

The second major area of literature themes reviewed describes EAs, how organizations 
use them to communicate a vision of their improved organization, and how EAs are used to evaluate complex enterprise investment alternatives. The EA literature review borrows the language of the Zachman Architectural Framework (1987) to focus on current trends in EAs, including its primary purpose of defining user requirements. This review highlights the gaps and inconsistencies found in the approach to EAs as the DoD's chosen method for satisfying DAS requirements. Several tacit rules for developing EAs are closely examined.

The third major literature review area investigates the science of the Semantic Web, with a focus on how semantic systems are instrumental in influencing current systems and engineering challenges. This investigation is warranted since the DoD has chosen a federated, relational database approach to electronically archiving and sharing organizational information and EA views across the department (DoD, 2009). Also, since the Semantic Web is ubiquitous in today's culture and technology; a review of Semantic Web literature in areas common to Systems Theory and EAs turns up some unique perspectives concerning applications for the future by noted Semantic Web visionaries. Critiques regarding the state of the Semantic Web as it pertains to this research purpose are summarized.

\section{Systems Theory}

Systems experts (Keating, Peterson, et al., 2003) emphasize that framing complex systems problems involves a way of thinking, not just a prescriptive approach. Since EAs are the chosen method for modeling various views depicting organizational improvement projects, it is logical to suggest that there must be a reliance on the foundational systems philosophy and principles that inform a more sophisticated perspective of the framing process, issues, and expectations. The contention is that the strategic and operational focus of the enterprise must be 
examined and understood in order to gain insight into what the Gartner Group defines as translating business vision and strategy into effective enterprise change (Lapkin, Burke, \& Bittler, 2008, p. 2). Systems theory encompasses the underlying theoretical foundation for understanding systems (Adams, 2011, 2012;Adams et al., 2014). Systems Theory is a theoretical construct that supports the ability to think and speak a new holistic language; a language of systems, interaction and design, while systems principles support the framework for Systems Theory and systems thinking. Systems Theory serves as a bridge for interdisciplinary dialogue between autonomous areas of study as well as within the area of systems science itself (von Bertalanffy, 1995). In general systems theory, Von Bertalanffy's objective was to bring together, under one heading, the organismic science that he had observed in his work as a biologist. His desire was to use the word system to describe those principles which are common to systems in general. He writes:

There exist models, principles, and laws that apply to generalized systems or their subclasses, irrespective of their particular kind, the nature of their component elements, and the relationships or "forces" between them. It seems legitimate to ask for a theory, not of systems of a more or less special kind, but of universal principles applying to systems in general. $(1995, \mathrm{p} .32)$

For this study, a collection of several systems principles provides an organized taxonomy for evaluating the current practice of developing and using of EAs. Therefore the literature describing the systems principles of holism, emergence, complementarity, hierarchy, selforganization, requisite parsimony, satisficing, and sub-optimization are examined to appreciate the emphasis on understanding complexity and how it manifests itself in the many facets of the business enterprise. Figure 4 shows the connections between the selected systems principles and the related hard and soft-systems frameworks that claim to have been influenced by these principles and their sub-constructs. 


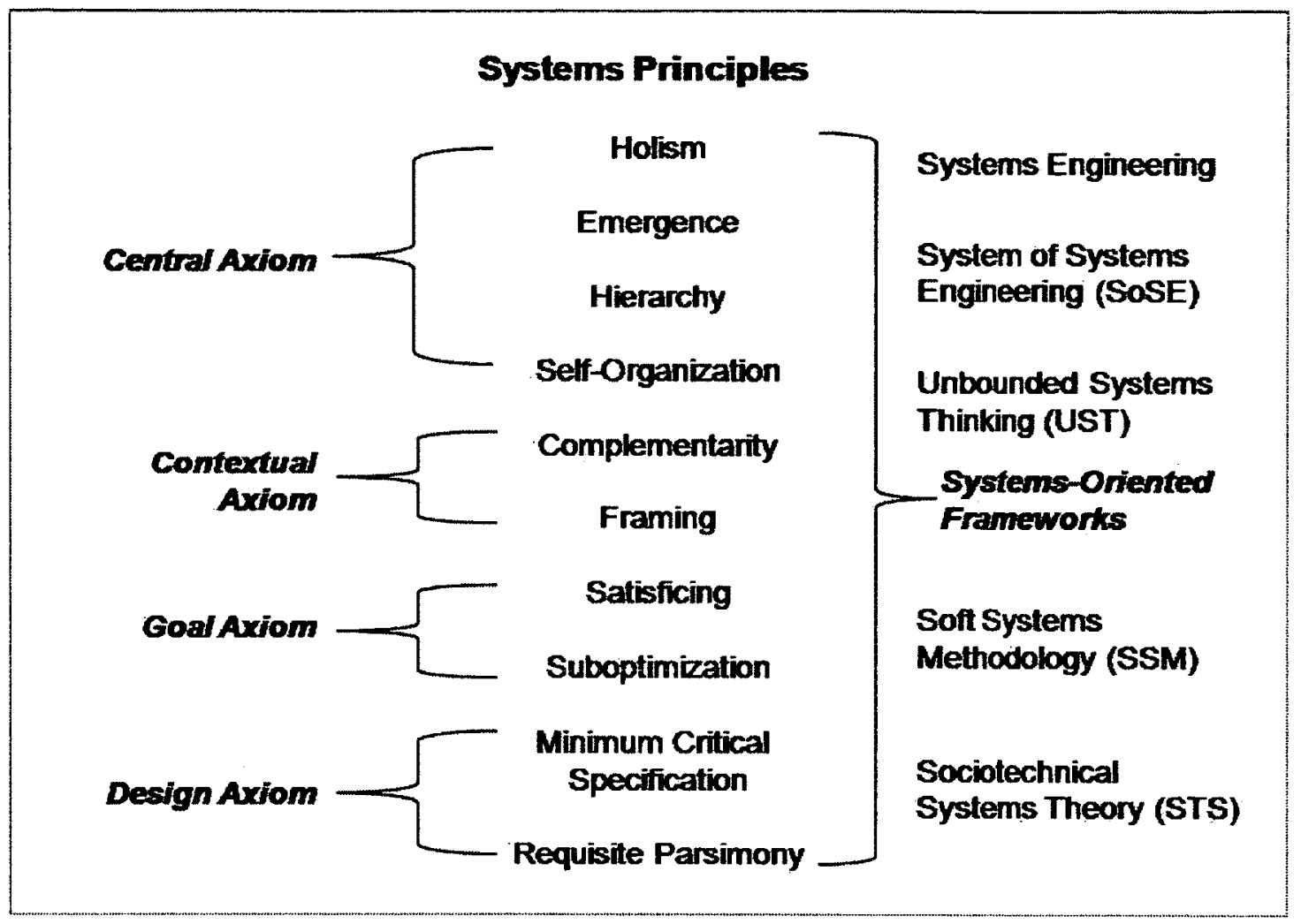

Figure 4: Systems Principles Literature Topics

\subsection{The Central Axiom}

The central axiom includes the principles of holism and emergence which are at times referred to as the foundation for all the other systems principles. The concept of emergence is explained in relation to the systems principle of hierarchy, while the notion of self-organization has been characterized as the seemingly magical emergence of structure without interference from outside the organization (Heylighen, 2001; Pattee, 1974). The core systems image is that of the whole entity which can adapt and survive in a changing environment (Checkland, 2000a, pp. s-29-30).

Aristotle (384 BC - $322 \mathrm{BC)}$ ) argued that the whole is more than the sum of its parts. A broad reaffirmation of the importance of wholes in nature occurred in the $1950 \mathrm{~s}$ with the rise of 
general systems theory (Corning, 2002; Skyttner, 1996). The organism is not merely an aggregation of elementary parts or units of behavior. Instead, it is a hierarchy of semiautonomous sub-wholes, or holons branching into sub-wholes of a lower order, and so on. The basic claim of emergent evolutionists, such as Peter Checkland, was that wholes had irreducible $\circ$ properties that could not be fully understood by examining the parts alone (1992, p. 1025).

Other researchers agreed that making successful decisions about an organization depends on recognizing not only the properties of the parts, but the unique property of the whole (Mitroff \& Linstone, 1993).

The system principle of emergence appears to support the principle of holism by implicitly stating that the essence of the higher-order system is not merely a larger collection of same type of sub-systems. Instead, at each level of complexity, entirely new properties appear (Anderson, 1972; Corning, 2002). From a super-system perspective, the deeper question is, what is the emergent characteristic that can never be obtained from gathering up all the primitives that make up the sub-systems? Therefore, emergence underlies the importance of determining which properties belong to the system, and which to the various sub-systems (Clemons \& Gu, 2003). When applied to the study of complex organizations, lack of understanding the principle of emergence implies a similar lack of clarity concerning role definitions and divisions of responsibilities.

The concept of emergence is related to the systems principle of hierarchy (Checkland, 1992) because emergence is what is observed between the layers of the hierarchical system structure. The systems principle of hierarchy is considered a central principle because it describes an evolutionary force that characterizes most complex systems. The connecting interface between the hierarchal layers gives rise to properties of effects that are the result of 
what happens between the two faces. The two faces of Janus, from Roman mythology, can be thought of as residing in this interface between hierarchies (Koestler, 1967). One side is looking down and acting as an autonomous system giving directions to the lower components. The other side is looking up and serving as part of the higher whole. Systems scientists have observed that this messaging between these levels is a form of emergence as well (Checkland, 1983; Emmeche, Køppe, \& Stjernfelt, 1997; Levins, 1974; Nowotny, 2005). In a systems principles sense, hierarchical control is capable of providing feedback between layers as an interface that serves as both a constraint on the trajectory of the subunits, and as well as a message similar to the role of language between individuals (Pattee, 1974).

A remarkable characteristic of nature's hierarchies is that as one level becomes very complex, it may self-organize and evolve a higher structure. The central principle of selforganization is useful in understanding how seemingly independent forces in nature act together without any visible intervention. An embryo that forms from rapidly dividing cells is an example of this principle. At some point, organs begin to form from the cells. Each organ originates from the cells, but as the organ evolves, it becomes more than just a collection of its cells. The organ takes on the more specific characteristics of its unique function. Pattee (1974) explains this as a structure-function duality arising at the hierarchical control interface. It is precisely at the interface between the detail of the structure and the abstraction of the function. This explains a natural selective loss of detail that leads to hierarchical control, but not loss of order. The cells still make up the organ, but the identity of the organ now serves to represent that collection of cells. The cellular complexity becomes a black box at the organ-system level. The cellular black box can then be symbolically replaced with an abstraction such as a name or definition relevant to the new hierarchy for reference. 


\subsection{The Contextual Axiom}

While the central axiom's principles can be considered the foundation of Systems Theory, there is a set of systems principles that provide a means of understanding the set of circumstances or facts that surround a particular system (Adams \& Keating, 2011b, p. 25). The contextual axiom and its supporting principles are useful for getting to the meaning of systems. This is accomplished when the conditions surrounding a system event are taken into account, and when the standards of performance required from the system can be identified (Keating, 2000).

The systems principle of complementartity states that different perspectives of a system will reveal different truths about that same system. These truths are neither entirely independent nor are they entirely compatible with each other (Adams \& Keating, 2011b), but taken as a set, these viewpoints add context for understanding the system. Graphical techniques used in modeling are an excellent example of complementarity. Graphical models that represent various facets of the whole are valuable to the modeling process because they serve as a communication medium, and communication is one of the most important functions of systems engineers (Buede, 2009). Typically analysts use models to simplify real world scenarios and evaluate the underlying, reduced problem. This is done in order to make a decision (Kovacic et al., 2008). On any problem of significance, models must be drawn from a range of disciplines, such as economic, scientific, psychological and/or social. Complementarity is vital for understanding the role that viewpoints play in modeling and characterizing an enterprise.

The ability to see alternative views, models, and data couplings is not a luxury but a fundamental necessity (Mitroff \& Linstone, 1993, p. 149). This is the vital initial phase of activities necessary in the complex systems improvement life cycle. Therefore, there must be a 
corresponding reliance on foundational systems philosophy and principles that inform a more sophisticated perspective of the framing process, issues, and expectations (Fairhurst \& Sarr, 1996).

\subsection{The Goal Axiom}

While the central principles emphasize holism, and the contextual principles add environmental considerations to understanding the system, it is the goal axiom and its supporting principles that address the pathways and means for implementing systems that are capable of achieving a specific purpose (Adams \& Keating, 2011b). Although identifying functional and performance goals for systems appears to be a worthy effort, the system principle of suboptimization cautions that making improvements to an enterprise without understanding it holistically, violates the principle of sub-optimization (Hitch, 1953). This systems principle states that optimizing each subsystem independently will generally not lead to an optimum system, and improvement of a particular subsystem may actually worsen the overall system.

Alternately, systems improvement goals that are too lofty can consume a great amount of time, effort and talent without yielding effectiveness equal to or greater that the costs. The systems principle of satisficing addresses this dilemma. Herbert Simon $(1916-2001)$ the Nobel Laureate in Economics in 1978, was honored with this prize because he observed that, from a holistic perspective, organisms adapt well enough to satisfice; they do not optimize (1956). He watched rats rush to the first mound of food available to them even if it wasn't the largest mound or the most nutritious. He internalized his studies of nature and her fondness for the hierarchical structure. He obviously understood this principle from a biological viewpoint, but went on to apply the same philosophy to production systems, computer systems and economic decision 
analysis (Simon, 1974b). Just as Simon's rats could not elevate themselves above their environment to survey their entire range of choices, humans working through problems in their organizations do not have perfect knowledge of their options.

\subsection{The Design Axiom}

Once appropriate goals are set, the process of system design becomes the focus of the change effort. The design axiom and its supporting principles address concepts that may be applied during the planning and instantiation of a purposeful system (Adams \& Keating, 2011b). The principle of minimal critical specification cautions that while it is admirable to be descriptive about what has to be done, it is rarely necessary to be precise abouthow it is to be done. Cherns writes that:

In any case, it is a mistake to specify more than is needed because by doing so options are closed that could be kept open. This premature closing of options is a pervasive fault in design; it arises not only because of the desire to reduce uncertainty, but also because it helps designers to get their own way. (1976, pp. 5-6)

Human actors are triggered to act by circumstances, context and roles (Pomerol et al., 2002). Too many restrictions on how they make decisions may provide more constraints on system performance when the context varies widely. Instead of providing better service, a rigid design may force humans to abandon system changes and self-organize by either resuming previous behaviors or by redesigning the system from their position within the system (Kroes, Franssen, van de Poel, \& Ottens, 2006).

System design, including analysis of alternatives, requires decision makers to evaluate options and make decisions (Clemons \& Gu, 2003). In practice, Warfield (1988) argues that the whole purpose of remembering information is to make decisions. Observations of how decision- 
makers function led to discovery of the law of requisite parsimony. This systems principle states that humans can only deal with a few observations at a time before becoming overwhelmed. It is based on studies that validate the hypothesis stating that the span of immediate memory is only large enough to accommodate seven chunks of information (Miller, 1956; Simon, 1974a). Since each chunk of data can be considered one in a basic set, the possible number of unique sets that can be made from only three chunks of information is six.

Warfield continued to consider how the human mind deals with complexity when he uncovered three laws of design. Because humans fail to comprehend complexity in detail, it is important to keep focus on the issues clear and simple. Groupings by category can assist the process of comprehension. The first is that the human absolutely requires cognitive assistance in dealing with large numbers of elements, i.e., four or more. By cognitive assistance, he means computer algorithms that can store information and attributes. The second law is that the human absolutely requires some form of incentive to behave responsibly from a cognitive point of view, to seek out the kind of cognitive assistance that is needed, and to use it. This law is seen in action as evidenced by the growing list of design failures (Bhopal, Challenger, Chernobyl, Three-Mile Island, etc.) that can be attributed to larger and larger systems. The third law recommends some form of protection for society from bad design, i.e., a court-assigned punishment to organizations and designers who ignore essential design practices (Warfield, 1988, p. 356).

While it may be counterintuitive to recommend less detail when providing design requirements, the systems principles of minimum critical specification and requisite parsimony make a good case for supporting less is more in regard to complex systems design specifications. 


\subsection{Systems Engineering}

Not all individuals and organizations have agreed with the holism arguments calling for a shift to holism as a way to grapple more effectively with complex problems characteristic of modern society. A battle of theories raged when reductionists expressed their belief that parts, and interactions between parts, are all that is necessary to characterize a system is appropriately referred to as the hard system approach (Checkland, 1983). While grounded in the central systems principles, systems engineering is considered a hard systems approach to manage organizational change. The systems engineering framework was developed by the Bell Telephone Laboratories in the 1940's in response to the need to identify properties of the system as a whole (Schlager, 1956). Later, Forsberg \& Mooz (1991) provided a common systems engineering process that emphasized integration of project architecture and activities in a validation-based life cycle model. Its primary purpose is to serve the interests of clients, managers and decision-makers; not to bring about the advancement of theory or knowledge (Jackson, 2003). In using hard systems thinking, scientists are required to address real-world problems and then test the solutions they produce in the operational domain, not the laboratory. They are cut off, therefore, from the usual experimental methods and controlled laboratory conditions necessary to test hypotheses. All varieties of hard systems thinking regard models, primarily mathematical models, as crucial (Buede, 2009). These Systems Engineering (SE) models are thought to perform the role of capturing the workings of the problematic system (Mesjasz, 1988; Noran, 2003; Williams et al., 2001; Yourdon, 1989; Zachman, 1996).

Ross (1985) pioneered modeling techniques useful for both manufacturing and its associated manufacturing technology requirements when he published Structured Analysis and 
Design Technique (SADT) in 1977. The principles in SADT would later be renamed Integration DEFinition for function modeling (IDEF0). In 1996, IDEF0 would provide the basis for DoD's Command, Control, Communications, Computers, and Intelligence, Surveillance, and Reconnaissance (C4ISR) architecture, the first DoD architecture framework to be required for all acquisition projects in response to the Clinger Cohen Act (PL104-106, 1996). Yourdon (1989) popularized Structured Analysis methods which would add data flow diagrams to the array of modeling methodologies springing up to handle requirements for information systems.

Even with all the complexity and expense involved, the effort devoted to constructing EA models is still worthwhile, as Checkland writes:

We use systems models because our focus is on coping with the complexity in everyday life, and that complexity is always, at least in part, a complexity of interacting and overlapping relationships. Systems ideas are intrinsically concerned with relationships, and so systems models seem a sensible choice; and since they have been found, time after time, to lead to insights, they have not been abandoned. (2000b, p. S29).

\subsection{System of Systems Engineering}

In contrast to the practice of systems engineering, the System of Systems Engineering (SoSE) Methodology is a combination of soft-and hard-systems approaches that invests heavily in understanding and framing the problem under study (Adams \& Keating, 2011a). Soft-systems concepts build upon the notion of the system, as described by Ludwig von Bertalanffy (Checkland, 1983). In reality, systems engineers are faced with complex systems, i.e. a SoS; that involves uncertainty and large scale problem domains with interacting elements that evolve over time. The heart of SoSE lies in its attention to the need to appropriately establish the systemic nature of the problem to be resolved. It is essential to SoSE, and any SE-based initiatives, to have a well framed problem upon which to focus further efforts (Keating, Peterson, et al., 2003). 
SoSE has been described as the design, deployment, operation, and transformation of higher level meta-systems that must function as an integrated complex system to produce desirable results (Keating, Rogers, et al., 2003, p. 40).

\subsection{Soft Systems Methodologies}

Checkland (2000), in his retrospective on Soft Systems Methodology (SSM), writes that both the problem situation and its interpretation are human judgments. Framing the system involves selecting the level or series of layers of the system model as well as its own Weltanschauung or world-view, in order to yield insights into the problem situation. He often invited his clients to draw rich pictures as a way to learn about their world and their purposeful activities as they worked to produce products and services. In forming the context of their worldview in their own unique symbols, he found they would inevitably describe this context much more holistically than had they been asked to limit their conversations to their organizational problems. Models of purposeful activity can only be built on the basis of a declared Weltanschauung, that is, the framework of ideas and beliefs through which an individual interprets the world and interacts with it. Text and rich pictures drawn by the business owners to frame their enterprise holistically have been shown to be more uninhibited than problem-focused discussions that often lead to stove-piped system solutions.

The industrial revolution was responsible for a view of the world as a machine. Since a machine can be broken down into its independent, constituent parts or components, the same was thought to be true of constituents of the human body, and humans in general. Because of the amazing economic success experienced by organizations in the years following World War II, the US did not recognize major problems within its organizations. The term failure of success 
meant that US plants that were inefficient or badly managed still turned handsome profits. The appearance of success masked organizational flaws that should have been corrected. Instead, the Japanese became synonymous with quality and efficiency while the US had to learn tough lessons. Mindful of the influence of the machine age, Ian Mitroff and Harold Linstone (1993) put forward an approach for a radically new framework based on Systems Theory, namely Unbounded Systems Thinking (UST). One aspect of UST is that assumptions about knowledge and information must be challenged periodically. This questioning of long-accepted assumptions is necessary so that new thinking about old problems can replace paradigms that have outlived their usefulness.

Socio-technical Systems (STS) is a framework that embodies several of the systems principles discussed above. For example, STS recognizes that organizational objectives cannot be realized by optimizing the technical system alone. Considering the social aspects of the holistic organization can move the organization forward by exploiting the adaptability and innovativeness of people in attaining goals. Adaptability and human innovation are superior methods compared to technologically constraining the manner in which these goals should be attained (Cherns, 1976). Research has shown that agents seek to act so as to choose at each moment from all available options the one that seems the best in terms of expected outcome (Kroes et al., 2006, p. 813). Workers performing non-routine activities need the freedom to be able to adapt to the environment and the flexibility to cope with variances. Some have characterized this as the world of the unexpected, and this work cannot be considered completely routine (Taylor \& Felten, 1993).

Those that study soft systems, also known as systems that respect the role humans play in the enterprise, find that the social aspect of the holistic organization is responsible for its 
adaptability and innovation. These are traits that cannot be delegated to technology alone. It is Weltanschauung, or the world viewed through the eyes of its workers and expressed as text and rich pictures, that reveal the traits of the organization. And in order to be open to new views of their organizations, enterprise managers should constantly reevaluate obsolete assumptions so as to make room for new ideas about their Weltanschauung.

\subsection{Summary of Systems Theory}

In summary, a review of literature was presented regarding several systems principles and systems frameworks that contribute to a more holistic approach to understanding organizations. Table 1 summarizes the themes investigated through literature review concerning Systems Theory and the questions posed in this study.

Table 1: Systems Theory - Summary

\begin{tabular}{|l|l|}
\hline \multicolumn{2}{|c|}{ Systems Theory - Syntheses } \\
\hline Holism, Emergence, Hierarchy, Self-Organization & Aristotle (384BC - 322 BC), Heylighten (2001), \\
& Patee (1974), Checkland (2000), Corning \\
& $(2002)$, Skyttner (1996), Mitroff \& Linstone \\
& $(1993)$, Anderson (1972), Clemones \& Gu \\
& $(2003)$, Koestler (1967), Emmeche et. al. \\
& $(1997)$, Levins (1974), Nowotny (2005) \\
\hline Complementarity, Framing & Buede (2009), Kovacic et al. (2008), Mitroff \& \\
& Linestone (1993), Checkland, Keating, et al. \\
& $(2011)$, Fairhurst \& Sart (1996) \\
\hline Satisficing, Sub-optimization & Adams \& Keating (2011), Hitch (1953), Simon \\
& $(1956)$ (1974), \\
\hline Minimum Critical Specification, Requisite Parsimony & Adams \& Keating (2011), Cherns (1976), \\
& Pomerol et. al. (2002), Kroes et. al. (2006), \\
& Miller (1956), Simon (1974), Warfield (1988) \\
\hline SE, SoSE & Checkland (1983) (2000), Schlager (1956), \\
& Forsberg \& Mooz (1991), Jackson (2003), \\
& Buede (2009), Masjasz (1988), Noran (2003), \\
& Williams, el al. (2001), Yourdon (1989), \\
& Zachman (1996), Ross (1985), DoD (2007), \\
& Adams \& Keating (2011) \\
\hline Soft Systems Methodology, Socio-technical Systems & Checkland (2000), Mitroff \& Linstone (1993), \\
& Cherns (1976), Kroes et al. (2006), Taylor \& \\
& Felden (1993) \\
\hline
\end{tabular}




\subsection{Critique of Systems Theory}

When the literature concerning Systems Theory as well as long-accepted assumptions concerning EAs is considered, it can be concluded that several systems-oriented frameworks have been constructed in a purposeful fashion to incorporate systems principles, as shown in Table 2. These endeavors yield insight into what happens when systems principles are applied to a system of problems that we call a mess (Ackoff, 2001) because they resist easy solutions. These modern theories and methodologies foster ways of shaping both the technical and the social conditions of work in such a way that efficiency and humanity will no longer be contradictory (Ropohl, 1999).

Table 2: Critique - Systems Theory

\begin{tabular}{|l|l|}
\hline \multicolumn{2}{|c|}{ Systems Theory Critique - Themes } \\
\hline $\begin{array}{l}\text { Systems thinking pertaining to the whole enterprise } \\
\text { has been virtually ignored in the literature of more } \\
\text { recent hard (systematic) approaches. }\end{array}$ & Checkland (1992) \\
\hline $\begin{array}{l}\text { Disregarding the essence of the holistic enterprise } \\
\text { could be responsible for stovepiped systems } \\
\text { development }\end{array}$ & $\begin{array}{l}\text { Bailey (2011), Goethals et al. (2006), Uschold } \\
\text { \& Gruninger (2004), Wisnosky (2011), Wood et } \\
\text { al. (2003) }\end{array}$ \\
\hline $\begin{array}{l}\text { Assuming large, complex enterprise organizations } \\
\text { operate like a simple machine is incorrect. }\end{array}$ & Mitroff \& Linstone (1993) \\
\hline $\begin{array}{l}\text { Socio-technical systems theory criticizes focus on } \\
\text { technology without considering soft systems attributes }\end{array}$ & $\begin{array}{l}\text { Jackson (2003), Taylor \& Felden (1993), Adams } \\
\text { \& Keating (2011) }\end{array}$ \\
\hline $\begin{array}{l}\text { SoSE methodology promises to incorporate soft } \\
\text { systems approach, but does not recommend soft } \\
\text { systems methods }\end{array}$ & Gap - no authors appear to address this \\
\hline
\end{tabular}

However, Checkland summed up the state of Systems Theory fifty years after its introduction as in an extremely primitive state compared with the intellectual state of established scholarly fields (1992, p. 1053), and that Systems Theory pertaining to the whole enterprise has been virtually ignored in the literature of more recent hard (systematic) approaches such as SE. That systems are developed and implemented as separate stovepipes (Bailey, 2011; Goethals, 
Snoeck, Lemahieu, \& Vandenbulcke, 2006; Uschold \& Gruninger, 2004; Wisnosky, 2011; Wood et al., 2003) could well be a consequence of disregarding the essence of the holistic enterprise.

While the United States enjoyed great success as a leader in the Industrial Revolution after WWII, there are those that remind us that incorrect assumptions regarding productive organizations could be at the core of our present day failure to more efficiently produce products and services (Mitroff \& Linstone, 1993). It is possible that several assumptions regarding the approach to characterizing large, complex enterprise organizations as a machine, and a simple one at that (p. 12) are incorrect and should now be challenged. There are others that insist the philosophy of socio-technical systems clearly challenges an isolated philosophy of technology, and instead recommend a social philosophy (Ropohl, 1999, p. 7).

A review of the major trends in Systems Theory applied to modern, complex organizations that produce output which can be considered non-standard shows a tendency away from the rigidly hard recommendations (Jackson, 2003; Taylor \& Felten, 1993), such as the guidance found in the tenets describing SE. The SoSE methodology is a framework that embraces both the hard and soft aspects of organizations that require improved decision-making as a result of any change to their enterprise (Adams \& Keating, 2011b). However, while the SoSE methodology holds the potential to incorporate a soft systems approach, there are few recommended methods that SoSE practitioners can rely on to capture both the hard and soft aspects of the organization. This appears to be a gap in the implementation of the SoSE methodology.

\section{Enterprise Architectures}

The Gartner Group describes the EA change process as one that is creating, 
communicating and improving the key requirements, principles and models that describe the enterprise's future state and enable its evolution (Lapkin et al., 2008, p. 2). EAs are important because they are regarded as the blueprints used to understand and change large, complex organizations (Ross, 1985; Wisnosky, 2011). In the United States, Department of Defense (DoD) organizations are mandated by law to build and maintain EAs. The Clinger-Cohen Act enforces the requirement to build architectures as a method of defining requirements during the capability development document (CDD) phase of DAS projects (Wisnosky \& Vogel, 2006).

The Clinger-Cohen mandate invokes important elements of the SE model, including:

- Articulated requirements

- Analysis of alternatives

- Acceptance by the customer

- Implementation

The SE methodology implies that to ignore any part of this life cycle while engineering the system can lead to sufficiently negative consequences, including failure at the extreme (Buede, 2009). There is significant agreement about the usefulness of EA models (Williams et al., 2001; Yourdon, 1989; Zachman, 1987). It is generally assumed that using models for EA development can assist managers (Jackson, 2003):

- To appreciate the systemic relationships of their business and the impact their decisions can make, and

- To change their mental models before business improvement can become possible

The use of EAs for technology development has its roots in the mechanistic view of organizations. The analogy that developing process improvements to an organizational enterprise is similar to improving repetitive industrial processes has persisted since the software crisis raged between 1965 and 1985 (Gibbs, 1994). This was about the same time that the use of 
systems engineering spread to the defense and space industries. A proliferation of EA modeling tool suites emerged that ranged from those that have mechanisms for checking and enforcing the syntax of modeling languages to others that are simply graphical editors without any mechanisms to identify modeling errors or provide different views of the same data (Jackson, 2003; Noran, 2003). The prominence of this machine-model perspective is also evidenced in literature describing the IDEF0 architecture methods of the 1990's (NIST, 1993; Uppington \& Bernus, 2003) that are still popular and in use today (Shen, Wall, Zaremba, Chen, \& Browne, 2004). IDEF0 was touted as useful for modeling requirements, software systems, project management and simulation. It made popular the term ICOM (Inputs, Controls, Outputs, and Mechanisms) as a mnemonic device for understanding core activities of any process (Ross, 1985).

In 1997, the three amigos at Rational Machines (later acquired by IBM), Grady Booch, Jim Rumbaugh and Ivar Jacobson, submitted their proposal for a synthesized set of modeling languages and graphics to support object-oriented (O-O) programming, to the Object Management Group (OMG) (Quatrani, 2003). This language would be known as the Unified Modeling Language (UML). It was an approach to presenting business activities in terms of activity diagrams, swimlanes, classes, methods and messaging. It popularized use case construction as a way for facilitators to get customers to talk about their business rules as a chunk of functionality that provides value to the actor in the organization. It was thought that by capturing some high level business scenarios and somewhat-ifs about the specific process, the customer would agree that the UML-modeled aspects of the business system could handle almost any non-standard business risks appropriately. By 2006, the Gartner Group estimated that more than 10 million IT professionals were using UML, and by 2008 over $70 \%$ of software 
development organizations worldwide were using it to freely exchange their designs (Watson, 2008, p. 2). Department of Defense Architecture Framework (DoDAF) ver. 2.0 (DoD, 2009) acknowledges and advocates architecture development using standard UML methods as managed by the OMG.

As the complexities surrounding the production of EAs grew, frameworks that conveyed unique facets of enterprise models were necessary as a way to determine EA equivalent views. John Zachman was an IBM consultant when he developed the architecture framework that bears his name. Some assert his framework is one of the most famous representations of EA frameworks, and it is still supported by many types of modeling tools and languages (Goethals et al., 2006; Noran, 2003). The Zachman (1987) framework uses tables to categorize the who, what, when, where, why, and how of architecture viewpoints so that systems engineers can facilitate users' decisions on how to manage technology projects. A graphic of the Zachman framework is shown in Figure 5. 
ENTERPRISE ARCHITECTURE - A FRAMEWORK ${ }^{{ }^{\top M}}$

\begin{tabular}{|c|c|c|c|c|c|c|c|}
\hline & DAA & FUnCTION & NETWORK Where & PEOPLE & TRE & MOTVRTON & \\
\hline $\begin{array}{l}\text { SCOPE } \\
\text { (CONIEXTYAI) }\end{array}$ & $\begin{array}{l}\text { Sit of Things Impotant } \\
\text { the Busoness }\end{array}$ & $\begin{array}{l}\text { Ruxtion }=C_{\text {chess of }} \\
\text { Busines Procosis }\end{array}$ & $\begin{array}{l}\text { List oflocations in which } \\
\text { the Business Opersits }\end{array}$ & 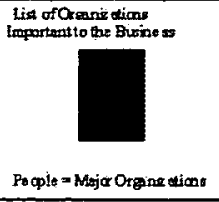 & Lime = Mkjos Euriness Evert & 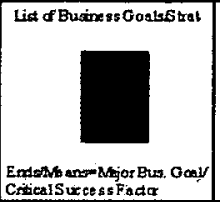 & $\begin{array}{r}\text { SOOPE } \\
\text { (CONIEXTUAL) }\end{array}$ \\
\hline $\begin{array}{l}\text { ENIERPRISE } \\
\text { NODEL } \\
\text { (CONDEPTUAL) }\end{array}$ & 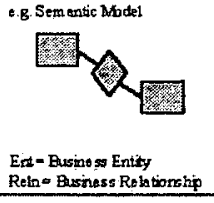 & 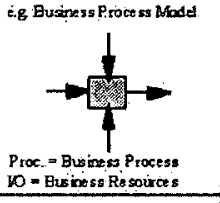 & 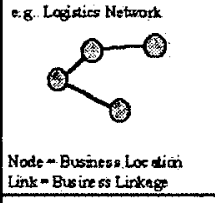 & 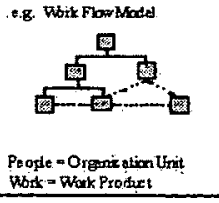 & C.8. Masters Sthodult & 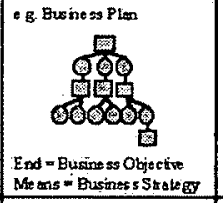 & $\begin{array}{r}\text { ENIERPREE } \\
\text { MODEL } \\
\text { (CONCEPTUAL) } \\
\text { Oaner }\end{array}$ \\
\hline $\begin{array}{l}\text { SYSTEM } \\
\text { MODEL } \\
\text { (LOGICAL) }\end{array}$ & 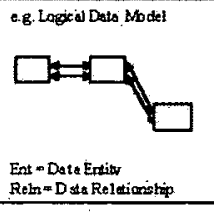 & 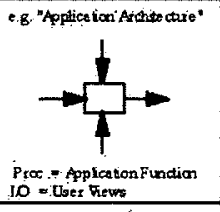 & 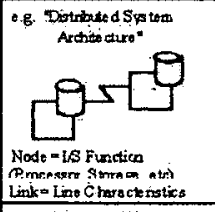 & 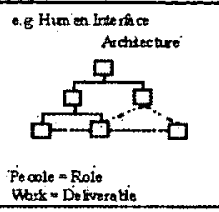 & S Processings Studture & 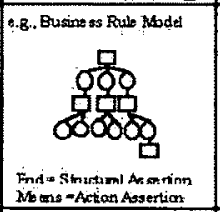 & $\begin{array}{l}\text { SYSTEM } \\
\text { MDDEL, } \\
\text { (LOGTCAL) }\end{array}$ \\
\hline $\begin{array}{l}\text { TECHDDLOSY } \\
\text { MODEL } \\
\text { (PHYSTCAI) }\end{array}$ & 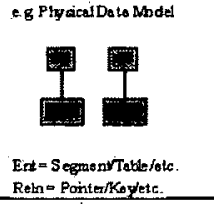 & 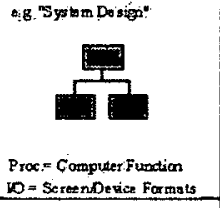 & 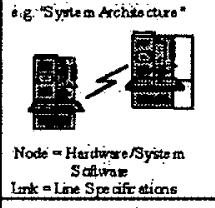 & 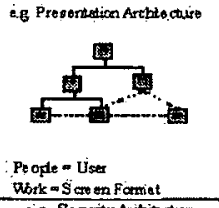 & 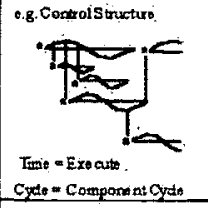 & 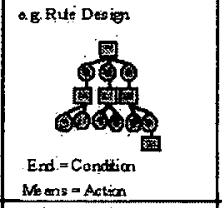 & $\begin{array}{r}\text { TECENOLOGY } \\
\text { CONSTR AIRED } \\
\text { NODEL } \\
\text { PHYSTCAI } \\
\text { Euiker }\end{array}$ \\
\hline $\begin{array}{l}\text { DETAIED. } \\
\text { REPRESEN- } \\
\text { IATONS } \\
\text { (OUTOF. } \\
\text { OONTEXT) } \\
\text { Sib. } \\
\text { Cantnator }\end{array}$ & $\begin{array}{l}\text { Ent }- \text { Fieds } \\
\text { Retn - Adtro ss. }\end{array}$ & $\begin{array}{c}\text { Proce Larguegs Strot } \\
\text { Yo-Contcd Hock }\end{array}$ & 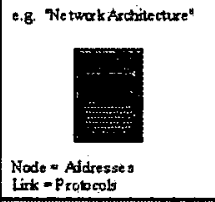 & e.e. Secunity Archit dus & O.g. Timing Defirition & 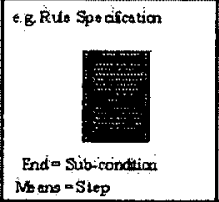 & 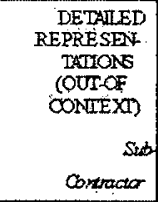 \\
\hline $\begin{array}{l}\text { FUNCTRONANG } \\
\text { ENIEEPRLSE }\end{array}$ & $y_{x}$ & 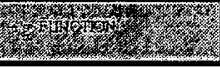 & $b_{2}$ & 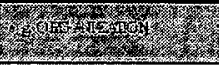 & 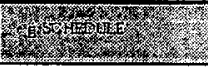 & 2 & $\begin{array}{l}\text { FUNCTTONEGE } \\
\text { ENIERPRISE }\end{array}$ \\
\hline
\end{tabular}

Figure 5: The Zachman Framework ${ }^{1}$

An examination of this framework reveals areas of correlation between several of the systems principles discussed above. For example, Zachman ensured the definition of each view of the organization described a different nature of the enterprise. This demonstrates the hierarchy systems principle:

They are not merely a set of representations, each of which displays a level of detail greater than the previous one. Level of detail is an independent variable; varying within any one architectural representation....each differs from the others

\footnotetext{
${ }^{1}$ Note: Permission to use of this illustration in this document has granted in writing by the author, Dr. Zachman.
} 
in essence, not merely in level of detail. (Zachman, 1987, pp. 281-282)

It may be inferred that Zachman was mindful of the principle of holism from his description of the business scope and the motivation, or why, an enterprise exists:

This ballpark perspective is a very high level of which is being used like the architect's bubble charts to establish the gross size and scope of the data strategy... a list of all the things that are important to the business, and therefore, that the business manages... a list of things (i.e., material-grammatically, nouns) as opposed to a list of actions (i.e., processes-grammatically, verbs). (Zachman, 1987, p. 284).

The Zachman framework (Figure 5) also identifies a data column. Metadata, that is data about data, is present in each cell and describes the essence of each cell. Just as the emergent interface between hierarchical levels has been described in physics as the thin layer that has properties that are different from the properties associated with the bulk on either side (Nowotny, 2005, p. 24), Zachman's own description of the meta-data layer appears to be closely aligned to the hierarchical control described by systems thinkers:

The data description column (entity-relationship-entity) is different from the process description column (input-process-output) and so on. Because each of the data elements on either axis is explicitly different from the others, it is possible to define precisely what belongs in each cell, and further, each cell in the matrix will be explicitly different from all the other cells. (1987, p. 292)

Zachman's use of the analogy of building architecture to convey the requirements important in developing information technology for businesses fostered understanding of all the pieces involved in the EA process. His work is also consistent with several systems principles that pertain to complex human organizations.

\subsection{Model-Based Systems Engineering for Stakeholder Requirements}

Model-Based Systems Engineering (MBSE) is an approach that focuses on the DoDAF model views and away from requirements written using only a word processor (Piaszczyk, 2011; 
van Ruijven, 2012). An MBSE EA would begin with the mission level enterprise business process models that extend the concept of UML use cases for modeling interactions between operators and the technology system.

Mission level "enterprise business process" Operations View (OV) use case analyses treat the system as a "black box." With the understanding derived from the OV analyses, DoDAF's System View (SV) artifacts are then used for "white box" analyses of the inner workings of the system itself with increasing level of depth. (p. 306)

The objective of the MBSE system functional analysis is to create a functional architecture. Functional architecture is a hierarchy of functions that the system must be capable of performing. These functions are derived from the operational capabilities that the stakeholders desire, articulated as use cases. This functional architecture provides the foundation for defining the system architecture in follow-on steps using UML, including allocation of functions and sub-functions to the proposed technology system components (Piaszczyk, 2011, pp. 311-317).

\subsection{Summary of Enterprise Architecture Themes}

Zachman's Framework is a useful taxonomy for communicating about organizational enterprises, as shown in Table. While the framework itself is not a method for evaluating EAs, many of Zachman's descriptions regarding the organization's multiple viewpoints appear to reflect Systems Theory. Specifically, terms related to the systems principles of holism and hierarchy, and complementarity are similar to those Zachman used as his language and framework for EAs. 
Table 3: Enterprise Architecture Summary

\begin{tabular}{|l|l|}
\hline \multicolumn{2}{|c|}{ Synthesis - Enterprise Architecture Themes } \\
\hline Definition - blueprints required to understand change & $\begin{array}{l}\text { Gartner (2012), Ross (1985), Wisnosky } \\
\text { \& Vogel (2006), Buede (2009), } \\
\text { Williams, et al. (2001), Yourdon (1989), } \\
\text { Zachman (1987), Jackson (2003) }\end{array}$ \\
\hline $\begin{array}{l}\text { Software crisis and assembly-line analogy for EAs } \\
\text { popularized between 1965-1985 timeframe }\end{array}$ & Gibbs (1994) \\
\hline IDEF0 architecture influence on practice of EA & $\begin{array}{l}\text { NIST (1993), Uppington \& Bernus } \\
\text { (2003), Shen, et al.(2004), Ross (1985) }\end{array}$ \\
\hline $\begin{array}{l}\text { UML language provides several graphical modeling language } \\
\text { diagrams for describing activities }\end{array}$ & $\begin{array}{l}\text { Quatrani (2003), Watson (2008), } \\
\text { Piaszczyk (2011) }\end{array}$ \\
\hline $\begin{array}{l}\text { Zachman EA Framework for software development provides } \\
\text { language for comparing EA views across tool suites }\end{array}$ & $\begin{array}{l}\text { Zachman (1987), Goethals, et al. (2006), } \\
\text { Noran (2003) }\end{array}$ \\
\hline Systems Engineering use of EAs & $\begin{array}{l}\text { Buede (2009), Williams, et al., (2001), } \\
\text { Yourdon (1989), Zachman (1987), } \\
\text { Jackson (2003), Piaszczyk (2011) }\end{array}$ \\
\hline
\end{tabular}

\subsection{Critique of Enterprise Architecture Themes}

While the Zachman framework indicates the Scope (Contextual) uppermost layer, and describes this as the view of the enterprise planner, it has been noted that this level can only be represented informally by prose lists and tables:

However, regarding the mission, vision and policy as well as the enterprise policies; it is probably not possible to express these concepts using formal tools or languages (Noran, 2003, p. 123).

Zachman himself echoes the problems management planners, owners, and designers may have with EAs they have invested time and resources to build:

First, in general, Rows 1, 2 and 3 models were seldom built ... and in many cases, Row 4 models were not even built (see Figure). The models which are not explicitly produced are implicitly assumed by default, and a lot of assumptions were made which have since proven to be, or have become, erroneous. Furthermore, the Rows 1 and 2 models can change as fast as Management can change their minds, whereas the Row 5 implementations are "poured in concrete, "resembling hundred story buildings. There simply is no way to keep the Row 5 reality in synch with the Row 2 perceptions without explicit formalizations and configuration control of the intermediate Row models as is done for physical products.(1996, p. 4) 
This admission that EAs have been, and still are (Gruninger, 2003), constructed in an incomplete manner brings to light several areas of concern. Using the language and structure of Zachman's framework, audits of the DoD enterprise have found that there should be "more effort to establish buy-in with mission and business owners, and complete the evolution to results-focused architecture" (OMB, 2009, p. 2). This underscores the related concern that if the needs of DoD's Combatant Commanders, as mission owners, are left out of the EA definition process, the complex DoD SoS will be built without understanding the views of DoD's planners as mission-success advocates during the EA construction process.

Cherns' (1976) views on adaptability recommend a focus on the product of the work vice control of the activities or actions of people at work and advises a corresponding shift away from modeling activities, stating that workers performing non-routine activities need the freedom to be able to adapt to the environment and have the flexibility to cope with variances. Metrics collected on the use of activity-based models, i.e., IDEF0 models (NIST, 1993) and UML models (Shen et al., 2004), constructed for the purpose of ultimately improving productivity in industrial organizations may show good results, but only if the activities are predictable and/or repetitive . However, assuming that organizations that provide creative and innovative solutions as their enterprise product can be represented using activity models may not be correct. Interconnections derived from the logic of situations such as arrangements to manufacture or assemble products, or situations dominated by a decision about to be taken to achieve a known objective, are usually too narrow in scope to characterize the complexity of organizational perspectives as a whole (Checkland, 1983; Mitroff \& Linstone, 1993).

Taylor and Felten (1993) believe that when seeking to improve the organization, relationships that map how workers interact with technology is less important than understanding 
relationships indicating who communicates with whom during work performance. However, the guidance of DoDAF Ver. 2.0 (DoD, 2009) recommends the process of defining and aggregating fragments of business activities using UML and UML-related tool suites so as to eventually define the whole enterprise. The systems principle of emergence states that the essence of the higher-order system is not merely a larger collection of same type of sub-systems. At each level of complexity entirely new properties appear (Anderson, 1972; Corning, 2002). By continuing to collect informatics detail at the atomic level, the important conceptual characteristics of the holistic EA will never be noticed (Tolk, 2006). As Bailey (2011) notes, the resulting combination of stovepipes is an aggregated view of organizational problems instead of the view of the enterprise as a whole:

Good systems engineering practice should ensure clear interface specifications between the subsystems. In fact, the approach of budgeting out the various subsystems tends to have a negative effect on information coherence... The tendency to develop data models from process models means that the scope for the information model is defined by the scope of the processes relevant to the given subsystem -i.e., there is no requirement to look beyond the subsystem boundary (p. 332).

Two prominent subject matter experts in the field of EAs comment about the failure of projects using EAs. Ian Bailey, one of the original developers of Ministry of Defense Architecture Framework (MODAF), a framework that has been incorporated in DoDAF version 2.0, observes that:

Customers of failed projects will say that engineers didn't properly understand their business requirements while engineers will say the customers failed to describe their requirements adequately (Bailey, 2011).

Shen, et al., (2004) describes the typical communication process between customers (business people) and engineers (developers):

Business people bring knowledge of the enterprise to the project and generally 
have a good idea about what needs to change in a business. They need to be able to explain this in a language that is understandable to the developers. Similarly, the developers have knowledge of the available software tools and the limitations of technology but must be able to apply this knowledge to the enterprise-specific domain. This is why a language that is understandable by both the end user and the developer is very important. The developers should not guess what the users need as this may lead to the implementation of technology for technology sake. These initiatives are driven by business and not by technology and for this reason the users and developers must have the same unambiguous understanding of the enterprise (p. 311).

At the heart of this typical description of the business owner, is the tacit assumption by developers that enterprise model owners are able to articulate necessary business rules that would uniquely and specifically describe missing capabilities within the enterprise. As stated, developers further assumed that owners must describe this using highly technical languages and abstract modeling techniques designed to exchange information between developers, i.e., a better modeling language. For example, using MBSE techniques, the system described as a functional architecture is a layer of abstraction, still independent of the actual physical implementation. This is the very same layer of business information that guides the DoD when operating as a Joint military force. Piaszczyk even defines this particular layer of abstraction as the essence of what defines the organization: If done correctly, this functional architecture layer of abstraction will remain the same in spite of the changing technologies (2011, p. 317).

However, instead of using the natural language of descriptive and authoritative DoD guidance and training documents to transition the operators' views to the technical SV, Piaszczyk (2011) describes a technically involved series of use case generation, based on interviews of personnel by MBSE facilitators, to develop use cases business owners and planners cannot read, understand, validate nor keep current, including:

- OV-1, High-level Operational View

- OV-2, Operational Architecture Diagram, presents the operational nodes and 
needlines between them.

- OV-6c, Operational Activity Sequence Diagram, shows lifelines for each operational node.

- OV-4, Organizational Relationships Diagram, defines the human roles.

- OV-5a, Activity Hierarchy, presents the decomposition of operational activities in hierarchical form.

- OV-5b, Activity Flow Diagram, presents the interfaces between activities.

- Operator Requirements derived from the OV-2

The OV-2 diagram lists all the nodes/operators, activities, and messages involved in the use case.

Through repeated application of combing through the diagram, a list of shall statements that

characterize the use case is composed and is declared the functional requirements of the use case under consideration.

The DoD's Chief Technology Officer, Dennis Wisnosky, has a related developercentered theory that DoD projects fail because of a lack of a common set of EA modeling symbols. He states that:

While the DoD Architecture Framework (DoDAF) provides the framework or views from which to build architecture, it does not prescribe a standard methodology of how to model the architecture within the views. This lack of a common standard means that the same work is being done over and over again. Certified Enterprise Architects cannot understand one another's work; and if enterprise architectures (EA's) cannot be read by anyone but the people and programs that created them, imagine the waste and cost associated with trying to integrate and/or federate. The cost in time and money within the DoD is substantial. (Wisnosky, 2011)

Perhaps the reason for the waste and cost associated with building EAs is the lack of understanding the social aspects of an enterprise that provides unique military services and must adapt to a wide variety of circumstances. This adaptability is difficult to capture using activity models, and will continue to be difficult to model even with standard symbols. 
Table 4 is a summary of the themes critiquing the use of EAs for change management of complex SoS that emphasize creative and innovative services as their primary product.

Table 4: Critique - Enterprise Architectures

\begin{tabular}{|l|l|}
\hline \multicolumn{2}{|c|}{ Critique of Current State of EA Development and Use } \\
\hline $\begin{array}{l}\text { Scope layer - probably cannot be formally modeled, leaving } \\
\text { mission planners out of the EA construction process. }\end{array}$ & $\begin{array}{l}\text { Noran (2003), Zachman (1996), } \\
\text { Gruninger (2003) OMB (2009) }\end{array}$ \\
\hline $\begin{array}{l}\text { Focus on activity control vice the product of the work reduces } \\
\text { the ability of workers to adapt to the environment. However } \\
\text { UML models of activities are most popular for EAs. }\end{array}$ & $\begin{array}{l}\text { Cherns (1976), Shen et al. (2004), } \\
\text { Watson (2008), }\end{array}$ \\
\hline $\begin{array}{l}\text { System Eng EAs produce stovepipes of technology because } \\
\text { Systems Theory pertaining to whole has been virtually } \\
\text { ignored, and project improvements are not able to sub- } \\
\text { optimize }\end{array}$ & $\begin{array}{l}\text { Tolk (2006), Bailey (2011), Gruninger, } \\
\text { Checkland, OMB (2009) audits (2004), } \\
\text { Anderson (1972), Corning (2002) }\end{array}$ \\
\hline $\begin{array}{l}\text { Proprietary EAs cannot be reused, no standard symbols } \\
\text { Proposed improvements to EA processes focus on improving } \\
\text { technology layer, i.e., fixing or inventing modeling languages }\end{array}$ & $\begin{array}{l}\text { Goethals, et al. (2006), Grunninger } \\
(2006), \text { Maier (1998), Uschold \& } \\
\text { Gruninger (2004), Pasmore \& Khalsa } \\
(1993)\end{array}$ \\
\hline $\begin{array}{l}\text { The assumption that building UML use case scenarios to } \\
\text { illustrate the tactical viewpoint will result in identification of a } \\
\text { holistic business process and technology gaps is incorrect. }\end{array}$ & Gap - no authors appear to address this \\
\hline $\begin{array}{l}\text { There are no formal models for planners to articulate the } \\
\text { Scope-level enterprise }\end{array}$ & Gap - no authors appear to address this \\
\hline $\begin{array}{l}\text { Current EA modeling tools are not able to characterize non- } \\
\text { routine jobs, nor focus on design for adaptability and } \\
\text { flexibility }\end{array}$ & Kroes, et al. (2006) \\
\hline
\end{tabular}

While some researchers in the field of software architecture identify holistic deficiencies in EA modeling, closer examination of their proposed gap solutions indicates that the overwhelming majority of proposed EA solutions focus rigidly on the technology model (Goethals et al., 2006; Gruninger, 2003; Maier, 1998 ; Uschold \& Gruninger, 2004), as shown in the gap illustrated in Figure 1 of Chapter 1. Today's modeling practices have been characterized by their users as proprietary, time-consuming and generally ineffective as tools for communicating strategic-level planning across all levels of the enterprise (Bailey, 2011; Wisnosky, 2011). It appears that many of the current EA methodologies selected for use (DoD, 2009) embody only the hard systems engineering approach (Gruninger, 2003; Hysom, 2003; 
Noran, 2003; Uppington \& Bernus, 2003), even when there is evidence that socio-technical theory requires models for adaptability and innovativeness of people in attaining goals instead of over-determining the technical manner in which these goals should be attained Cherns, 1976; Emery \& Trist, 1978; Ropohl, 1999). In addition, system design must allow for actors within the system who will continuously be changing or redesigning the system. Kroes, et al (2006), surmised that highly adaptive systems require a significantly different design system from traditional engineering design practices, and these different design methods do not currently exist. Despite the preponderance of both theoretical and practical evidence presented concerning the importance of successful social innovations regarding enterprise organizations, managers are more likely to pay attention to technical rather than social innovation (Pasmore $\&$ Khalsa, 1993).

While it is precisely the attention to the central systems principles that differentiates the SoSE methodology from SE as a potential to overcome stove-piped solutions, the SoSE methodology requires an exact understanding of how creativity can be enhanced by using systems approaches in combination (Jackson, 2003). Yet this understanding is neither trivial nor common to modern organizations that desire innovative, high-tech solutions and are heavily invested in traditional hard systems change methods. This dichotomy appears to indicate that enterprise design cannot rely on the knowledge of the way machines and technical systems behave alone. However, the holistic EA modeling paradigm that embodies these strategic-level, soft system attributes that the enterprise planners require to understand change does not exist today.

\section{Semantic Web}

The third construct selected to assist in understanding challenges to organizational 
enterprise change is the Semantic Web. It has been described by Tim Berners-Lee, the creative mind that launched the World Wide Web twenty years ago, as:

A social technology that thrives on growth and therefore needs to be trusted by an expanding user base - trustworthiness, personal control over information, and respect for the rights and preferences of others are all important aspects of the Web. $(2006$, p. 3)

If he was intent on keeping the concepts behind his invention secret until he could charge royalties for its use, Berners-Lee would easily have earned billions. Instead, in 1994 he gave it to the world without a patent. To maintain this work, he also created the W3C to help spread the highly technical standards for building the components we recognize today as the web. A look back at the evolution of the web since its beginnings in the 1990s highlights the importance of the decision to allow open participation in the World Wide Web concept. This decision has resulted in many recognizable web properties that are now self-organizing into the Semantic Web, and shown in Figure 6. The vision of extending and adding value to the Web is intended to exploit the possibilities of logical assertion over linked relational data (Berners-Lee et al., 2006). Research and development has been underway on developing the languages and formalisms that will support querying, inference, aligning data models, visualization and modeling.

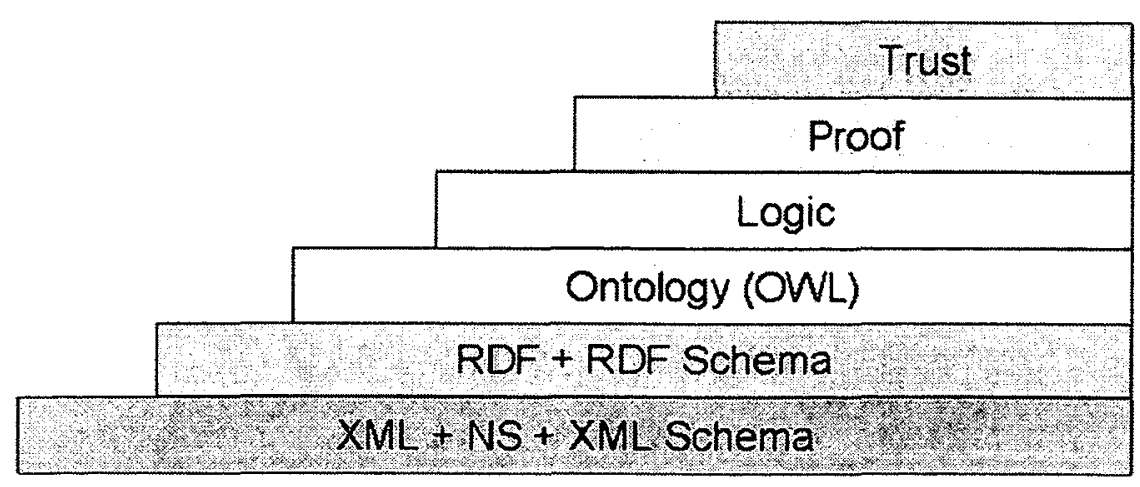

Figure 6: W3C Semantic Web Stack 
In 1998, a metadata language, called Meta Content Framework (MCF) was built to help Netscape describe content rating of web pages. Around that time, the W3C also became involved in managing standards for a general-purpose metadata language called RDF (Resource Description Framework) that was based on the original MCF specification built by Guha and Bray (Pollock, 2009). In 1999 the Defense Departments of the US as well as Europe independently developed ontology languages that were strikingly similar. The US product was developed by the US Defense Advanced Research Projects Agency (DARPA) and it called its ontology language DAML (DARPA Agent Markup Language); while the European Union created OIL (Ontology Inference Layer). The two formats were combined into what is today called OWL (Web Ontology Language).

The Semantic Web was created to extend the potency of the web from merely sharing documents via HTML (HyperText Markup Language) to sharing data by enabling links, i.e., Uniform Resource Identifiers (URIs), and to find and dereference data from web servers where the data is stored. This allows linked data to be shared effectively by wider communities and when enabled, be processed automatically by robotic tools. The W3C standard RDF language continues to be useful for organizing XML document data into a type of relational database. It is analogous to a spreadsheet, as it uses namespace terms to define column headers while the data content of the RDF document is analogous to rows of data that have been input for storage. The ontology layer of the Semantic Web is meant to stack on top of the RDF layer (Figure 6), indicating its potential for adding value to relational data structure. This additive benefit is described as follows:

Ontologies contain specification of the concepts that are needed to understand a domain, and the vocabulary required to enter into a discourse about it, and how those concepts and vocabulary are interrelated, how classes and instances and 
their properties are defined, described and referred to. An ontology can be formal or informal. The advantage of formality is that it makes the ontology machine-readable, and therefore allows a machine to undertake deeper reasoning over Web resources. The disadvantage is that such formal constructs are perceived to be hard to create. (Berners-Lee et al., 2006, p. 27)

RDF is particularly intended for representing metadata about Web resources, such as title, author, and modification date of a Web page, copyright and licensing information about a Web document. RDF provides a common framework for expressing this information so it can be exchanged between applications without loss of meaning (W3C, 2004b). Terms for the various parts of the RDF statement that describe, for example, an article written by John Smith are:

- The subject is the URL http://www.example.org/index.html

- The predicate is the word "creator"

- The object is the phrase "John Smith"

The subject-predicate-object combination is sometimes called a triple. In this way, two metadata schema items can be linked together with the verb-like predicate indicating the relationship. When the RDF triple is invoked as an XML namespace contributor in the header of an electronic document, a web-crawling algorithm can identify the tagged information to return precise results. Also, since the RDF information is an XML document itself, it can be transformed into source code that can be viewed by humans and/or displayed any number of ways as a webpage.

In philosophy, ontology is defined as a theory of the nature of existence (e.g., Aristotle's ontology offers primitive categories (Gruber, 2008), such as substance and quality, which were presumed to account for All That Is). Tom Gruber, a computer scientist at Stanford University, presented a paper in 1993 that formally introduced the analogy of ontology to the computer science community (Jepsen, 2009). Gruber described his concept of ontology as a technical term 
denoting an artifact that is designed for a purpose, which is to enable the modeling of knowledge about some domain, real or imagined (2008, p. 1). It conveys rules about terms and how they should be used. For that reason, and because ontology languages such as RDF and OWL are open standards, they offer the promise of non-proprietary, and therefore reusable terms. When ontology is referenced by an agent or application, it is reasonable to expect greater understanding and increased communication (Uschold \& Gruninger, 2004). For example, FOAF is a shallow ontology because it uses just a handful of terms to describe the entire population of the FOAF ontology (Brickley \& Miller, 2000):

FOAF is a project devoted to linking people and information using the Web. Regardless of whether information is in people's heads, in physical or digital documents, or in the form of factual data, it can be linked. FOAF integrates three kinds of network: social networks of human collaboration, friendship and association; representational networks that describe a simplified view of a cartoon universe in factual terms, and information networks that use Web-based linking to share independently published descriptions of this inter-connected world. FOAF does not compete with socially-oriented Web sites; rather it provides an approach in which different sites can tell different parts of the larger story, and by which users can retain some control over their information in a nonproprietary format.

FOAF still exhibits formalism in the language it uses to express the triples conveying descriptions of people, the links between them and the things they create and do (Berners-Lee et al., 2006; Graves et al., 2007; Heyman, 2008; Paolillo, Mercure, \& Wright, 2005; Prater, Mueller, \& Beauregard, 2012).

A broader range of semantics-based technologies includes areas of knowledge representation (KR). This larger category includes entity-relationship (ER) models, UML and database dictionaries. These are also items included in Zachman's framework for EAs. Considering its widespread utility, it is not surprising to note a wave of interest in using the Semantic Web for developing EAs (Bailey, 2011; Gruninger, 2003; Sowa, 2011; Tolk, Litwin, \& 
Kewley, 2008). For example, CTO Wisnosky (2011) recommends use of non-proprietary W3C standards for constructing some views of DoD's architecture models in an effort to convey reusable, meta-data terms to DoD EA builders and users using non-proprietary standards. Reusability of business models means that the granularity of the model has to be unique enough to adapt to the particular needs of users, but generic enough to still allow interoperability with other models (Shen et al., 2004). Wisnosky (2011) advocates a standards-based approach to architectures to identify fragments of business process models he calls primitives. A query to the DoD semantic web will find the data (Wisnosky, 2011, p. 12) so it can be assembled end-to-end for reuse. He believes that the intended reuse would be to build the DoDAF Event-Trace Description Operational Views that are part of the required EA views of a DAS.

\subsection{Summary of Semantic Web Themes}

Table 5 is a summary of the themes regarding the Semantic Web that are associated with a relatively new possibility for describing organizational EAs. The Semantic Web is a ubiquitous technology that has also been described as a study in self-organization not only because of its wide acceptance, but because it reflects many social aspects of human nature.

Table 5: Semantic Web Summary

\begin{tabular}{|l|l|}
\hline \multicolumn{2}{|c|}{ Synthesis - Semantic Web Themes } \\
\hline Semantic Web is a social technology & Berners-Lee (2006), W3C (2004) \\
\hline OWL was originally developed as DoD ontologies & Pollock (2009) \\
\hline $\begin{array}{l}\text { Ontology - a computer science analogy for knowledge models } \\
\text { - used to create greater understanding of data }\end{array}$ & $\begin{array}{l}\text { Gruber (2008), Jepsen (2009), Uschold } \\
\text { \& Gruninger (2004) }\end{array}$ \\
\hline $\begin{array}{l}\text { FOAF is an ontology that describes social connections, and } \\
\text { exhibits a high degree of formalism while using few terms } \\
\text { (shallow) of description }\end{array}$ & $\begin{array}{l}\text { Brinkley \& Miller (2000), Gruninger \& } \\
\text { Uschold (2004), Berners-Lee et al. } \\
\end{array}$ \\
$\begin{array}{l}\text { (2006), Heyman (2008), Paolillo et al. } \\
(2005), \text { Prater et al. (2012) }\end{array}$ \\
$\begin{array}{l}\text { Semantic-based technologies in the areas of knowledge } \\
\text { representation also appear to have utility for generating EA } \\
\text { models described by Zachman's framework }\end{array}$ & $\begin{array}{l}\text { Bailey (2011), Gruninger, (2003), Sowa } \\
(2011), \text { Tolk et al. (2008), Wisnosky } \\
(2011)\end{array}$ \\
\hline
\end{tabular}

In an effort to understand models of all types, the Generalized Enterprise Reference 
Architecture and Methodology (GERAM) was developed. It is the result of a ten year project by the combined United Nations-founded International Federation of Information Processing (IFIP) and the IT Association of Canada (IFAC) task force. GERAM was designed to generalize the contributions of a number of EA Frameworks, and in doing so, define a tool box of concepts that could be used for designing and maintaining enterprises during their entire life cycle (IFIPITAC, 2003). For example, when the Zachman Framework (1987) was mapped to GERAM the results showed its strong association to models that are most suited to information systems development requirements. When the OWL ontology-specification language was evaluated, it was found that because OWL was designed for the Semantic Web (Broekstra, Klein, Fensel, \& Horrocks, 2000), it was therefore compatible with emerging web standards such as RDF Schema (RDFS) (W3C, 2000). When the UML was evaluated in 1999, GERAM findings concluded that as an ontology, UML did not have clearly specified declarative semantics. This evaluation finding stated it was difficult to assert that any particular UML design was correct or consistent with its own internal guidelines (Gruninger, 2003). In addition, as an ontology, UML was judged as too implicit in describing its activity concepts, thereby making it difficult to integrate with other process-related applications whose semantics are not equivalent to the semantics of the corresponding UML concepts.

Gruninger and Uschold (2004) documented a continuum of ontology based on the concept's capacity for specifying meaning. They found extremes based on formalism, that is, the extent to which the ontology requires terms to be specified; and depth. Formalism differs from depth in that deep ontologies have an abundance of attributes that describe the objects in its domain. For example, FOAF is a shallow ontology because it uses just a handful of terms to describe the entire population of the FOAF ontology (Brickley \& Miller, 2000). However, 
FOAF still exhibits formalism in the language it uses to express the triples conveying descriptions of people, the links between them and the things they create and do. The FOAF system uses a carefully designed file format and a simple, common information model. Alternately, if the comments regarding UML as an ontology were graphed on the ontology continuum, it would be considered a deep ontology, but UML lacks the formality that would enforce repeatability.

Because of its almost universal use (Watson, 2008), building UML use case scenarios to illustrate the tactical viewpoint has been used to identify the capabilities, resources and materials needed for most organizational modernization efforts (Shen et al., 2004). DoD's blueprint for strategic business operations is captured in the Business EA (BEA) view, or what Zachman calls the conceptual, enterprise model. This view now recommends the use of triples, as described in the W3C RDF standard, as a way to define primitive sets of activities (Wisnosky, 2011). However, even though ontologies use much of the same text that makes up the semantics of the EA modeling languages, comparison using the GERAM framework show that modeling languages and their supporting proprietary enterprise engineering tools may be significantly diverse (IFIP-ITAC, 2003). In addition, there is substantial expert agreement that recognizes that even a simple, descriptive ontological structure requires thoughtful human participation (Bergman \& Giasson, 2009; Berners-Lee, 1997; Emmeche et al., 1997; Flake, Pennock, \& Fain, 2003; Gruninger, 2003). It is for this reason that several of those involved with the GERAM project contend it may be not reasonable to assume that a multitude of unrelated activities can be crawled with automated robots to produce a useful ontology (IFIP-ITAC, 2003; Uschold \& Gruninger, 2004):

Semantic mapping among ontologies will need to be human-assisted, rather than 
fully automated ...creating mappings is a labor-intensive and error-prone activity, even for humans (Uschold \& Gruninger, 2004, p. 63).

Ontology, as defined by the computer science community, is useful in describing some aspects of an EA. This concept embodies several concepts including formality, depth, and linkage.

\subsection{Critique of the Semantic Web for Enterprise Architectures}

A study of the Socio-Technical Systems framework recommends that social systems analysis be linked to the technical analysis. The social system provides messages about the work and is a wider mechanism for flexible response to a changing environment (Taylor \& Felten, 1993). If RDF triples replace current modeling methods without a corresponding examination of the state of developing EAs as a whole, then focusing entirely on the technical solution could create stovepipes that lead to an integration mess later on (Kroes et al., 2006; Mitroff \& Linstone, 1993). Therefore, employing new technology for developing EAs without changing the underlying mechanistic focus on activities, i.e., how the organization performs its tasks, vs. the more human-focus on what must be done appears to be a gap in applying Systems Theory to construction of EAs. The Semantic Web and its use in constructing EA views has the potential to better reflect the needs of the social infrastructure of the DoD community, and this potential has not been sufficiently explored.

The summary review of literature on the topic of EAs (Table 4) revealed various gaps describing the need for a more systems-principled-approach. In this section, the trend toward using the Semantic Web for developing and implementing EAs (Table 6) again highlights some of the same topics:

- The users, more specifically the strategic planners, continue to be ignored as 
prime stakeholders in construction and use of Semantic Web for EAs.

- While ontology is recognized as a major feature of EA construction, there is little evidence that a holistic, top-down EA ontology for DoD communities has ever been developed as the authoritative model for all of DoD.

- Technology is again the focus of DoD's EAs using the Semantic Web. This approach leaves out the important soft science supported by STS, SoSE, and UST methodologies. The EAs of the machine age continue to dominate the BEAs with little recognition of DoD's non-routine jobs that must allow for adaptive and flexible performance.

Table 6: Critique - Semantic Web for Developing EAs

\begin{tabular}{|l|l|}
\hline \multicolumn{2}{|c|}{ Critique - Semantic Web Use for Developing EAs } \\
\hline $\begin{array}{l}\text { GERAM framework assessment concludes the } \\
\text { Semantic Web can be used for representing EAs }\end{array}$ & $\begin{array}{l}\text { IFIP-ITAC (2003), Zachman (2011), Broekstra } \\
(2000), \text { W3C (2000) }\end{array}$ \\
\hline $\begin{array}{l}\text { UML, currently used for modeling detailed business } \\
\text { activities, is a deep ontology, but lacks formalism for } \\
\text { repeatability }\end{array}$ & $\begin{array}{l}\text { Gruninger (2003), Shen, et al. (2004), Zachman } \\
(2011)\end{array}$ \\
\hline $\begin{array}{l}\text { Semantic mapping among ontologies will need to be } \\
\text { human assisted rather than fully automated. }\end{array}$ & $\begin{array}{l}\text { Uschold \& Gruninger (2004), IFIP-ITAB (2003), } \\
\text { Bergman \& Giasson (2009), Berners-Lee (1997), } \\
\text { Emmeche et al. (1997), Flake et al. (2003) }\end{array}$ \\
\hline $\begin{array}{l}\text { Employing new Semantic Web technology for } \\
\text { developing EAs without changing the underlying } \\
\text { mechanistic focus on activities violates tenets of } \\
\begin{array}{l}\text { Systems Thinking regarding the socio-technical } \\
\text { framework. }\end{array}\end{array}$ & $\begin{array}{l}\text { Taylor \& Felton (1993), Kroes et al. (2006), } \\
\text { Mitroff \& Linstone (1993) }\end{array}$ \\
\hline $\begin{array}{l}\text { While ontology is recognized as a major feature of } \\
\text { EA construction, there is little evidence that a } \\
\text { holistic, top-down EA ontology for DoD planner } \\
\text { communities has ever been developed as the } \\
\text { authoritative model for all of DoD. }\end{array}$ & Gap - no authors appear to address this \\
\hline $\begin{array}{l}\text { The EAs of the machine age continue to dominate } \\
\text { EA construction using Semantic Web triples with } \\
\text { little recognition of DoD's non-routine jobs that must } \\
\text { allow for adaptive and flexible performance. }\end{array}$ & Gap - no authors appear to address this \\
\hline
\end{tabular}

In conclusion, several authors have identified EA areas that do not appear to have been revisited as technology has progressed. As a result, the rapid advancement of technology has not been matched by required advancement in understanding the human side of these enterprise changes. 


\section{Summary of Enterprise Architecture Critiques and Gaps}

The center of Figure 7 illustrates the critiques from literature regarding EAs, as well as critiques on use of the Semantic Web for developing EAs. This figure also shows gaps indicating areas regarding the practice of EAs where Systems Theory has been ignored.

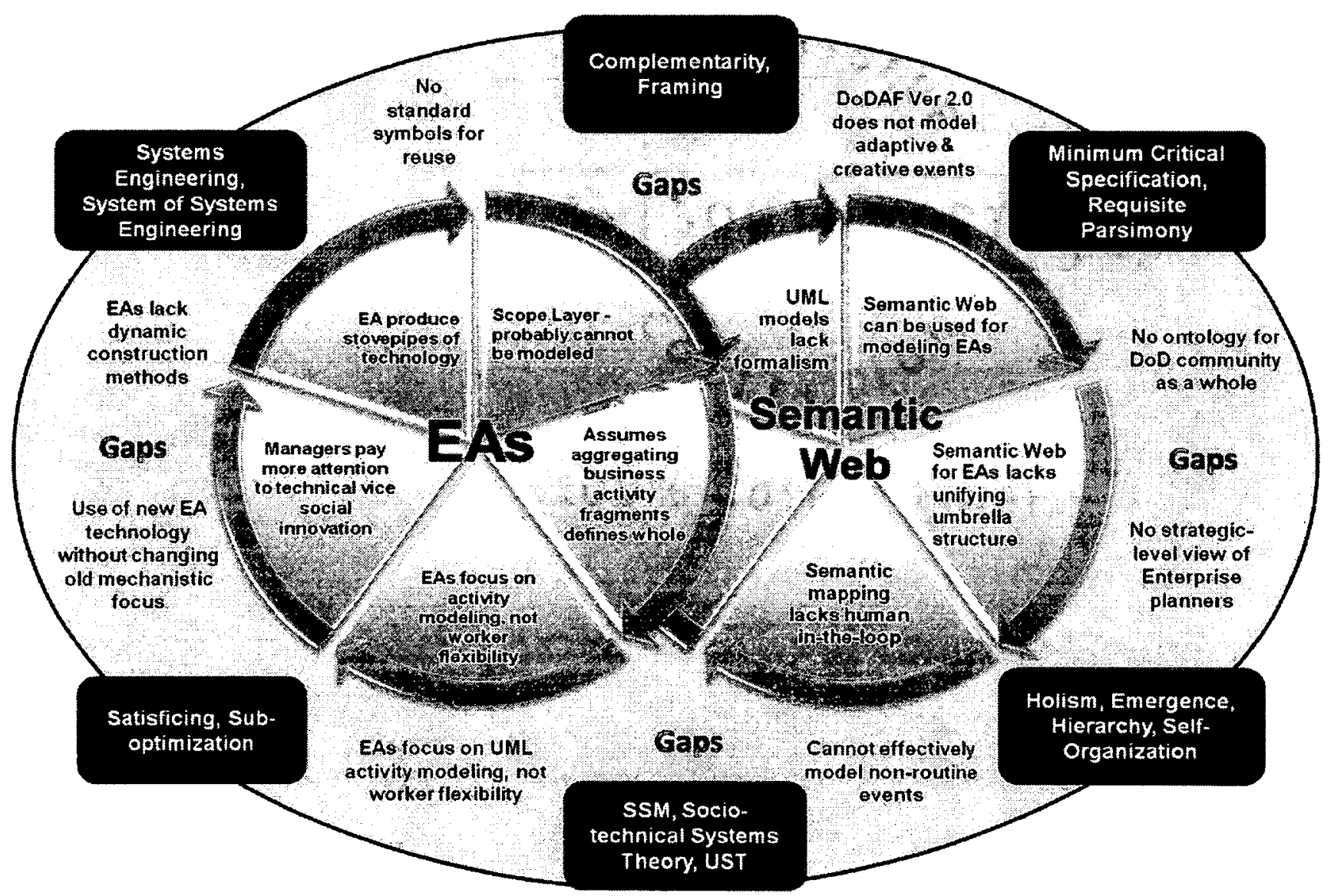

Figure 7: Summary of Critiques and Gaps

What will lead to holistic EAs? Vernadat (2002) defined this need as a unifying umbrella, based on clear ontologies and a meta-model that would unite existing languages rather than enforcing yet another modeling language. This umbrella would sit on top of existing modeling tools, rather than coercing these tools to comply with it. It would somehow implement constructs contained in its meta-language in order to allow the holistic view of an enterprise. 
The International Conference on Enterprise Integration Modelling Technology Conference, jointly supported by the European Commission and the United States through the Department of Commerce' National Institute of Standards and Technology (DOC/NIST)- Manufacturing Enterprise Integration, was attended by 100 experts in the fields of engineering, business administration and computer science, the majority from academia, coming from all five continents (Zelm, 1997). Its goal was to consider and address human aspects in addition to technical aspects of the enterprise, then capture and evaluate the business benefits of Enterprise Integration. After several iterations, this project ultimately resulted in generating more recommendations for uniting the UML language with the Unified Enterprise Modeling Ontology (UEMO) (Opdahl, Berio, Harzallah, \& Matulevičius, 2012). Instead of a unifying umbrella that a planner or business owner could appreciate, UEMO claims to offer only the developer more ways to understand technology symbolism.

Just as Simon's (1956) rats could not rise above their environment to see the most nutritious or most plentiful mounds of food, it appears that the practice of EA cannot rise above the technology level of Zachman's framework (1987). Perhaps there is another avenue toward achieving useful EAs that as Checkland (2000) states it, can describe the complexity of human affair. As with any complex enterprise that carefully and authoritatively documents its business plan and its major philosophic approach to product development, Joint doctrine describes human situations in which people are attempting to take purposeful action (CJCS, 1996). Until now, these documents have not been utilized in a disciplined way as representative of the conceptual skeletal structure of a comprehensive EA. Perhaps, when combined with more socially oriented ontologies recognized by the W3C, corporate knowledge could instead act in concert with Vernadat's (2002) unifying umbrella, because it is based on clear ontologies and an easily 
understood meta-model, it could hover over existing languages to extend the planner's language out to the developer instead of optimizing the current technical focus.

A complex system resists control, but tends to self-organize to a state where it regulates itself... by understanding the underlying mechanism, we may be able to facilitate and simulate such self-organization, or to drive it in one direction rather than another (Heylighen, 2008, p. 16). Therefore, it can also be argued that by recognizing the self-organizing nature of the Semantic Web (Berners-Lee, 1997), its ontological social structure may provide a modern and powerful analogy useful for characterizing DoD's EAs. Systems Theory can assist in understanding complexity, and its reliance on the nature of its workforce. This workforce is well-trained in using Joint doctrine. Therefore, these corporate business documents could provide the prime environment for encouraging an EA that, with the minimum set of critical specifications, creatively collaborates to generate new capability requirements efficiently and effectively, using standards developers can also learn to understand. 


\section{CHAPTER 3 - RESEARCH DESIGN}

The purpose of this chapter is to present the methodology and the corresponding detailed research design. The ultimate goal of this research is to add to the cross-section of knowledge concerning Systems Theory and the Semantic Web as applied to EAs. First, research methods and validation techniques are assessed to provide the theoretical foundation necessary to establish the context for the objectives of the research. The important philosophical basis for selecting the research methodology are discussed and presented as a framework. Then, the theories regarding various research methodologies are scrutinized to identify the attributes of a rigorous design that supports finding answers to the stated research questions. The research design builds on the literature review from the previous chapter where the key elements of the RQ-Tech Methodology were described. Relevant factors for evaluating a paradigm shift regarding EAs are listed as well as the criteria for analyzing those results. Considerations regarding how to best manage the data required for answering each research question are explored. Requirements for data collection and analysis methods are articulated, including the pros and cons of implementing a content analysis methodology for research. The two RQ-Tech research questions prompt a series of data collection introspections that show how the naturalistic canons of dependability, auditability, credibility and transferability are supported by this research design. The key elements concerning how to ensure the research design will support validity and reliability requirements round out the phased research design presented in this chapter.

\section{High-level Research Design}

The high-level approach for this study is presented in Figure 8. As shown, each distinct 
stage of development was influenced by Systems Theory as well as the canons of science for research paradigms. In order to construct each phase, thought was given as to how to describe theoretically-grounded tasks designed to implement a rigorous research framework. The output from each phase is intended to be utilized as input to the next phase. As illustrated, exploration of research theory is emphasized in the early phases of the research design thereby providing a strong foundation for the validation techniques employed in the following phases of this research design. The three-pronged literature review conducted in phases zero and one are used to evaluate a list of contributions, implications and future initiatives that, if significant, would add to the established body of knowledge in any of the three areas of Systems Theory, EAs, and the Semantic Web.

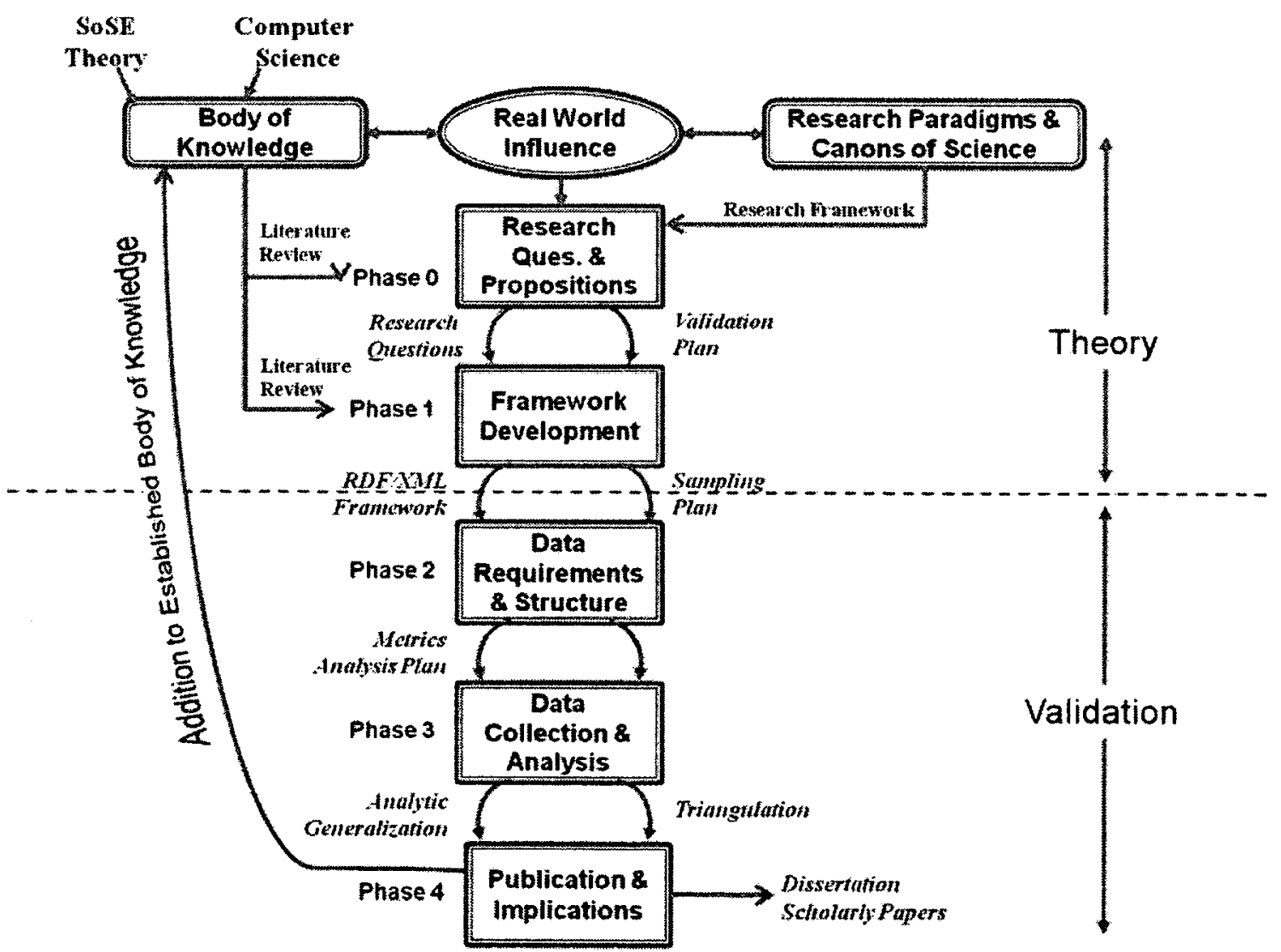

Figure 8: Phased Research Approach 
The detailed phased research approach includes:

- Phase 0 Research Questions and Propositions Overview: Research papers document both systems engineering and software engineering approaches to EA. Some express dissatisfaction with the cost, schedule and quality of current EA models (GAO, 2009; Gruninger, 2003; Levin, 2009; Tolk, 2006). Additionally the Government Accountability Office (GAO) validated the need for better EA processes, indicating this is an area in need of research. The critiques and gaps found as a result of the literature concerning Systems Theory, EAs, and the Semantic Web; are highlighted. Input regarding research paradigms and the canons of science are incorporated into a thorough validation plan. The two research questions explored are:

- What are the most significant factors to consider when translating authoritative text and rich pictures into semantic models?

- To what extent are enterprise models aligned to Joint doctrine useful in representing operational scenarios to illustrate warfighter capability needs?

- Phase 1 Framework Development Overview: The literature review required to develop the RQ-Tech Semantic Web data collection technique spans systems theory as well as computer science topics. Additionally, technical descriptions and tutorials associated with the Altova ${ }^{\mathrm{TM}}$ software suite are studied in order to develop the research framework.

- Phase 2 Data Requirements and Structure Overview: The initial attributes used to select a representative sample of Joint doctrine are developed. These attributes represent the variety and organizational importance of information contained in Joint doctrine publications. Methods for analyzing the sample are developed and deployed

- Phase 3 Data Collection and Analysis Overview: The results from the research methods used to analyze the document are reviewed. Both qualitative and quantitative methods are used to analyze and display the results. Subject matter experts are brought in to comment on a prototype example of how the data could be displayed for use.

- Phase 4 Publication: Reporting supports and defends anything found (significant or not) during this research project. At this point, the contributions, implications and future initiatives, as supported by the data collected and analyzed, are documented.

The research design unfolds in phases, and describes what needs to be done while the philosophical foundations of the research design provide guidance as to how the research should be conducted. 


\subsection{Philosophical Foundations of the Research Design}

Philosophical assumptions in research consist of a basic set of worldviews, or paradigms, that guide inquiries. Various worldviews have common elements but differ in the nature of their reality, i.e., ontology; as well as how knowledge is gained, i.e., its epistemology (Cresswell \& Plano Clark, 2011). The assertion of truth begins with the researcher's idea. The individual researcher must generate a set of propositions that will establish truth, and somehow demonstrate the truthfulness of that idea (Brewer \& Sousa-Poza, 2009). When the researcher can successfully communicate her truth to others, then knowledge is created.

A canon, defined as a general rule, fundamental principle, aphorism, or axiom governing the systematic or scientific treatment of a subject (OED, 2013); is developed within disciplines to meet specific requirements for creating knowledge from truth. Mapping ontology and epistemology to worldviews yields recommendations for arriving at the best fitting research methods of the three possibilities; qualitative, quantitative, or mixed (Cresswell \& Plano Clark, 2011; Leedy \& Ormrod, 2005). For example, the positivist values the objectivity gained through controlled experiments while the constructivist seeks truth from intellectual examination (Brewer \& Sousa-Poza, 2009). A strictly qualitative approach will yield more inductive results, that is, patterns, theories and generalizations. The qualitative researcher's epistemology is characterized by the close relationship the researchers have to the participants in the study. This is more logically aligned to the worldview held by constructivists (Cresswell \& Plano Clark, 2011; Leedy \& Ormrod, 2005; Patton, 2002). On the other end of the spectrum, traditional positivists are guided by methods that require them to propose a hypothesis and use a deductive approach to statistically test the theory (Cresswell \& Plano Clark, 2011; Leedy \& Ormrod, 2005; Patton, 
2002). Their desire for impartiality would dictate use of data collection tools vice contact with study participants.

Both qualitative and quantitative methods contain biases toward seeking uniformity and overlooking multiplicity. This is especially problematic when there is an implied emphasis on finding common themes or patterns as well as an assumption that similarities are theoretically more significant than differences (Maxwell, 2010). In this context, mixed methods research designs can use quantitative analysis methods as an important check on such biases. For example, adding a step to count or report percentages of the qualitative data may provide the evidence that was overlooked by both the researcher and participants during a previous qualitative data collection task.

These recommendations from the literature are important to consider early in the research design. If the research approach is not well-suited to the type of data required for the research study, then results from data collection and analysis may have limited scholarly contribution. There are numerous attributes that are useful in identifying appropriate research designs. In general, research experts Leedy and Ormrod (2005) recommend starting the research method selection process by remaining open-minded to the basic format of all research instead of bounding the research design by discipline-specific constraints too quickly. When the study matures to the point where the questions and goals of the research become specific, the researcher can then focus on what type of data will be required, and how it can be obtained, sampled, and analyzed. Leedy and Ormrod (2005) describe this point as the link between Absolute Truth and the researcher's inquiring mind (p. 93). 


\subsection{Case for Selecting Content Analysis}

This section describes the scholarly perspective for selection and utilization of content analysis as an appropriate approach for this research effort. The most common use for content analysis is data about communication between people or groups of people. Researchers utilize forms of data such as observations, interviews, written documents, audiovisual materials, and electronic documents to answer their research questions (Cresswell \& Plano Clark, 2011; Leedy \& Ormrod, 2005; Patton, 2002). Content analysis may be considered a quantitative method when research designs require tabulation of the frequency of identified characteristics (Zhang \& Wildemuth, 2009 ). Qualitative data gathered using content analysis may be analyzed using frequency or percentage calculations. Adding this quantitative aspect to a qualitative content analysis design is consistent with research designs that are classified as mixed methods. This blending of approaches, i.e., mixed methods, gained popularity in the last decade because merging narrative with statistics adds depth and multiplicity to research (Cresswell \& Plano Clark, 2011).

As this specific research design took shape, distinguishing characteristics of quantitative, qualitative and mixed approaches were iteratively examined for best fit. The research questions for this study are clearly oriented toward the more social aspects of EAs, where literature confirms the mostly hard systems engineering approach has been applied. This researcher wondered if applying the soft systems approach would yield better results. Clearly this study is made up of qualitative aspects, but the essence of the research questions also demands rigor that a systematic approach would provide. The qualitative method of content analysis appears as the best fitting methodology for providing answers to the study questions stated for this research. 
Content analysis is a formal methodology used widely in the social sciences. The method involves detailed and systematic examination of the contents of a specified body of material in order to identify patterns, themes and/or biases.

Characteristics of the study that point to use of content analysis techniques for this study include the following (Cresswell \& Plano Clark, 2011; Leedy \& Ormrod, 2005; Patton, 2002; Zhang \& Wildemuth, 2009):

- Topic includes forms of human communication,

- There is time in the project plan that can be allotted to the up-front planning required for data identification and sampling

- The data needed can be identified and processed in a purposeful manner

- The study lends itself to development of a coding or rating procedure

- The study requires a second type of data collection to support ideas, e.g., crosssectional studies or quasi-experimental studies

- The study benefits from aspects of frequency and/or percentage tabulation

- The study is looking for emergence of patterns, themes and trends during analysis.

- The study seeks to validate and extend a conceptual framework or theory.

Naturalistic research seeks to observe participants without changing the routines of those being observed. Any type of observation, survey, interview, or other interaction between subjects and the researcher will change the behavior of the subjects, although the change could range from minimal to significant. This phenomenon, known as the Hawthorne effect (Western Electric Company, 1929), acknowledges that human subjects who know they are being observed will behave differently than when they are not under observation. Therefore, the use of content analysis regarding the document-review process does not risk changing behaviors. This aspect of content analysis makes the approach particularly appropriate for the present research design, which emphasizes an extensive use of documents for data analysis.

Although content analysis of published data is widely used in history, journalism, and 
anthropology, it is also extensively used in the business policy area (Jauch, Osborn, \& Martin, 1980; Krippendorff, 2004). Those using content analysis seek to understand what context data means to people and what the information conveyed by them does (Jauch et al., 1980; Morgan \& Smircich, 1980).

In summary, content analysis was selected for this research design because it is frequently used for analyzing communication between people or groups of people. The data gathered from content analysis may be analyzed both qualitatively and quantitatively. Its multifunctional use as a mixed method provides information about qualitative aspects of organizational communications as well as the rigor of a systematic approach to identify critical factors. Analyzing organizational documents using content analysis does not risk changing the behaviors of the subjects, and content analysis has a history of use in the business policy area making it well-suited to this research study.

\subsection{Challenges in Using Content Analysis}

A common issue regarding the use of qualitative research methods finds that more detailoriented researchers may find and code aspects of the documents that could be overlooked by a researcher with a different capacity for detail and/or a different dominant worldview. A set of strategies to mitigate the potential risk of using content analysis for scholarly research has been aptly synthesized by Zhang \&Wildemuth (2009):

- To improve the credibility of qualitative content analysis, researchers should construct data sampling, coding, and analysis processes and include these documents in their research report. Doing so helps to show transparency in analysis.

- Documenting the experience coders have should be included along with the precise coding instructions and what training coders received prior to collecting data. This was also shown to have significant positive impact on the credibility of research results. 
- Audits are a useful technique for establishing dependability.

Several researchers (Jackson, 2000; Mitroff \& Linstone, 1993; Morgan \& Smircich, 1980 ), find there is a perceived need for a more reflexive approach to understanding the nature of social research, with a focus on tacit underlying assumptions often linked to favored research techniques. While Jackson observes that when methodology, such as content analysis is accepted, practitioners tend to take the underlying theory for granted. This could mean that underlying assumptions are not examined as often as needed to be to see if they are still valid. This echoes Morgan and Smircich's findings:

....preoccupation with methods on their own account obscures the link between the assumptions that the researcher holds and the overall research effort, giving the illusion that it is the methods themselves, rather than the orientations of the human researcher, that generate particular forms of knowledge. (1980, p. 499)

While content analysis appears to be an excellent fit as a research methodology for this study, there are challenges worth considering. Data collected using individuals who must make decisions about what the data means is a risk. The specific research design that follows has been crafted to address concerns and incorporate strategies to mitigate criticisms of the approach.

\subsection{Content Analysis Methodology Summary}

The content analysis data collection methodology has been selected because it supports the naturalistic worldview of social science. When carried out responsibly, a properly constructed content analysis research design has the potential to satisfy the canons of science pursued for rigorous research. That is, the research design will be able to provide credible findings for revealing the required truth value, and it will be able to demonstrate transferability when the same research design is applied to other setting or contexts judged to have sufficient congruence to the present research. Content analysis qualifies as a rigorous research method 
when the research designs that specify its use include purposeful sampling plans, comprehensive coding instructions, profiles for competent data collectors, and transparent data analysis techniques. Content analysis may not be touted as useful by natural scientists. However, there appears to be a growing trend among systems thinkers who find this research approach useful for learning how the soft side of engineering affects changes to complex organizations (Cresswell \& Plano Clark, 2011). This was one of the most important reasons for selecting content analysis for this research design.

Incorrect assumptions concerning research techniques can negatively impact the outcomes of a content analysis research effort, just as faulty assumptions can subvert empirical research studies as well. Content analysis has the potential to be successfully used either as a qualitative approach or combined as a mixed methods design approach. However, it remains up to the individual researcher to do the preliminary planning to evolve a solid research concept, as well as explore the use of many types of research methods before selecting those that will provide the best ways to manage and present the data necessary to credibly represent the study findings.

For this study, content analysis was selected as a methodology well after the research questions were proposed, the literature was reviewed, and the requirements for the research methodology were taking shape. It was selected before the data collection instrument was finalized, the research design was still evolving, and the drawbacks of this research methodology were being investigated. Selected at the optimum time in the research, content analysis promised to be the solid research concept that this study requires. 


\section{Specific RQ-Tech Methodology Research Design}

The tenets of the constructivist approach to research methodology have been used to form the foundation of the specific RQ-Tech Methodology research design. In this section, the specific aspects of research are discussed and detailed descriptions of each phase of the RQ-Tech Methodology research plan is revealed and explained. The RQ-Tech Methodology research design is mapped to the selected canons of science for the naturalistic method. This linkage is used as a way to summarize how each of the requirements for research is addressed. In addition, the specific design provides the particular strategies and safeguards employed to provide rigor to enhance the scholarly grounding of the research.

The concept for the RQ-Tech Framework that provides answers to the first research study question is presented in Figure 9. This graphic outlines the progression of steps involved in determining how Joint doctrine would be categorized using the unique RQ-Tech schema-based instrument developed specifically for analyzing content. First the FOAF W3C standards were researched to identify how friends identified themselves and their interests on an internet site and how they linked their profiles to others they considered their friends. 


\section{RQ-Tech Framework}

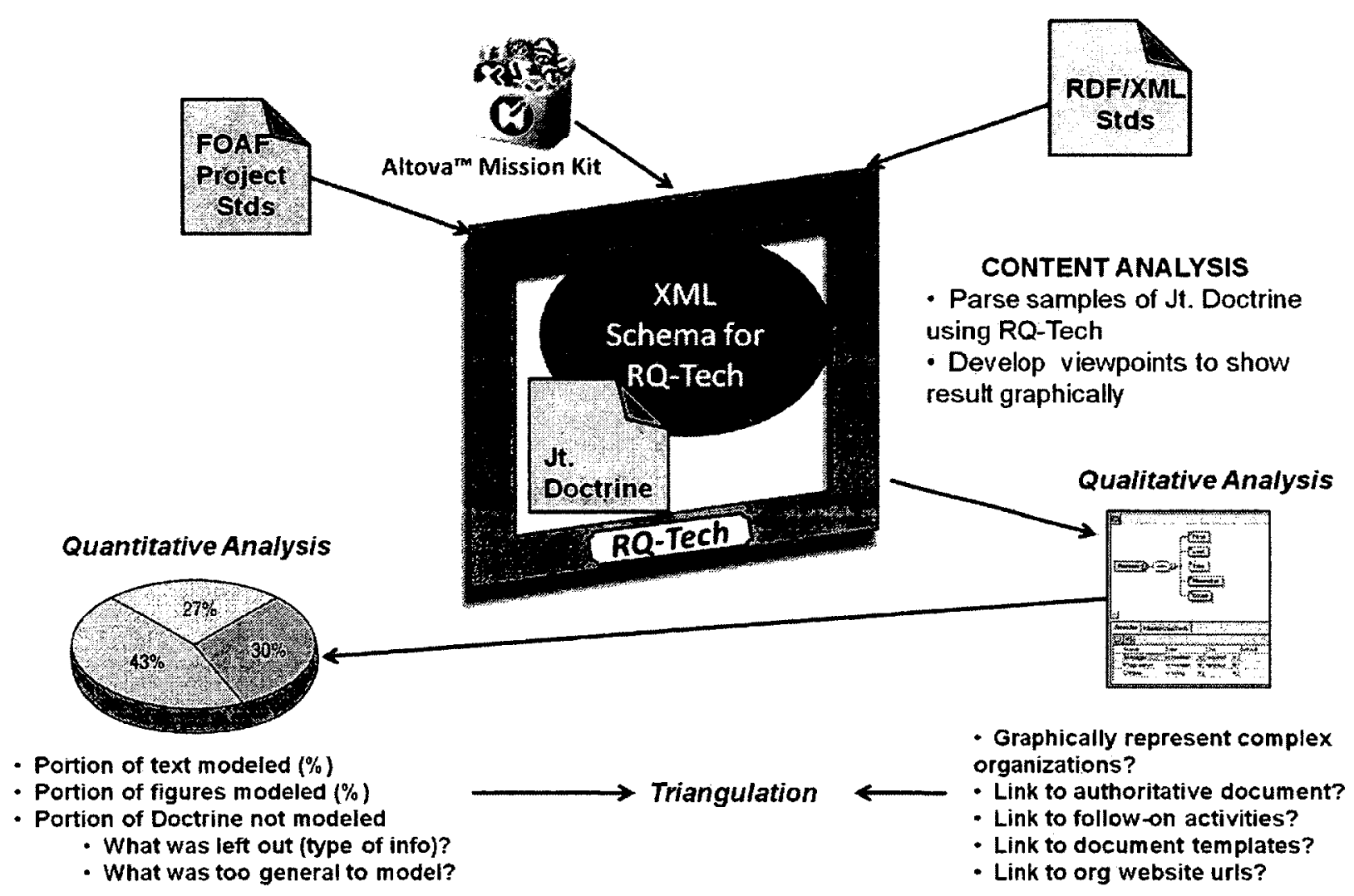

Figure 9: RQ-Tech Research Design

Then, using Altova ${ }^{\mathrm{TM}} \mathrm{XML}$ software, a trial schema would be constructed to document the data rules for the selected FOAF Semantic Web expressions. The Altova ${ }^{\mathrm{TM}}$ software was constructed so that it would be populated from spreadsheets containing trial samples from various Joint doctrine publications. Samples would continue to be parsed until various qualitative and quantitative analysis methods started to show positive results, indicating the RQTech Framework was mature enough to use for extended data collection activities.

Systematic data-collection activities involved parsing each block of text in the selected Joint doctrine publication to identify the appropriate category (meta-data) tag(s), as described by the schema. In this fashion, important entities (classes) and communication relationships 
(properties) identified in the doctrine publication would be collected and coded as they were copied and pasted under the appropriate column header of the data collection spreadsheet. As discussed, this content analysis method used the schema and parsing instructions together with the data collection instrument. Performing the triangulated qualitative and quantitative analysis shown in Figure 9 would eventually provide the answers to the first research question pertaining to the most significant factors that were found useful for translating authoritative text and rich pictures into semantic models.

If the resulting qualitative and quantitative analysis from these samples had shown that Joint doctrine could not be formally captured in the RQ-Tech semantic model, then the research would have ended, without proceeding to research question two. The findings would agree with Williams, et al. (2001) who wrote that the text and rich pictures of the scope level of a complex enterprise probably cannot be formally modeled. This answer to this question and subsequent analysis is covered in Chapter 4.

Alternately, if specific inputs, outputs, and activities of this research indicate a positive result to research question one, follow-on research activities would begin. These activities would include gathering results from a participant survey designed to characterize viewpoints of potential users of this EA concept. Figure 10 represents the question-driven work breakdown structure (WBS) for continuing the research design. These tasks describe the series of research activities required to continue the framework of inquiry and provide answers to the second research question, to what extent would enterprise models aligned to Joint doctrine be useful in representing operational scenarios to illustrate warfighter capability needs. 


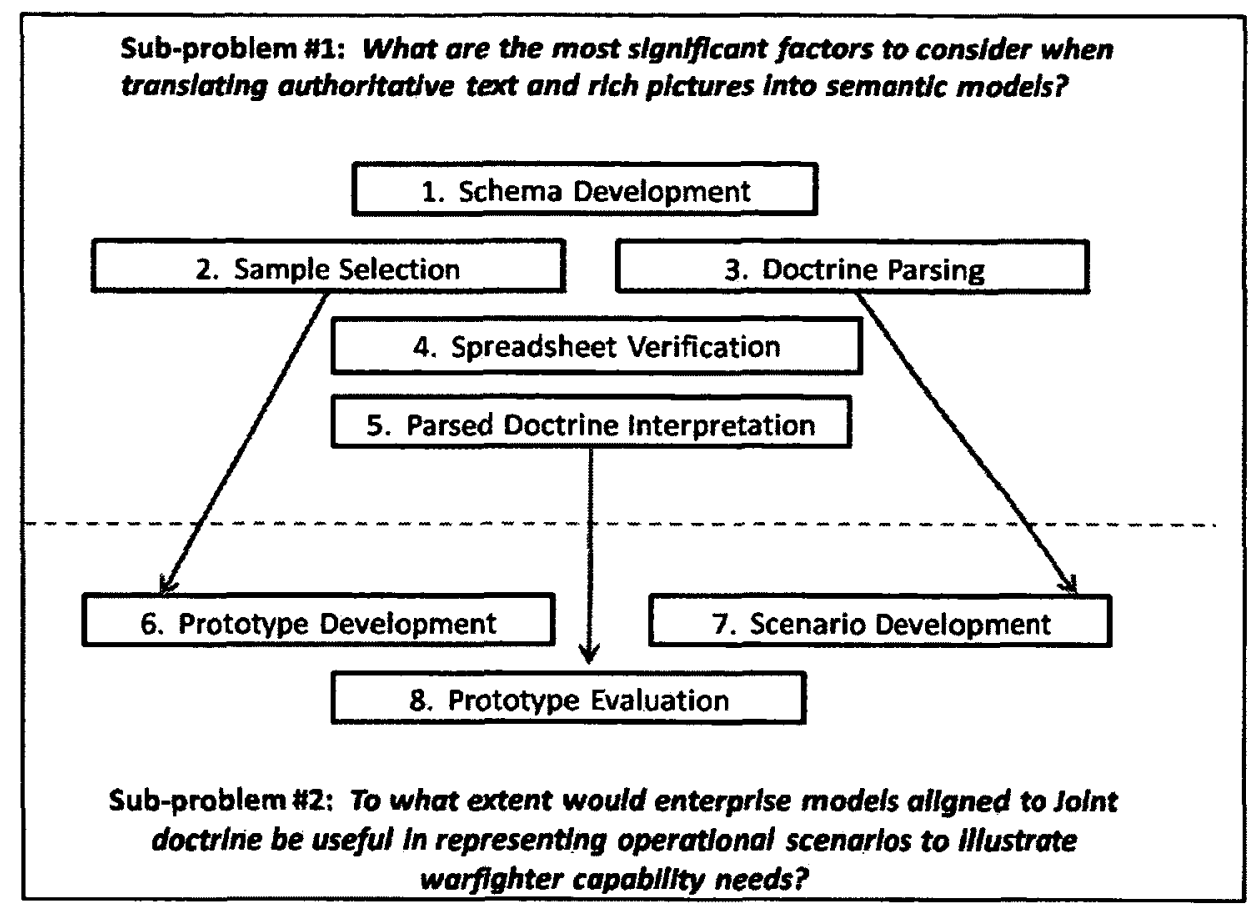

Figure 10: RQ-Tech Research Work Breakdown Structure

As the details of data collection and analysis are clarified, the WBS begins to takes shape. Connecting each data-oriented task shown in Figure 10 in a logical sequence resulted in the structure of a project plan. This plan included specific, assignable tasks for organizing and managing the research design. These sets of activities can now be considered as justified (Leedy \& Ormrod, 2005), that is, they reflect a portion of the chosen research approach that is the objective of this research. Describing the characteristics of the research data at each step of the design forms the solid foundation of the research design.

The following task descriptions illustrated in Figure 10 pertain to question one, what are the most significant factors to consider when translating authoritative text and rich pictures into semantic models:

Task 1 - Schema Development: An XML schema is used as a precise way to define the structure, content and semantics of XML documents so that the data can be collected. The 
schema can be thought of as a definition of the column headers of a table or spreadsheet.

According to the $\mathrm{W} 3 \mathrm{C}$, the purpose of an XML Schema is to define the legal building blocks of an XML document. An XML Schema:

- defines elements that can appear in a document

- defines attributes that can appear in a document

- defines which elements are child elements

- defines the order of child elements

- defines the number of child elements

- defines whether an element is empty or can include text

- defines data types for elements and attributes

- defines default and fixed values for elements and attributes

Since the schema is developed using Altova ${ }^{\mathrm{TM}} \mathrm{XMLSpy}$, which is an advanced XML editor, the schema is continually checked to ensure that it agrees with the W3C standards for a well-formed and valid XML document.

Task 2 -Sample Selection: For this study, it is assumed that the set of documents known as Joint Doctrine (Appendix A -Joint Publication Status) is the entire population of authoritative text and rich pictures that serves to describe the DoD mission. The mission of the DoD is to provide the military forces needed to deter war and to protect the security of our country (DoD, 2013). Joint doctrine presents fundamental principles that guide the employment of US military forces in coordinated and integrated action toward a common objective (Joint_Staff-J7, 2013):

- It promotes a common perspective from which to plan, train, and conduct military operations.

- It represents what is taught, believed, and advocated as what is right (i.e., what works best).

- It provides distilled insights and wisdom gained from employing the military instrument of national power in operations to achieve national objectives.

In order to provide answers to question one, the keystone publication, Joint Logistics 4.0 
was chosen for the following reasons:

- At the keystone level, the detail is expected to be granular enough to identify what is involved in strategic and operational planning for logistics, and to provide a broad structure of organizations and agents needed to carry out logistics planning. It serves to create a taxonomy of logistics planning documents that would be required for organizing the more detailed logistics publication material contained in the more specialized Joint Doctrine pubs on the subject of logistics

- The topic of logistics is integral to all strategic, operational and tactical planning decisions

- This keystone publication was published using the template common to all Joint Doctrine publications. This element of homogeneity provides the basis for demonstrating probability that it is representative of how all Joint doctrine is written. It is therefore reasonable to expect any other Joint Doctrine publication could be processed using the RQ-Tech methodology.

Schema development and sample selection are the first two tasks in the RQ-Tech methodology research design. The schema defines the building blocks in a manner that is continually checked to ensure it is well formed and valid. The sample of Joint doctrine selected has been evaluated to ensure it is a representative publication. In this way the first two activities of the research design exhibit the attributes of rigor and validity.

Task 3 -Doctrine Parsing: The final version of the RQ-Tech schema for this study (Appendix B-RQ-Tech XML Schema), was used for predefining the tags of the RQ-Tech XML document. An XML document is designed to carry data. It is analogous to the content of the rows of the table or spreadsheet where the column headers are defined by the schema. Together the RQ-Tech schema and RQ-Tech XML document form the collection instrument designed to receive the parsed data from the Joint publication library sample. The method for selecting the most appropriate XML tag(s) for each parsed document-block of text or picture is described in Appendix C - Method for Document-Parsing.

While the document parsing activities required a considerable amount of time in the 
beginning, this researcher observed it quickly became easier to perform the parsing tasks with good quality in much less time. Some text paragraphs were clearly written leaving little that could be considered subjective while other paragraphs were long and involved. The researcher was constantly reminded to look for key elements in the paragraph that conveyed the meaning of the rest of the paragraph. Soon perusing the various chapters of the Joint doctrine sample to note evidence of team planning and communicating became more systematic and objective.

Task 4 -Spreadsheet Verification: The Altova XMLSpy ${ }^{\mathrm{TM}}$ editor clipboard feature allowed data entry via spreadsheet. Working with spreadsheets allows researchers to utilize their spreadsheet skills to check for errors and typos prior to upload into the Altova XMLSpy ${ }^{\mathrm{TM}}$ editor. This is performed by sorting and comparing the data in various configurations to find errors. A sample of the spreadsheet workbook used for input into the Altova XMLSpy ${ }^{\mathrm{TM}}$ editor is shown in Appendix D-RQ-Tech Spreadsheet Workbook Sample. After the spreadsheet was loaded into Altova ${ }^{\mathrm{TM}}$, the built-in editor was used to ensure the document was well-formed, that is, it followed the W3C standards for all XML documents. Then the Altova ${ }^{\mathrm{TM}}$ editor was used to check to see of the data was entered correctly according to the RQ-Tech schema developed for this purpose. When all the data entered passed both Altova XMLSpy ${ }^{\mathrm{TM}}$ editor checks, the RQTech XML document, developed from the spreadsheets of the parsed Joint doctrine sample, was declared both well-formed and valid.

Task 5 -Parsed Doctrine Interpretation: Even though Joint doctrine publications follow a typical outline, they are mainly a collection of descriptions written by various subject matter experts and edited to form a publication that can be accepted as authoritative by a designated committee of Joint doctrine experts. Therefore the natural language and writing style varies between blocks of text. In addition, there are many English language terms that can be 
used to correctly, yet creatively, describe the same set of information. Some of these inconsistencies have been resolved by using attributes of the RQ-Tech schema. For example, the attribute generic $=$ true, is applied when a general term or title is encountered. However, awkwardly-worded sections of the publication where the author's true intention cannot be discerned without doubt is an example of other issues that are addressed in the findings section of Chapter 4 of this study.

With regard to research question two: to what extent are enterprise models aligned to Joint doctrine useful in representing operational scenarios to illustrate warfighter capability needs, the WBS task descriptions six through eight apply, as follows:

Task 6 -Prototype Development: The Altova XMLSpy ${ }^{\mathrm{TM}}$ editor for modeling, editing, transforming and debugging the data from research question one was repurposed to use as the Semantic Web prototype application. Although lacking full automation, the prototype was intended to mimic the dynamic function of an Enterprise modeling tool user-front-end for the purpose of providing relational groups of data in return to user queries. In this fashion, users who are experienced in working with Joint doctrine could experience a Semantic Web view of the information they have studied and used in the past. As subject matter experts (SMEs), members of the Joint Force Staff College (JFSC) are able to form opinions about this functionality and provide qualitative assessment regarding research question two of this study. Several screen shots of the RQ-Tech prototype are provided in Appendix E-RQ-Tech Prototype (Screen Shots).

Task 7 -Scenario Development: An exercise outline to facilitate users in developing EA artifacts using role-play about a problem they could experience as a warfighter was developed. Scenarios help users express the complexity of their working conditions. This 
provides the context surrounding the problematic event. In this way, users reveal how they make decisions. Technology designers need to know about some of the implicit organizational tradeoffs in order to develop new automation (Pomerol et al., 2002). The specific scenario-building activity used for this research was designed to allow the SMEs to produce a fictitious as-is environment based on past exercises the SMEs had facilitated with their own students. As a scene-setter, a simplified scenario concerning logistics planning was developed (Appendix F Logistics Planning Scenario).In this fashion, the participants had the freedom to explore the prototype and interact with the researcher from the warfighter perspective.

It is common practice to describe problems experienced using examples. Participants can use the general activities described in Joint doctrine as the context-free event at the core of the example. Then real world examples invite the audience to mentally envision the context of the event that makes the core event a problem worth investigating.

Task 8 -Prototype Evaluation: User feedback, in the form of a survey (Appendix G User Feedback Survey), was designed to be elicited individually from the participants after they had the opportunity to interact with the prototype and work through the scenario. Specific survey questions were constructed to measure what the participants thought about certain aspects of the prototype. A Likert-type (1932) definition was provided to assist the SMEs in determining their level of agreement with the survey statements. Ample space on the survey was allocated for comments on any portion of the survey and/or the prototype session. Although the Likertscale answers provide quantitative responses to the survey questions, the participants provided qualitative opinions based on how they felt regarding the prototype and its projected implementation. The term for this type of research technique is scaling, that is, the quantification of qualitative measures (Jick, 1979). 
At the conclusion of this task, the second research question can be answered. Potential users have the opportunity to decide if Joint doctrine presented as a flexible and adaptable model would be useful to them and their organizational mission in the future.

\section{Strategies for Rigorous Research Design}

In order for the RQ-Tech Methodology research to be considered worthwhile, the research design must satisfy the canons of science for the most appropriate research design worldview. The researcher's selection of the qualitative method, namely content analysis, is considered a naturalistic worldview that emphasizes the naturalistic, or constructivist set of canons (Brewer \& Sousa-Poza, 2009). Content analysis is the formal methodology that is most commonly used for aspects of communication between people or groups of people (Cresswell \& Plano Clark, 2011; Leedy \& Ormrod, 2005; Patton, 2002). Figure 11 illustrates the high-level RQ-Tech Methodology research design WBS hierarchy mapped to the primary tenets of the naturalistic method. Each primary naturalistic tenet is discussed here in detail, including its influence on research task design and deployment. 


\section{RQ-Tech Research Design Work Breakdown Structure}

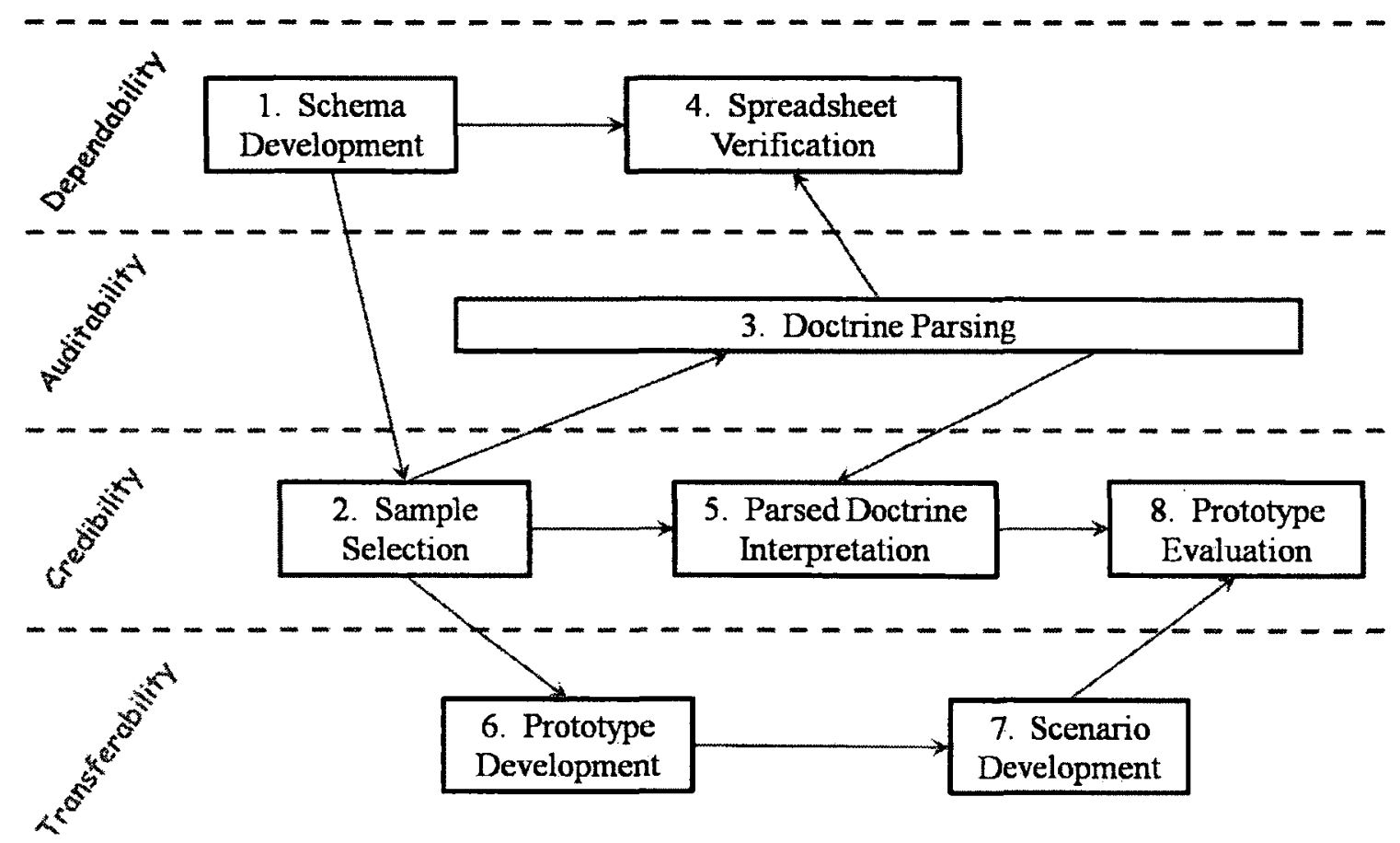

Figure 11: RQ-Tech WBS for the Naturalistic Method

Dependability: This attribute was demonstrated by thoughtful construction and

disciplined use of the RDF/XML schema that provided the coding and data collection instrument for this research design.

- The XML schema was used to validate the contents of the data elements. The RQ-Tech Methodology schema utilizes several classes and properties of the social network FOAF experiment (Brickley \& Miller, 2000). It also extends the FOAF schema with additional class and property elements so that the RQ-Tech schema can be used initially as a data collection instrument.

- The RQ-Tech Methodology schema provides XML namespace documentation to anyone who needs to understand the data (Walmsley, 2002).

- By following the FOAF guidelines as well as the XML/RDF construction recommendations (W3C, 2004b), hyperlinks to the exact paragraph where the data element is found provides provenance to the source text block (url link to Joint doctrine) and allows continuous verification by SMEs during future use and/or audits.

- Methods of verifying correct use of the schema, e.g., spreadsheet verification, 
enhanced the dependability of this data collection effort. To minimize typing errors, sections of doctrine text were cut and pasted into the spreadsheet. Also, the spreadsheet was sorted and analyzed in several different ways designed to spot and fix mismatched entries. The Altova XMLSpy ${ }^{\mathrm{TM}}$ tool provided a built-in validation function that provided pointers to data-entry errors. The checking process would not proceed until the errors found were corrected.

Dependability of the research design is evidenced through the use of the XML schema validation tools, the XML namespace documentation, the hyperlinks back to the source in the Joint doctrine document, and validation techniques employed during data collection.

Auditability: Well designed research may be demonstrated by an external audit of the procedures used, how the data was processed, and/or how it was reviewed and interpreted. The canon of neutrality for this research design was demonstrated in the following ways:

- An audit trail was built into the RQ-Tech schema in the form of hyperlinks back to the exact part of the Joint doctrine page where each element was described. This design element is most importantly an integral part of the theory behind the RQ-Tech methodology, because links back to doctrine enforce flexibility and adaptability features. In addition, these links allow further determinations of the accuracy of each decision the coder made when building the RQ-Tech XML document.

- Keeping a color-coded hard copy of each publication to document what words and phrases were entered into the collection instrument. This type of highlighting also facilitated quantitative analysis by allowing a count of how many blocks of text were able to be documented using the parsing methods relative to the number of blocks of text in the entire document.

- An analysis of the blocks of text that did not match any of the schema data. This was repeatedly conducted to identify what types of content could not represented in the collection instrument, and why this was so. This analysis is consistent with good research practice that actively looks for evidence outside the boundary to determine if there are other considerations that would later affect the validity of the findings (Leedy \& Ormrod, 2005).

Auditability of the RQ-Tech research design is demonstrated via the audit trail left by

hyperlinks from the Joint doctrine document to each entry in the RQ-Tech XML document. A hard copy mark-up document keeps track of the amount of doctrine that could be parsed and 
coded, and an analysis of doctrine that does not match any doctrine parsing rules clearly reveals to auditors what types of doctrine is resistant to the rules of RQ-Tech doctrine parsing.

Credibility: A well thought-out content analysis research design has the ability to provide credible indicators of the required truth value. The RQ-Tech research design demonstrates this attribute by:

- Processing a sample Joint publication considered representative of the entire Joint doctrine library. The document parsed contained a variety of emergent planning requirements as well as maintenance activities. It provided a unique slice of warfighter considerations that if neglected would have high impact on the mission.

- The principal researcher made the final decisions about how the data was parsed. This approach made the most of the principal's significant background in using Joint doctrine publications, as well as minimized the need for inter-rater reliability.

- Potential users (JFSC instructors) were invited to visualize the doctrine they use on a daily basis as a social network. They were also provided a lab environment and individual surveys to capture their thoughts on the potential of this modeling method as a more holistic picture of the complex DOD system of systems.

Credibility of the RQ-Tech methodology is evidenced by the following indicators; the sample is representative of most Joint doctrine, the researcher responsible for coding the document has significant experience handling Joint doctrine, and SMEs with ample Joint military experience provided a qualitative assessment of the RQ-Tech methodology potential for representing Joint doctrine.

Transferability: Scenario development and prototyping was utilized for the demonstration portion of the research design, illustrating the naturalistic tenet of transferability:

- Eliciting comments, both positive and negative, on the projected implementation of the prototype gave JFSC users an opportunity to imagine future uses for the prototype based on their past, real-world experiences

- Various types of scenarios were required to be constructed during the prototyping phase of the research design. These techniques also provided dual-utility for illustrating the complex military world as a user-built model. 
- Use of W3C standards for the prototype allows for further model testing, comparison and validation with existing business process models and ideas or new models that also conform to the W3C RDF/XML standards. As Gruninger (2003) writes;

One problem is that enterprise design knowledge is currently descriptive and adhoc. It is a collection of heuristics that are not applicable in all circumstances. Therefore, it is desirable to define a theory of enterprise design by discovering its underlying principles. (p. 536)

The attribute of generalizability is demonstrated as survey results and comments from the SME's are compiled. These participants had the opportunity to interact with the resultant flexible RQ-Tech model of the sample Joint doctrine document, and could testify as to its potential for other uses.

\section{Considerations of Validity and Reliability in Research Design}

Various validity and reliability types were used throughout the research design and implementation phases of the RQ-Tech methodology. Specifically, the following activities were used to deliver a rigorous research project:

- The literature review indicated requirements for a set of classes and properties used by social networks to classify interactions between friends. The research question prompted development of a schema that used these identified classes and properties to form the structure for a data collection instrument - demonstrating internal consistency reliability.

- A parsing process was developed and performed as a trial to demonstrate that Joint doctrine could be parsed using the data collection schema-demonstrating descriptive validity.

- A sample selection strategy was constructed that indicated which publication of Joint doctrine would be parsed to satisfy requirements for answering the both research questions - demonstrating content validity.

- Sets of graphics that show the qualitative data were constructed - demonstrating construct validity

- Sets of parsed and coded data, arranged as classroom exercises that were later presented to staff from the JFSC for feedback on the quality of the datademonstrating qualitative validation. 
- Groomed qualitative data was arranged graphically to show resultant patterns of data results - demonstrating evaluative validity.

- The results of the qualitative data quantified as statistics and percentages, i.e., what portion of the text was modeled in the schema, what portion of the figures were modeled, what portion of the document was not modeled because it did not fit the schema, what type of data was not modeled, and why was it not included in the model - demonstrating theoretical validity.

The qualitative and quantitative data was triangulated to find out how the two types of methods supported or did not support each other - demonstrating possible external validity.

Table 7 is a summary of the various forms of research data validity and reliability that are manifest in the RQ-Tech Methodology research design (Cresswell \& Plano Clark, 2011; Crowther \& Lancaster, 2008; Hannes, Lockwood, \& Pearson, 2010; Leedy \& Ormrod, 2005).

Table 7: Validity and Reliability Summary

\begin{tabular}{|c|l|}
\hline $\begin{array}{c}\text { Talidity/Reliability } \\
\text { internal consistency } \\
\text { reliability }\end{array}$ & $\begin{array}{l}\text { The extent to which all items within a single instrument yield similar } \\
\text { results }\end{array}$ \\
\cline { 2 - 2 } Schema in Altova ${ }^{\mathrm{TM}}$ \\
\hline \multirow{3}{*}{ descriptive validity } & $\begin{array}{l}\text { The extent to which descriptive information such as events, subjects, } \\
\text { setting, time and places are accurately reported }\end{array}$ \\
\cline { 2 - 2 } & Parsed samples of joint doctrine \\
\hline \multirow{3}{*}{ content validity } & $\begin{array}{l}\text { The extent to which the measuring instrument is a representative } \\
\text { sample of the domain being measured }\end{array}$ \\
\cline { 2 - 2 } & Sampling plan \\
\hline \multirow{3}{*}{ construct validity } & $\begin{array}{l}\text { The extent to which an instrument measures a characteristic that } \\
\text { cannot be directly observed, but must instead be inferred from patterns }\end{array}$ \\
\cline { 2 - 2 } & Graphical viewpoint development \\
\hline \multirow{3}{*}{ evaluative validity } & $\begin{array}{l}\text { The extent to which the information obtained through the data } \\
\text { collection is accurate }\end{array}$ \\
\cline { 2 - 2 } & SME Review \\
\hline & $\begin{array}{l}\text { The extent to which an evaluative framework or critique is applied to } \\
\text { the object of study }\end{array}$ \\
\cline { 2 - 2 } & Qualitative Analysis \\
\hline
\end{tabular}




\begin{tabular}{|c|l|}
\hline \multirow{2}{*}{ theoretical validity } & $\begin{array}{l}\text { The extent to which a theory developed from a research study fits the } \\
\text { data }\end{array}$ \\
\cline { 2 - 2 } & Quantitative Analysis \\
\hline \multirow{2}{*}{$\begin{array}{c}\text { external validity } \\
\text { (generalizability) }\end{array}$} & $\begin{array}{l}\text { The extent to which the investigator can conclude that the results } \\
\text { apply to a larger population }\end{array}$ \\
\cline { 2 - 2 } & Triangulation \\
\hline
\end{tabular}

It would appear from the table and the prior description of the research design that there is ample evidence validity has been designed into the RQ-Tech research methodology.

\section{RQ-Tech Research Design Summary}

The phased RQ-Tech research design was described. This was followed by literature review of content analysis, detailing the reasons it is appropriate for supporting the objectives of this research. A discussion of the canons of science for rigorous research included both the advantages, as well as the challenges, of employing content analysis as the selected research methodology.

The specific research design for the RQ-Tech Methodology was presented. This research design focused on the two research questions that support this research objective, namely, to develop and apply a system theoretic-based methodology and corresponding model for EA development. Table 8 and Table 9 summarize the specific RQ-Tech Methodology research design.

Table 8: Data Collection for Research Question 1

\begin{tabular}{|c|c|}
\hline \multicolumn{2}{|r|}{ Sub-question \#1 Research Approach Justification } \\
\hline \multicolumn{2}{|c|}{$\begin{array}{c}\begin{array}{c}\text { Sub-question \#1: What are the most significant factors to consider when translating authoritative text } \\
\text { and rich pictures into semantic models? }\end{array} \\
\end{array}$} \\
\hline Data Needed & Criteria Governing Admissibility of the Data \\
\hline \multirow{2}{*}{$\begin{array}{l}\text { Documents that describe } \\
\text { the vision and mission of } \\
\text { Joint warfighters, i.e., } \\
\text { Joint Doctrine } \\
\text { publications: }\end{array}$} & $\begin{array}{l}\text { Joint doctrine publication(s) selected from the entire library ( } 83 \\
\text { publications) of Joint doctrine that can form a representative sample of } \\
\text { strategic, operational, and tactical collaborations that can occur during a } \\
\text { complex mission }\end{array}$ \\
\hline & $\begin{array}{l}\text { - Entire publication(s) that depict one or more facets of strategic, } \\
\text { operational, and tactical guidance }\end{array}$ \\
\hline
\end{tabular}




\begin{tabular}{|c|c|}
\hline & $\begin{array}{l}\text { - Entire publication(s) that depicts a mission thread support function } \\
\text { such as force support and logistics }\end{array}$ \\
\hline \multirow[b]{3}{*}{ Nature of the Data: } & Text, rich pictures, document templates, glossaries of terms \\
\hline & $\begin{array}{l}\text { Description of mission requirements devoid of specific context, i.e., } \\
\text { standards and conditions }\end{array}$ \\
\hline & $\begin{array}{l}\text { Authoritative, that is: Joint doctrine presents fundamental principles that } \\
\text { guide the employment of US military forces in coordinated and integrated } \\
\text { action toward a common objective. It promotes a common perspective from } \\
\text { which to plan, train, and conduct military operations. It represents what is } \\
\text { taught, believed, and advocated as what is right (i.e., what works best). It } \\
\text { provides distilled insights and wisdom gained from employing the military } \\
\text { instrument of national power in operations to achieve national objectives. }\end{array}$ \\
\hline Data Location: & JEL (http://www.dtic.mil/doctrine/) \\
\hline Data Availability: & $\begin{array}{l}\text { The majority of publications are available to download as .pdf files from } \\
\text { the JEL. Current versions are available. (However some publications are } \\
\text { classified or available only to those with. mil access.) }\end{array}$ \\
\hline $\begin{array}{l}\text { Data Collection } \\
\text { Instrument: }\end{array}$ & $\begin{array}{l}\text { Altova }{ }^{T M} \text { XMLSpy is an advanced XML editor for modeling, editing, } \\
\text { transforming, and debugging XML-related technologies. The XML editor } \\
\text { allows creation of advanced XML and Web applications, while remaining } \\
\text { flexible enough to allow interoperability with any XML technology } \\
\text { (including the FOAF RDF/XML format) in a way that best suits the } \\
\text { complexity of the document. It allows development in text views as well as } \\
\text { graphical views. The graphical XML Schema editor allows editing of } \\
\text { XML Schema files in a visual manner. The XML editor includes a } \\
\text { clipboard to cut-and-paste from spreadsheets and provides graphical } \\
\text { representation of data relationships for reporting and analysis. }\end{array}$ \\
\hline Data Needed & Criteria Governing Admissibility of the Data \\
\hline $\begin{array}{l}\text { Data Collection } \\
\text { Instrument Schema: }\end{array}$ & $\begin{array}{l}\text { Classified text objects: } \\
\text { - Organizations, } \\
\text { - Agents, and } \\
\text { - Documents (these can be publications (Joint publications as well } \\
\text { as those created by others), work documents (e.g., planning } \\
\text { templates, and/or messages), or cross references that have been } \\
\text { cited to indicate more information is contained elsewhere). }\end{array}$ \\
\hline
\end{tabular}




\begin{tabular}{|c|c|}
\hline & $\begin{array}{l}\text { Classified text predicates (State of being): } \\
\text { - (has a) workplaceHomepage, } \\
\text { - (has a) depiction (url link to an image file) } \\
\text { - (modeled in a) pastProject, } \\
\text { - (what-if modeled in a) currentProject } \\
\text { - (has a) nick (name), } \\
\text { - (is a) member, } \\
\text { - } \text { made (a document or plan), } \\
\text { - (has a) depiction, } \\
\text { - (is) based_near (where), } \\
\text { - } \text { - receiveMessageTo (an Organization), } \\
\text { - resource and resourceFrag (url of precise block of text/image } \\
\text { - where the object was found) } \\
\text { xReference (to more information in another document) }\end{array}$ \\
\hline & $\begin{array}{l}\text { Attributes (to facilitate follow-on ontology development and support } \\
\text { queries): } \\
\text { - swimlane (Organization type choice list: NGO,IGO, USGov, } \\
\text { DoD, and JtForce) } \\
\text { - generic (default = false, but if true; then Organization or Agent } \\
\text { described does not pass the test, i.e., is not specific enough to ever } \\
\text { have a specific address) } \\
\text { - type (Document choice between Document or Message) }\end{array}$ \\
\hline Data Needed & Criteria Governing Admissibility of the Data \\
\hline $\begin{array}{l}\text { Qualitative Data } \\
\text { Collection and } \\
\text { Interpretation Method: }\end{array}$ & $\begin{array}{l}\text { Both written and interactive guidance were provided to data collectors. } \\
\text { Instructional highlights include: } \\
\text { - Read through each paragraph (block) of the selected Joint } \\
\text { publication to determine the purpose of the block. } \\
\text { - Electronically cut-and-paste the text objects and text predicates } \\
\text { into the appropriate cell of the spreadsheet (created to reflect the } \\
\text { schema), including a link to the block containing the text selected. } \\
\text { - Because text is imprecise, implied objects and predicates are } \\
\text { also added to the spreadsheet along with a link to the block in } \\
\text { the Joint publication containing the interpretation to facilitate } \\
\text { future validation. } \\
\text { The hardcopy Joint publication is highlighted with a color- } \\
\text { coded highlighter to indicate it has been used in the spreadsheet } \\
\text { The spreadsheet data is incorporated into the AltovaTM tool to be } \\
\text { verified as a well-formed and valid RDF/XML document. }\end{array}$ \\
\hline
\end{tabular}




\begin{tabular}{|c|c|}
\hline $\begin{array}{l}\text { Quantitative Data } \\
\text { Collection and } \\
\text { Interpretation Method: }\end{array}$ & $\begin{array}{l}\text { The objects captured in the spreadsheets that can be classified as } \\
\text { who, what, when, where, and why. The objects that remain un- } \\
\text { highlighted in the hardcopy Joint doctrine publication: } \\
\text { - These data are first evaluated to see if the Qualitative Data } \\
\text { Collection and Interpretation Method should be revised to } \\
\text { include a missing object type and/or predicate. } \\
\text { - Then the remaining data is evaluated and put into categories to } \\
\text { determine their nature. For example: } \\
\text { - Objects that specify how the work is to be performed } \\
\text { - Objects that are completely composed of generic objects and } \\
\text { predicates and are too general to classify }\end{array}$ \\
\hline $\begin{array}{l}\text { Data Triangulation and } \\
\text { Interpretation Method: }\end{array}$ & $\begin{array}{l}\text { The qualitative and quantitative data is triangulated to determine: } \\
\text { - Patterns found in collected data } \\
\text { - Support between the various interpretation methods } \\
\text { - Disagreement between the various interpretation methods } \\
\text { - Areas where data should undergo further validation } \\
\text { If the conclusion is positive, then continue to research question } \# 2 \text {. }\end{array}$ \\
\hline
\end{tabular}


Table 9: Data Collection for Research Question 2

\begin{tabular}{|c|c|}
\hline \multicolumn{2}{|r|}{ Sub-question \#2 Research Approach Justification } \\
\hline \multicolumn{2}{|c|}{$\begin{array}{l}\text { Sub-question \#2: To what extent would enterprise models aligned to Joint doctrine be useful in } \\
\text { representing operational scenarios to illustrate warfighter capability needs? }\end{array}$} \\
\hline Data Needed & Criteria Governing Admissibility of the Data \\
\hline $\begin{array}{l}\text { Data Collection } \\
\text { Instrument: }\end{array}$ & $\begin{array}{l}\text { Altova }{ }^{\mathrm{TM}} \text { XMLSpy editor for modeling, editing, transforming, and } \\
\text { debugging XML-related technologies populated with the data from } \\
\text { Question 1. } \\
\text { The graphical XML Schema editor and the spreadsheets that provide } \\
\text { graphical representation of data relationships for reporting and } \\
\text { analysis. } \\
\text { A prototype in the form of a website that can mimic the dynamic } \\
\text { function of an Enterprise modeling tool front end powered by the } \\
\text { contents of the RDF/XML RQ-Tech data. }\end{array}$ \\
\hline Nature of the Data: & $\begin{array}{l}\text { Develop a facilitation plan to describe: } \\
\text { - How to query the spreadsheet (or develop a query capability } \\
\text { within the Altova } \\
\text { An XMLSpy editor). } \\
\text { problem experienced by warfighters that was due to inadequate } \\
\text { collaboration, and that matches some of the topics covered in the } \\
\text { selected Joint doctrine in the data collection instrument. } \\
\text { A discussion outline to facilitate a group of students in assessing } \\
\text { the possible consequences of using the collected data as a model } \\
\text { for describing how their doctrine publications work together }\end{array}$ \\
\hline Location of the Data: & ODU NCSoSE Lab, Monarch Way, Norfolk, VA \\
\hline $\begin{array}{l}\text { Access to Instructor and } \\
\text { Students: }\end{array}$ & $\begin{array}{l}\text { - Planning session with identified instructor } \\
\text { - Scheduled class session with both instructor and students to } \\
\text { develop the prototype model } \\
\text { - Scheduled session to obtain group discussion output }\end{array}$ \\
\hline $\begin{array}{l}\text { Qualitative Data } \\
\text { Interpretation: }\end{array}$ & - Transcribe both negative and positive feedback on use of prototype \\
\hline $\begin{array}{l}\text { Quantitative Data } \\
\text { Interpretation: }\end{array}$ & $\begin{array}{l}\text { - Follow-up with a written user evaluation form using a Likert scale } \\
\text { - Graph the results. }\end{array}$ \\
\hline
\end{tabular}

In summary, the RQ-Tech Methodology research design was illustrated as a task WBS for the purpose of mapping each major task to the applicable tenets of naturalistic research design. The result of this mapping showed how aspects of the research incorporated important factors regarding required rigorous research. The content analysis methodology was shown to support the specific RQ-Tech Methodology research design. 


\section{CHAPTER 4 - RESEARCH RESULTS}

The purpose of this chapter is to convey the results of deploying the RQ-Tech Methodology research design described in Chapter 3. The study findings unfold in two stages. The purpose of the first stage is to answer research question one regarding a formal method for documenting text and rich pictures that organizational planners typically use to reflect on the strategy and high-level operations of the enterprise. For this study, the research design directed construction of the RQ-Tech XML schema using W3C Semantic Web standards to capture the essential components of the organization. This schema was then used as a data-coding and collection instrument designed to facilitate content analysis of the selected sample of Joint doctrine. The first-stage analysis culminated in an assessment of the potential of the approach for representing Joint doctrine as a dependable strategic/operational-level EA model of Joint force logistics. Stage two activities involved constructing a prototype for the purpose of displaying the results of the content analysis of the data sample selected for inclusion. The stage two prototype was designed for the purpose of allowing SMEs, role playing as enterprise planners, to interact with doctrine arranged to respond to Semantic Web-type queries. The opinions of the SMEs served to answer research question two regarding the value of the RQTech Methodology as a credible approach to model Joint doctrine.

\section{Research Question One}

The stage one findings report provides the answer to the research question concerning the most significant factors to consider when translating authoritative text and rich pictures into semantic models. Using the W3C standards for constructing a schema (W3C, 2004c), this process was completed in several iterations. 


\subsection{Population for Application of the Method}

First, the entire collection of Joint doctrine publications in the JEL listed on its webpage, http://www.dtic.mil/doctrine/new_pubs/jointpub.htm and shown in Appendix A -Joint Publication Status, was examined. All 59 publications that are approved for use by Joint Forces but not classified or access limited for security purposes, nor slated to-be-deleted; were considered as likely candidates (Figure 12) to be parsed into the trial RDF/XML document.

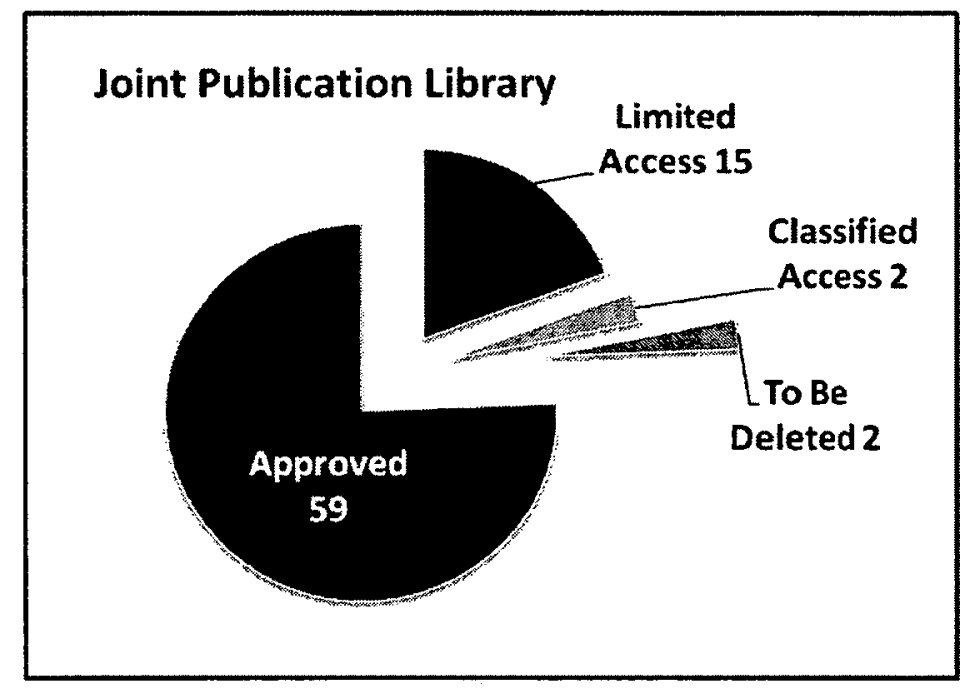

Figure 12: Joint Doctrine Population

Several approved Joint Doctrine publications were used to initially develop and test the RQ-Tech Schema, including JP 3-08, Interorganizational Coordination During Joint Operations; JP 3-57, Civil-Military Operations; and JP 1-0, Joint Personnel Support. In the end, JP 4-0, Joint Logistics, described on the JEL webpage for Logistics, Series 4-0 Publication as the keystone document of the joint logistics series was selected. For the purpose of executing of the research design, this document is representative of the JEL population because it embodies both strategic and operational tenets of Joint doctrine, and includes descriptions of planning, execution and control operations; including those in cooperation with multinational partners and 
other US Government agencies. This publication sets forth Joint doctrine as guidance for the activities performed by the Armed Forces of the United States in Joint operations and provides the doctrinal basis for the conduct of Joint logistics.

\subsection{Collection Instrument - RQ-Tech Schema Development}

Once the decision regarding which Joint doctrine publication would be the subject for content analysis, as outlined in the research design (Chapter 3), the construction of the XML schema could be finalized. As described previously in the research design, the researcher proceeded to first select three classes; Organization, Agent, and Document, from the FOAF standard (Brickley \& Miller, 2000) for the initial RQ-Tech schema. Several FOAF predicates that could also describe types of communication between DoD Organizations were selected. For example, the statement "Agent (is a) member (of the) Organization" would represent the block of text in Joint doctrine stating the Secretary of Defense (is a) member (of the) Office of the Secretary of Defense.

The FOAF standard uses the predicate knows to indicate linkage between two Organizations. However, when scanning various blocks of text in doctrine, it became clear that communications between Organizations were of a more intense nature than mere acknowledgement. Accurately representing Joint doctrine that assigns required tasks or requests urgent information necessitated more descriptive predicates. Also, in some cases, the directionality of communication is described in doctrine, indicating message traffic flow. Therefore, in order to represent the text as written in doctrine, several predicates were added to the RQ-Tech schema, including sendMessageTo and receiveMessageFrom. Having several ways to represent doctrine-implied communication proved useful for replicating authorized directives 
to accurately convey their meaning. For example, the block of doctrine text that indicates ongoing collaboration between two organizations is represented by the use of both sendMessageTo and receiveMessageFrom predicates. This dual-predicate use serves to characterize continuous communications when this is what is implied by doctrine. Using dual predicates insures the communication described will be returned when queries using either predicate, or both predicates are constructed. The FOAF predicate knows is still an option that can be selected in the RQ-Tech schema as away to characterize communication between two Organizations. The predicate knows is recommend for use when doctrine writes about two entities and description implies they are aware of each other, however no specific message exchange nor communication directionality is described.

While assessing the use of FOAF standards in an early draft of the RQ-Tech schema, the researcher noticed there was no way to communicate what the teams were exchanging information about, other than to link to their workplaceHomepage. The researcher resolved this dilemma by constructing message as a type of Document that could convey topics. Since message is a type of document, the attribute type was added to the RQ-Tech schema Document class. By adding the attribute type, doctrine text that describes a planning document is referred to as type $=$ document, while Document that is a message is referenced as a document type $=$ message. In the RQ-Tech schema, the predicate title that is associated with Document is now coded as the message subject line, while the predicate description is coded to signify the wordfor-word description referenced by doctrine.

The Document type message is useful for illustrating two aspects of Zachman's EA taxonomy. First, the act of receiving a message can trigger some event, that is, when the message is received, something needs to happen. Second, doctrine also describes what should be 
done in response to events, or triggers. These details of doctrine text are conveyed as the message title and description, directed at Organizations who are required to act when these events occur.

The researcher also noticed that Joint doctrine describes various events in terms of activities using action verbs. In Joint doctrine, the activities are described in general language; i.e., no specifics are used to describe how to perform what needs to be done. This observation confirmed that the RQ-Tech approach was appropriate for uncovering important triggers and events described at the enterprise strategic- and operational-levels while also providing rules for parsing doctrine text describing activities:

- When activities are described, first evaluate the text to determine what is described, and use this phrase as title of Document type = message .

- Then include the doctrine text describing the details of the events the description of the Document type $=$ message.

The amount of text that could be coded during content analysis using the RQ-Tech schema increased substantially when the message type was added to the data collection schema.

There were several other changes and additions made to the initial version of the RQTech Methodology schema based on execution of the research design. The following modifications served to refine it for uses the prototype shown in Appendix B - RQ-Tech XML Schema:

- xReference - the third type of Document class. This attribute represents documents that are cross-referenced in doctrine for more information about the topic described

- based_near - this FOAF predicate defines text pertaining to a specifically located Organization, thus allowing, for example, information about the geographically specific Combatant Command (command authority) PACOM to be organized under the same Organization class with other information regarding all Combatant Commands. In this way, information pertaining to the entire Organization is able to be associated with Organizational branches defined by their geographic 
location

- swimlane - an attribute that describes the level of hierarchy of an Organization. This knowledge is required to ensure the proper level of communication etiquette required to show proper respect and/or authority. There are five attributes that are consistently used in doctrine, namely, United States Government (USGov), Department of Defense, (DoD), Joint Forces (JtForce), Inter-governmental Organization (InterGovOrg), and Non-governmental Organization (NonGovOrg). Since Joint doctrine is written to focus on Joint Forces, the JtForce viewpoint is central to understanding Joint doctrine, and is oriented as the center lane. The DoD has the direct supervisory role over US Joint Forces, and functions as a the contact between other USGov agencies and JtForce Organizations.

Communications with InterGovOrg follow specific protocols. Communications with civilian NonGovOrgs can be sensitive and/or require, for example, contract administrative assistance.

- depiction - this FOAF predicate is meant to associate a rich picture with any class (Organization, Agent or Document) in the form of a url. Upon click, the url will dereference the picture in html format from where it is stored on the server.

Methods and rules for implementing content analysis were also revised several times during stage one of RQ-Tech Methodology development. Each iteration of the schema required changes to the instructions for parsing Joint doctrine text and adding jpeg illustrations to the $\mathrm{RDF} / \mathrm{XML}$ document. Constructing the RDF/XML document is similar to populating a relational database by adding rows of information under appropriate column headers. As more rows of parsed text were added into the RDF/XML document, the amount of doctrine sample left unparsed decreased.

During schema-building iterations, several categories of unincorporated text were noted.

Some were resolved using follow-on procedures:

- Text that was inadvertently overlooked. The data collection spreadsheet resulting from parsing the doctrine document was periodically sorted by page number and then by block number. Blocks in the doctrine document that had no associated spreadsheet entries were reexamined, and any additional objects that appeared to be relevant were added to the spreadsheet. Deficiencies of this type were mainly noted in sections that had been processed first, when the parsing technique was still new to the researcher. This problem was labeled as a learning curve issue. It was resolved by instituting required, periodic sorting and statistical 
sampling to ensure additional attention would be directed on deficient areas and that the parsing process was being conducted in a consistent manner.

Other categories were accepted as reasonable explanations for text that should not be included in

the RDF/XML document:

- Photographic figures and inspirational quotes. It became clear that while photographs of typical military themes interspersed throughout the publication made for a more visually intense reading experience, these photographs did not appear to add value to the warfighters' body of knowledge. Quotations from famous military leaders were inspirational, but did not appear to convey relevant information regarding the subject presented elsewhere on the page. It was decided to leave all these sections of Joint doctrine out of the RDF/XML document, as they added no content or specific value to the analysis.

- Text too general to code. Some doctrine information that was difficult to categorize was noticed at the beginning and end of several of the sample Joint doctrine chapters. Much of the introductory and summary information was so general that nothing specific could be regarded as directive. If added to the $\mathrm{RDF} / \mathrm{XML}$ document, the inherent vagaries might muddle the intention of more precisely written sections of text. It was decided these sections of doctrine were more a writing style than specific guidance. These areas were noted on the hard copy as too general to code.

In summary, stage one of the research was designed to provide answers to the first research question, that is, what are the most significant factors to consider when translating authoritative text and rich pictures into semantic models? To start with, a representative sample of Joint doctrine was selected. Then the RQ-Tech schema, based on the FOAF standard, was developed in iterations. The FOAF standard was extended with several new predicates so that the text as written in Joint doctrine could be accurately represented. An important discovery was made while developing the schema. It became apparent that service-provider organizations react to events that trigger certain responses. Therefore a message type of document object was created to handle event descriptions. Once the instructions for defining this message object were added to the parsing instructions, the amount of doctrine text that could be categorized using the RQ-Tech schema increased greatly. The process for parsing sample documents was reevaluated 
periodically and revised to include more specific details that would make the parsing process less subjective. Also, acceptable criteria for not parsing certain Joint doctrine blocks of text and rich pictures were added to the parsing instructions.

\subsection{Data Analysis - Research Question One}

As described in the previous chapter, qualitative data gathered from content analysis may be analyzed using frequency or percentage calculations. Analysis of the amount of Joint doctrine text and rich pictures parsed during preliminary schema development was the basis for declaring that the rules for parsing Joint doctrine were satisfactory and could be officially used to parse the selected sample publication. With content analysis rules in place, the selected sample was parsed. Then, according to the research design, the percentage of coverage was calculated and analyzed. The results of coding the chapters and appendices of Joint Publication 4.0 in its entirety are shown in Table 10.

Table 10: Joint Publication 4.0 - Parsing Results

\begin{tabular}{|l|c|c|c|}
\hline $\begin{array}{c}\text { Chapter/ Page } \\
\text { Results }\end{array}$ & Total Blocks/ Page & $\begin{array}{c}\text { Number Blocks } \\
\text { Modeled }\end{array}$ & $\begin{array}{c}\text { \% Chapter/ } \\
\text { Appendix Covered }\end{array}$ \\
\hline Executive Summary & & & 0 \\
\hline Chapt I & & 47 & 0 \\
\hline Chapt II & 65 & 25 & $72 \%$ \\
\hline Chapt III & 44 & 14 & $57 \%$ \\
\hline Chapt IV & 19 & 35 & $74 \%$ \\
\hline Chapt V & 49 & 10 & $71 \%$ \\
\hline Appendix A & 13 & 9 & $77 \%$ \\
\hline Appendix B & 9 & 24 & $100 \%$ \\
\hline Appendix C & 27 & 20 & $89 \%$ \\
\hline Appendix D & 20 & 4 & $100 \%$ \\
\hline Appendix E & 4 & 2 & $100 \%$ \\
\hline Appendix F Trals & 4 & $\mathbf{1 9 0}$ & $50 \%$ \\
\hline & $\mathbf{2 5 4}$ & $\mathbf{7 5 \%}$ \\
\hline
\end{tabular}

The Executive Summary and Chapter I, Joint Logistic Overview sections were judged too 
general to code. These sections were therefore not included in the RDF/XML document representing this Joint Publication. Of the five figures contained in Joint Publication 4.0, none appeared to represent rich pictures of organization, events and/or communications identified in the RQ-Tech Methodology Schema:

- Three were located in Chapter 1, Joint Logistic Overview (judged too general to code). These figures did not appear to add any additional understanding to the general text material contained in subject chapter, as judged by the researcher. However, there were some overarching definitions, keywords, and philosophy regarding Joint logistics in this introductory chapter. Figure I-3 of the publication, Core Logistics Capabilities, could be useful for providing keywords regarding logistics documents. This is an item that could be addressed in a future version of the RQ-Tech Methodology.

- Two figures were cited in the chapter on planning Joint logistics. The figures were high-level flow diagrams of activities, and various phases of activities. Because they were too general to imply what needed to be done, they were excluded from the parsed data contained in the RDF/XML document.

Figure 13 displays composition metrics regarding information parsed into the RQ-Tech

Methodology RDF/XML document. The results of content analysis performed on Joint Publication 4.0 revealed a total of 188 unique Organizations that are involved in the business of providing Joint logistics. 


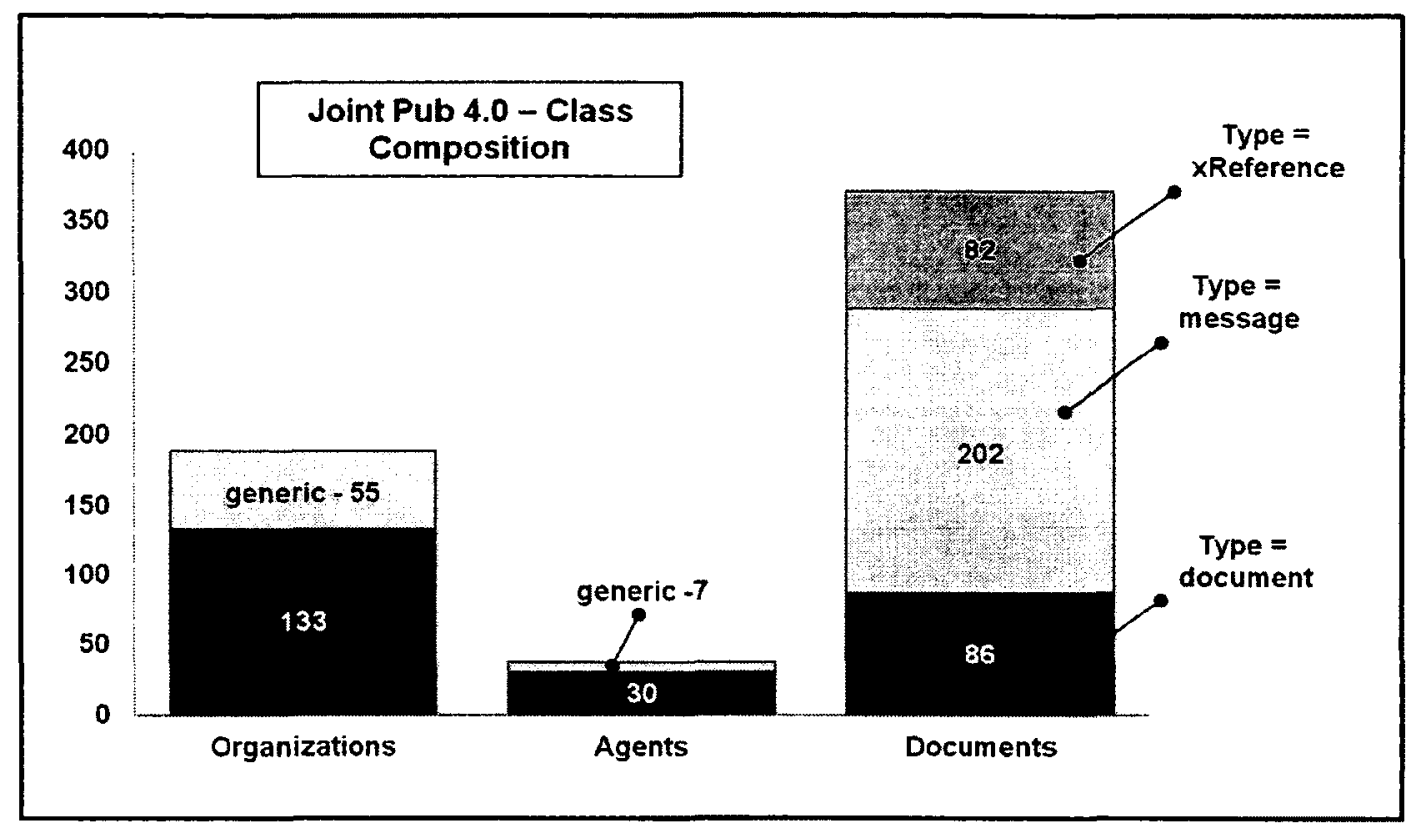

Figure 13: JP 4-0 Class Composition Results

It appears that Joint doctrine favors describing doctrine in terms of organizational directives instead of unique assignments to specific organizational team members (Agents), demonstrated by the sparse number of organizational positions described. There were eighty-six uniquely described documents, many of them representing output required from Joint logistics organizations. As expected, an equally long list of references that offered additional information on the subject matter indicated that logistics planning is complex and requires input from a variety of trusted sources.

The new message type was used over two hundred times while analyzing the content of JP 4-0. Although beyond the scope of the present research, analyzing this set of data could provide a rich source of communication topics and patterns.

Initial data analysis reveals pivotal organizations, such as the COCOM, have numerous entries indicating numerous social communiqués. Figure 14 is a graphical summary of all the connections associated with the Combatant Command (command authority) identified by 
analyzing, then querying and sorting the RDF/XML Joint publication JP 4-0 document. The Combatant Command is the central organization described in this selected Joint publication. It is located in the center of the figure, surrounded by color purple indicating it is in the Joint force swimlane. There are eight light-colored diamonds surrounding the COCOM diamond. These represent specific positions within the Combatant Command organization that could be filled by an agent of the organization. There are also eight purple diamonds surrounding the COCOM diamond indicating other Joint Force organizations that this Joint doctrine document has designated as a member of the COCOM. One grey-colored diamond signifies a generic organization that doctrine states may also be a member of the Combatant Command organization as well. All of these member organizations are also in the Joint force swimlane.

All the information for this graphic was found through querying the data parsed from the sample Joint doctrine. The array of members of the Combatant Command was found by looking for all the agents or organizations described somewhere in the publication as a member of the COCOM. There are various diamonds connected to the Combatant Command organization by various types of arrows. For example, two headed arrows represent two-way communications that are both received from and sent to the COCOM. Listing each organization in its own diamond would have made the graphic too busy to read. However the type of message designation within the diamond also displays how many of those types of communications were with organizations in the designated swimlanes shown in the figure. As illustrated, over half of the organizations shown corresponding with the COCOM were described by doctrine in a generic way.

A profile graphic, such as this one, can be constructed for each organization described in the Joint doctrine publication, thereby qualitatively revealing how the RQ-Tech methodology can 
be used to show the social interaction of the central Joint organization concerning logistics. This is only one example of the numerous graphical representations that could be constructed from the content analysis information gathered to answer research question one.

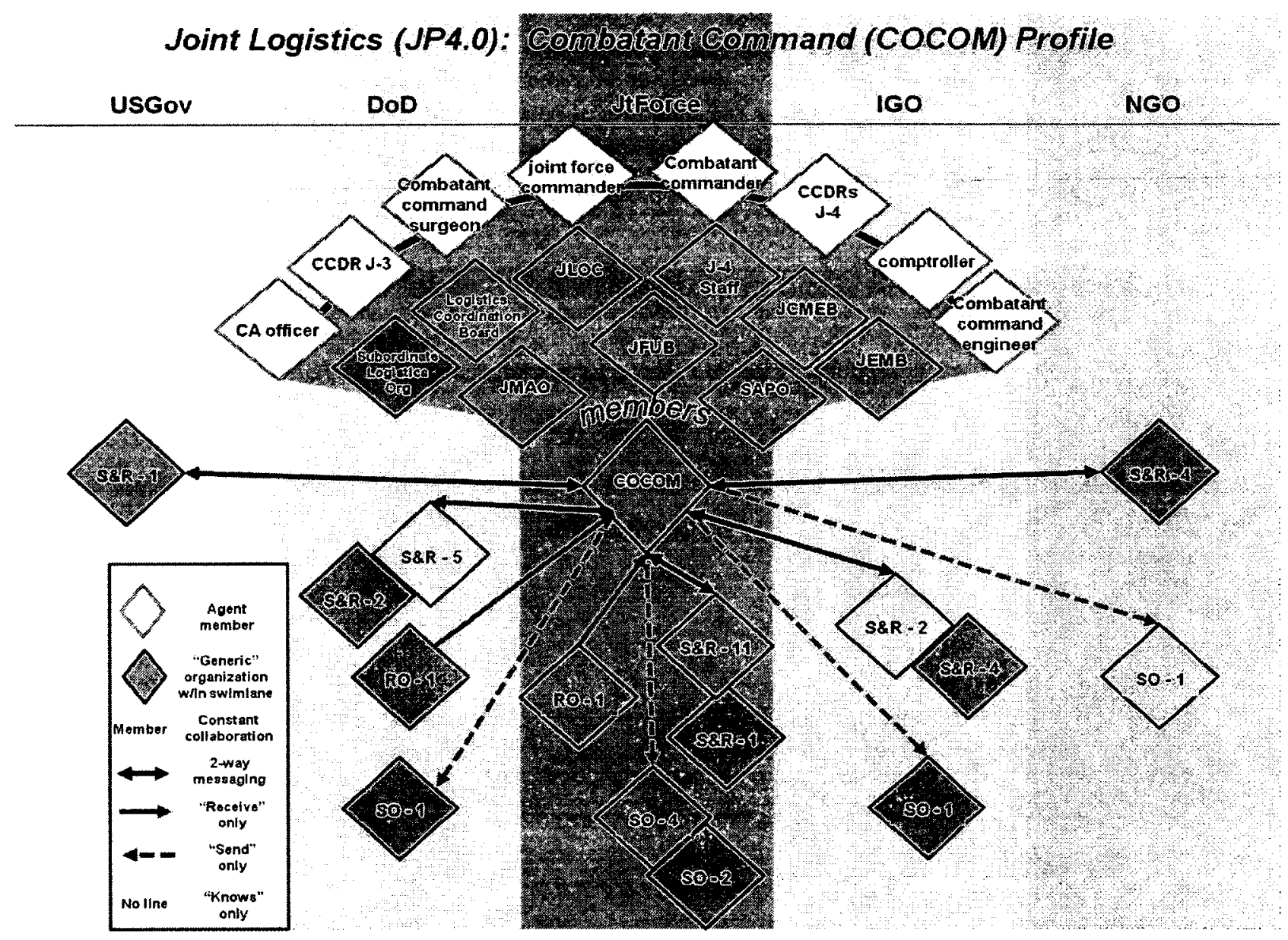

Figure 14: COCOM JP 4-0 Logistics Communication Profile

\subsection{Research Question One - Conclusions}

It has been shown that a substantial percentage of all but the most general information contained in the strategic- and operational-level document, JP 4-0, Joint Logistics; could be categorized into the data structure defined by the RQ-Tech Methodology schema. Text coverage of the Joint doctrine hard copy document, shown in Table 10, averaged approximately seventy- 
five percent. The recorded metrics from this research indicated that only one quarter of the sample document (that is, the document parts that were not summary text, photos, or inspirational quotations) did not fit the profile for an aspect of social interaction. These metrics support the conclusion that the most significant factors for translating authoritative text into semantic models have been identified and incorporated into the RQ-Tech Methodology schema.

However, not all text and rich pictures of the selected Joint doctrine sample could be mapped to a pertinent parsing rule. For example, none of the figures in Joint Publication 4.0 appeared to describe any of the defined Organizations, Agents or Documents identified by the content analysis process. As defined, a depiction can only describe a class, and it cannot exist in the resultant RDF/XML document without that linkage, as the RDF/XML document will not pass W3C standards for being valid and well-formed. However during the prototype development phase, the RQ-Tech Methodology proved that it does incorporate the method and means to link a depiction to an already defined class. For example in the RDF/XML document constructed from JP 3-08, the url for Figure III-2. Model for Coordination Between Military and Nonmilitary Organizations - Foreign Operations, was added as a depiction link to several Organizations parsed in JP 3-08 because the graphics in that figure showed communication paths too difficult to explain using text. It therefore may be concluded that while organizational documents written in text and rich pictures may be formally documented as a scope-level model of the organization, there still may be improvements that can be made to the parsing and graphical representation processes required to develop this model.

Stage one analysis made use of the RQ-Tech practice of nesting all the parsed data between the beginning and end tags of the hyperlink location code in the original doctrine publication. The Joint doctrine sample was first downloaded in .pdf format. Then using an 
Adobe $^{\mathrm{TM}}$ transformation utility, the translation of the .pdf document into html format was confirmed to be accurate. Tags that identified each block of text were inserted into the resultant html document and stored in a virtual server on a website. These tags were used to contain the class properties found during the content analysis process. As a result, the RQ-Tech Methodology schema enforces auditability back to the parent document, and forward to any query and display of this Semantic Web standard data.

Because Joint doctrine is written using natural language, it is possible that blocks of text could be misinterpreted, especially if the document is parsed by someone without a background in the document subject matter. However, by wrapping each parsed object with a hyperlink back to the block of doctrine text used to determine its nature, the parsing decisions can always be reevaluated and corrected, if required. In this way, the attribute of auditability is built into the resultant model.

\section{Research QuestionTwo}

The analysis for stage two served to answer the research question two, to what extent would enterprise models aligned to Joint doctrine be useful in representing operational scenarios to illustrate warfighter capability needs? By following the RDF/XML standards, the document that is created can be queried to get precise responses in return. By enabling the use of triples, much more accurate and precise data is returned to the user when compared with simple word searches within documents that have not been parsed and formulated into an RDF/XML document. RDF is particularly intended for representing metadata about Web resources because its common framework for expressing triples allows information exchange between different applications, and makes that information available to applications other than those for which it 
was originally created. This can be interpreted to mean that Joint doctrine does have the potential to be reformulated into dynamic EAs representing US military organizations.

The answer to research question two involved developing a prototype of what a dynamic EA model would look like and how SMEs could interact with it to develop models based on guidance from Joint doctrine.

\subsection{Prototype Development}

The Altova ${ }^{\mathrm{TM}}$ XMLSpy editor for modeling, editing, transforming and debugging XMLrelated technologies was used to transform Joint doctrine to support analysis and response to research question one. The graphical XML Schema editor and corresponding Excel spreadsheets provided graphical representation of data relationships for reporting and analysis. For research question two, it was necessary to build a prototype using the RDF/XML document. A website that can mimic some of the basic dynamic functions of an Enterprise modeling tool was constructed using Altova ${ }^{\mathrm{TM}}$ StyleVision. On-line training and tools were provided with this Altova ${ }^{\mathrm{TM}}$ software package. Using these, the researcher supplemented rudimentary programming skills to learn enough to build a simple prototype that would display the contents of the RDF/XML document.

The researcher started with the concept of a FOAF Card, that is, a single webpage that describes a person or an organization. In a manner similar to current social web communities, users provide their photo and some background information to describe and highlight their interests and accomplishments. Links to people the user knows are also displayed. This basic framework was adapted by creating a compact view of the Organization that could display, at a glance, important membership and location characteristics, as well as products the Organization 
made, that is, the planning Documents they author (Figure 15).

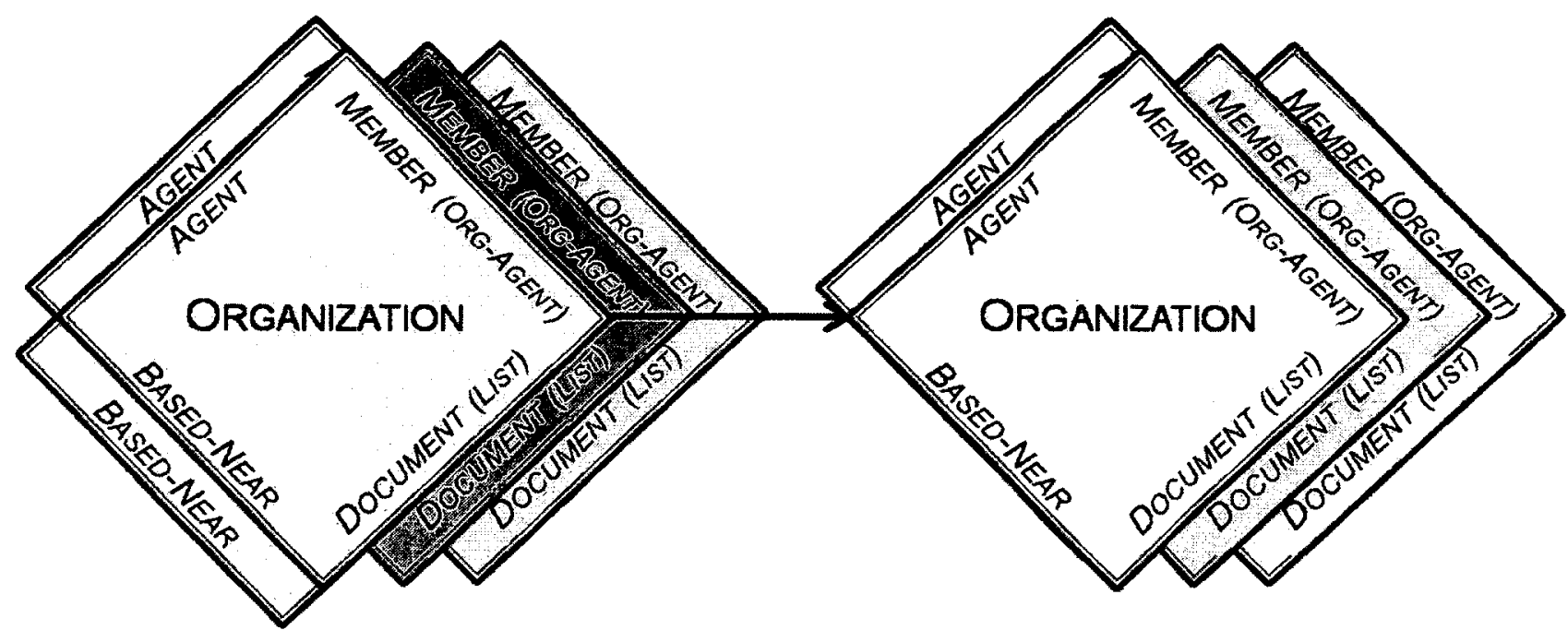

Send (Message or Task)

Receive (Message or Task)

Figure 15: RQ-Tech Organization Representation

To implement this concept in the prototype application, a more conventional Org Card was constructed. This less compact representation was made using the table tools in Altova ${ }^{\mathrm{TM}}$ Stylevision, and is shown in Figure 16. When the Org Card prototype is accessed in html format, the user can browse the entire list of organizations defined in the query until an organization of interest is displayed. Upon selection, the user sees the entire page of information that was identified from the blocks of Joint doctrine text. It shows the identity information, including a depiction of the organization, if there is one, at the top of the page. Next, the geographic location(s) is shown, followed by lists of Agent and Organization membership. This is followed by a table showing the products this Organization is required to develop as defined in the guidelines of this Joint doctrine publication. The user can click on the hyperlinks in the table and see the exact block of text from the Joint doctrine page that describes the product. 


\section{(foaf:passprojedy Organization Card}

\section{Organization Identity:}

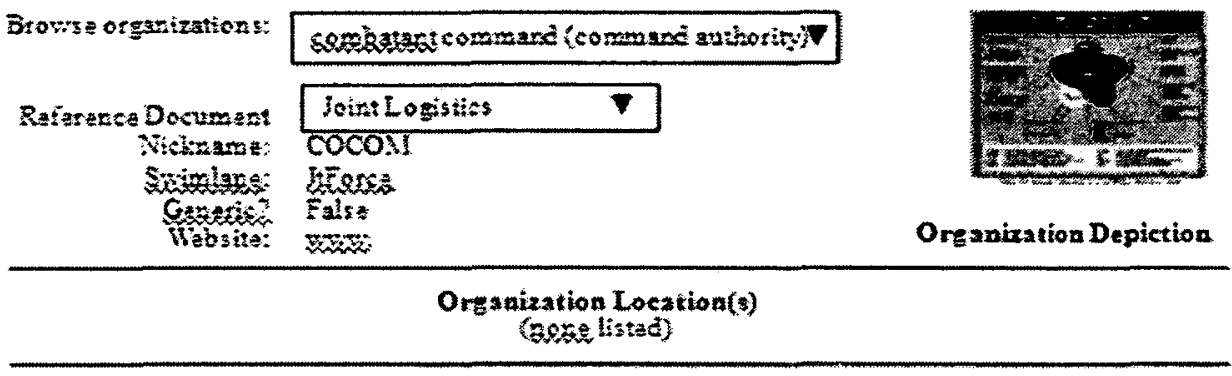

Organizational Membership

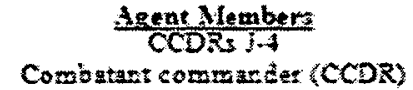

Agent Member

Combatant commander (CCDR)
Orsanization Texms

Joint Logistios Opetations Cantat JOO

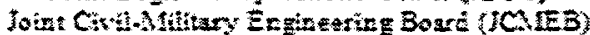

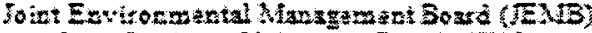

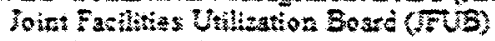

Lozintiter Coordination Brare

Suborticute Logiaties Organization I. Stat

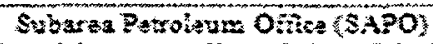

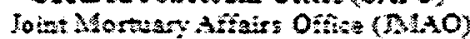

Oranaizational Producks

\begin{tabular}{|c|c|c|c|}
\hline Tite & Acrongm & XRet & Created $\mathrm{By}$ \\
\hline 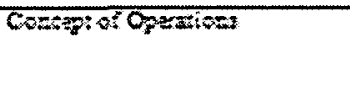 & coxoss & 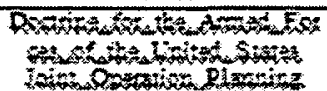 & \\
\hline Opanston Flos & DPLAY & 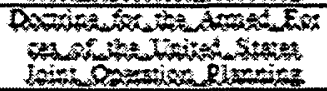 & 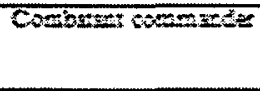 \\
\hline 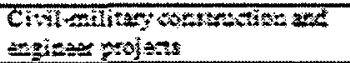 & & & 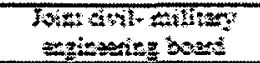 \\
\hline 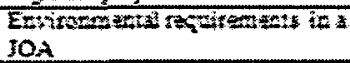 & & & 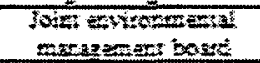 \\
\hline 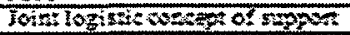 & & & Cenbras ocenteres \\
\hline \multicolumn{4}{|l|}{ 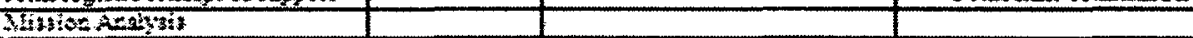 } \\
\hline 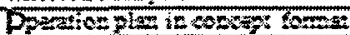 & COSTLN & & 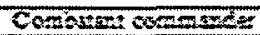 \\
\hline 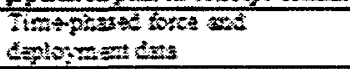 & TPEDD & & Cososse: cosentest \\
\hline 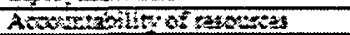 & & & \\
\hline
\end{tabular}

क

Organizational Conmunication:

\begin{tabular}{|c|c|c|c|}
\hline $\begin{array}{l}\text { Receire Mlessage } \\
\text { From }\end{array}$ & Slessiage & X-Ref & Send Mleswage To \\
\hline 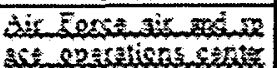 & & & 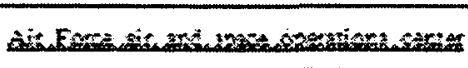 \\
\hline 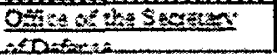 & 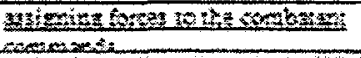 & & \\
\hline
\end{tabular}

Figure 16: RQ-Tech Org Card

In a second table, all the communications between this Organization and other

Organizations are listed, along with a brief message title. Again, clicking on the title will bring up the block of text where the subject was discussed in Joint doctrine. While the word message 
is usually not contained in the block of doctrine text, the guidance in doctrine generally implies some communicated need or event that precipitates discussion concerning this subject. It is up to the user of the Org Card to check out the discussion in section of Joint doctrine to ensure this is the passage in doctrine he or she wants to use.

\subsection{Participants}

To answer research question two, the researcher contacted an instructor from the JFSC in Norfolk, Virginia, for the purpose of getting feedback on the RQ-Tech Methodology prototype. This point of contact was instrumental in providing the researcher information about current training events at the college, as well as agreement to invite JFSC faculty with good backgrounds in Joint doctrine to participate in the study. The researcher secured the agreement to participate, then scheduled the prototype session, and invited the participants, via the JFSC point of contact to attend. In total, four participants from the JFSC accepted the invitation. They had all previously served in the military (experience ranged from four years to thirty years of active duty). Each participant also identified additional years of civil service on military projects (ranged from four years to thirty-four years). Their education ranged from an Associates Degree in Technology, to Bachelor of Arts and Bachelor of Science. In addition, three of the four were currently involved in graduate level education; one in a Masters program and two in $\mathrm{PhD}$ programs. The JFSC participants were all well versed in the use of the military decision making process (MDMP) and familiar with the concepts declared in Joint doctrine. Therefore they were capable of drawing conclusions with respect to the utility of the RQ-Tech prototype.

On the day of the prototype, the four participants gathered at the ODU's NCSoSE lab shortly past noon. Elements of the prototype included a form of the RQ-Tech prototype, a simple 
scenario, and a survey that would be used to gather the evaluation of the prototype from the users, Appendix G-User Feedback Survey. The researcher began the session with a welcome and a short briefing explaining the RQ-Tec prototype tool. Next the researcher described the role-play event to the participants and conducted a demonstration of the RQ-Tech methodology. Workstations were equipped with the RQ-Tech prototype tool so that the participants, in teams of two, could work through the exercise. The researcher stayed and answered any questions about the RQ-Tech tool and/or the prototype demonstration that surfaced. After a short break, the participants collectively exchanged comments about their experience with the prototype, including some of their reactions and comments about the prototype. Then surveys were distributed to the participants and time was allotted for them to individually fill out the forms. The entire prototyping event was completed within four hours.

\subsection{Scenario Development}

The researcher set the scene for a scenario the JFSC participants would use during the prototype demonstration session. This scene setter was sent as a read-ahead so the participants could have some time to familiarize themselves with the role they would play during the prototype (Appendix F - Logistics Planning Scenario).

Scenario development for this prototype was approached in a manner similar to constructing a project schedule. First the main tasks were identified. Next, some of the details of these tasks were defined. Then thought was directed to who would perform these tasks, and what prerequisites were necessary before the task could start. For the RQ-Tech Methodology scenario, the sequence of events began at $t=0$, that is, when the first triggering event occurred. Then various milestones were identified, and their logical sequence was ordered, with the 
understanding that events could occur in parallel. This is similar to constructing a project schedule, except that it identified what needed to be done in response to the triggering event, and in what order each event should occur.

In order to use the RQ-Tech Methodology to build a scenario, two attributes were included in the schema; currentProject and timeLineIndex. Users would be able to identify the $t=0$ triggering event by using the RQ-Tech prototype to find and identify that event in the guidance of Joint doctrine. For example, the scenario begins with a message conveying a Warning Order that triggers Combatant Command-level activities; codename Purple Eclipse. At $t=0$, the scenario states that this message is sent from the Office of the Secretary of Defense (OSD). The prototype participants are advised to use the RQ-Tech Methodology prototype Org Cards to find messages sent to the Combatant Command (command authority) Organization from the OSD Organization to determine if there is a similar message contained in the RQ-Tech prototype. When a general message is found that appears to convey a warning concerning unrest in the region, a fully operational RQ-Tech Tool would allow the found message to be copied into currentProject $=$ PurpleEclipse. At this point, the event message would be edited by the user to reflect specific details of the message that the Secretary of Defense might be sending, and the title of the message would also be edited to more specifically describe the event. The users would continue to identify what would need to happen next. For example, would the Combatant Commander ask someone on his staff to begin a Mission Analysis. The users would again query the fully functional RQ-Tech Tool to find some examples of messages directing reviews of the current situation to begin developing the Mission Statement and assumptions. The users would search Joint doctrine using the various utilities in the fully functional RQ-Tech Tool to construct all the planning documents and determine what logistics items would be necessary to develop the 
logistics plan, as required in order to satisfy the tenets of Joint doctrine for this type of situation. The Org Card (Appendix E - RQ-Tech Prototype (Screen Shots)) would be updated with the newly entered information so users could continue to build what-if events from doctrine guidance until they were confident they constructed the scenario that would handle the situation best.

The prototype lacked many of the features envisioned in the fully functional RQ-Tech Methodology tool, so several compensating adjustments were devised and the RQ-Tech prototype was used as follows:

- RQ-Tech Prototype users were invited to work as a team to put their plan together based on the guidance they found in the RQ-Tech html prototype representation of logistics Joint doctrine publication 4-0.

- They were asked to select and investigate all the active hyperlinks of the Org Cards in the RQ-Tech prototype as a way to scan all the documents and messages associated with each Organization.

- When they found one they wanted to use for the exercise, they were asked to jot it down on a list as preparation for a follow-on step in the scenario building process.

After some RQ-Tech prototype familiarization time, the facilitator asked for the attention of all the participants. She projected a blank current project template and asked the participants about their first triggering event. The facilitator added various icons to the blank template to represent the information given by the participants. These activities would be equivalent to copying and editing items in the XML document using a dynamic form a user could actively control. Because this was a prototype, that functionality can only be simulated by the facilitator adding icons to the current project template she creates as a PowerPoint slide (Fig. 17). The facilitator and the participants continued adding icons representing organizations and documents such as plans that these organizations are required to develop to the current project template.

- The facilitator arranged these icons according to their swimlane attribute and 
according to their sequence in time.

- The facilitator also copied the links from the prototype to the template page. This action simulated how the link back to the original place in Joint doctrine can be carried forward into the currentproject. This means that when the link is activated, the original block of text from Joint doctrine is de-referenced and can be viewed and compared to determine how well original Joint doctrine was applied in this new scenario.

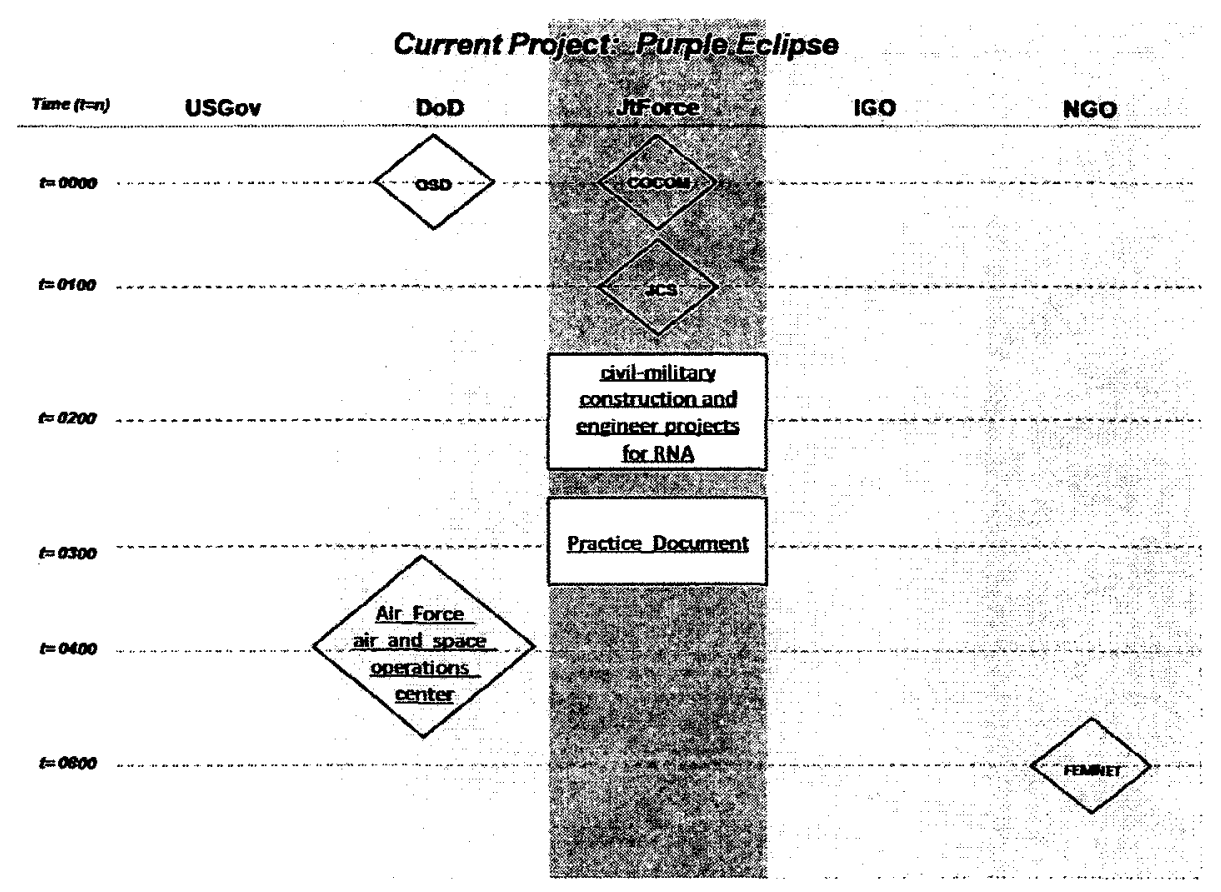

Figure 17: RQ-Tech Current Project Sequence

Scenario development is an excellent way for organizational personnel to describe situations that present problems they would like to have resolved. Describing the current state of their organization, i.e., the as-is view, allows enterprise architects to understand the users' problems and find out what they would like for their to-be organization. The use of the RQ-Tech methodology encourages users to describe what they were trying to do, i.e., the should-be view, as guided by their doctrine, and then describe the problems they experience when they try to carry out their mission, i.e., the as-is parts they would like to resolve. It is the contention of this 
research that when the users can access all the options that are described in doctrine, they will be better equipped to articulate the complex set of guidance that must be navigated correctly so that their missions can be successful. By adding Semantic Web elements that parallel the guidance they use to plan for the services they provide, these elements can be save and reconstructed to form the basis of a dynamic EA modeling technique. Without describing the EA process, or discussing the merits of the various model views, the RQ-Tech method of building a scenario using the information from the parsed Joint doctrine sample, the JFSC SMEs were simply asked to provide their comments on the value of having Joint doctrine presented in a different format.

\subsection{Survey results}

The research survey asked for opinions about the RQ-Tech prototype user interface, including ease of selecting an Organization of interest. There was consensus that selecting an organization was simple, since the list of organizations was presented in an alphabetical, hyperlinked list format (Figure 18).

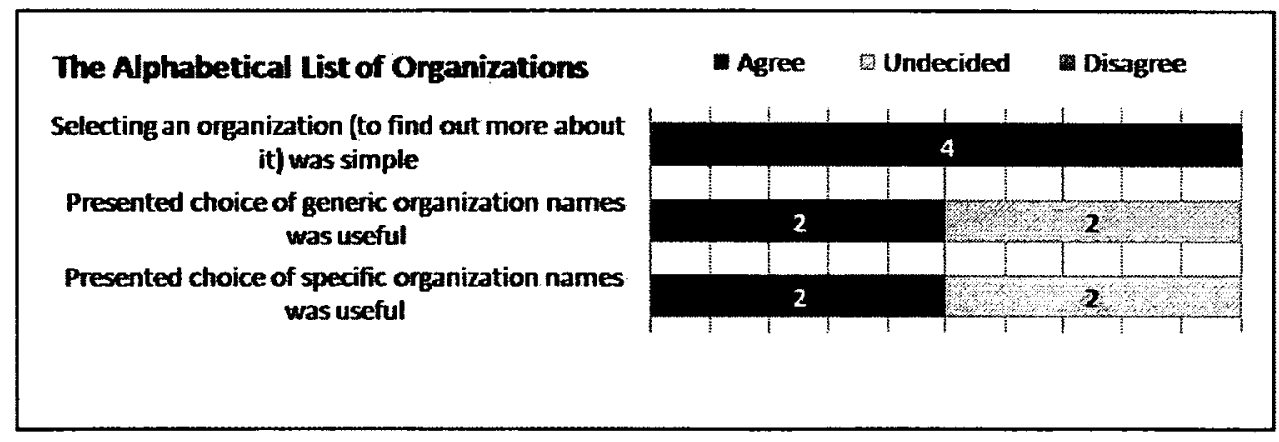

Figure 18: List of Organizations Survey Results

Aspects of the Org Card were included in the survey, with results shown in Figure 19. However, the table describing organizational communications was rated by all as having undecided value. In the prototype, the table that displayed message titles was too long to be scanned quickly. In addition, the table contained several columns of information for each entry. 
These included Organization(s) that sent messages, as well as Organizations that received messages from the Organization selected. The responses to this area of the Org Card indicate a need to further categorize messages to reduce the complexity of the existing organizational communications table.

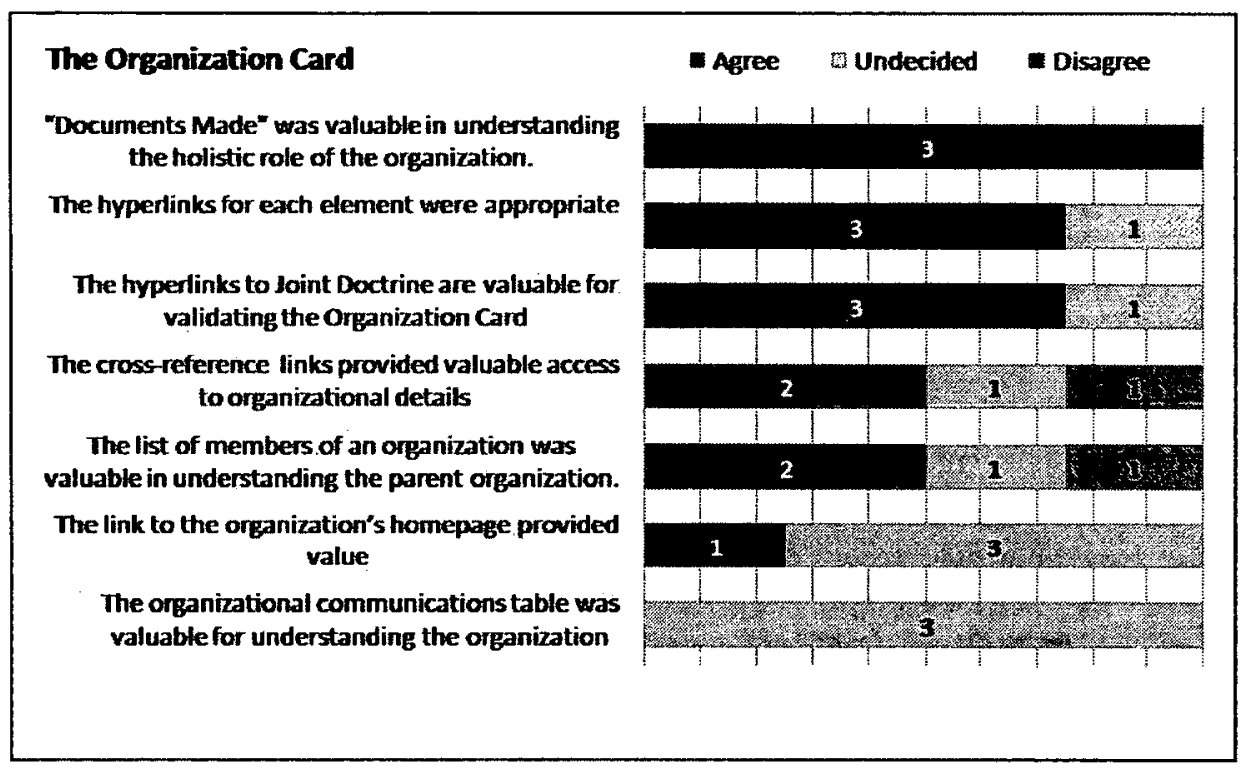

\section{Figure 19: Org Card Survey Results}

The participants were asked their opinion of the demonstrated value of RQ-Tech (Figure 20). In general, there was agreement that the value of the RQ-Tech Methodology was demonstrated during the prototype. Comments from the participants indicated they were overwhelmed by the amount of information the Org Card displayed. However, the links back to the block in doctrine was well received, prompting one SME to write: link to doctrine was very important for accuracy, credibility and specificity. 


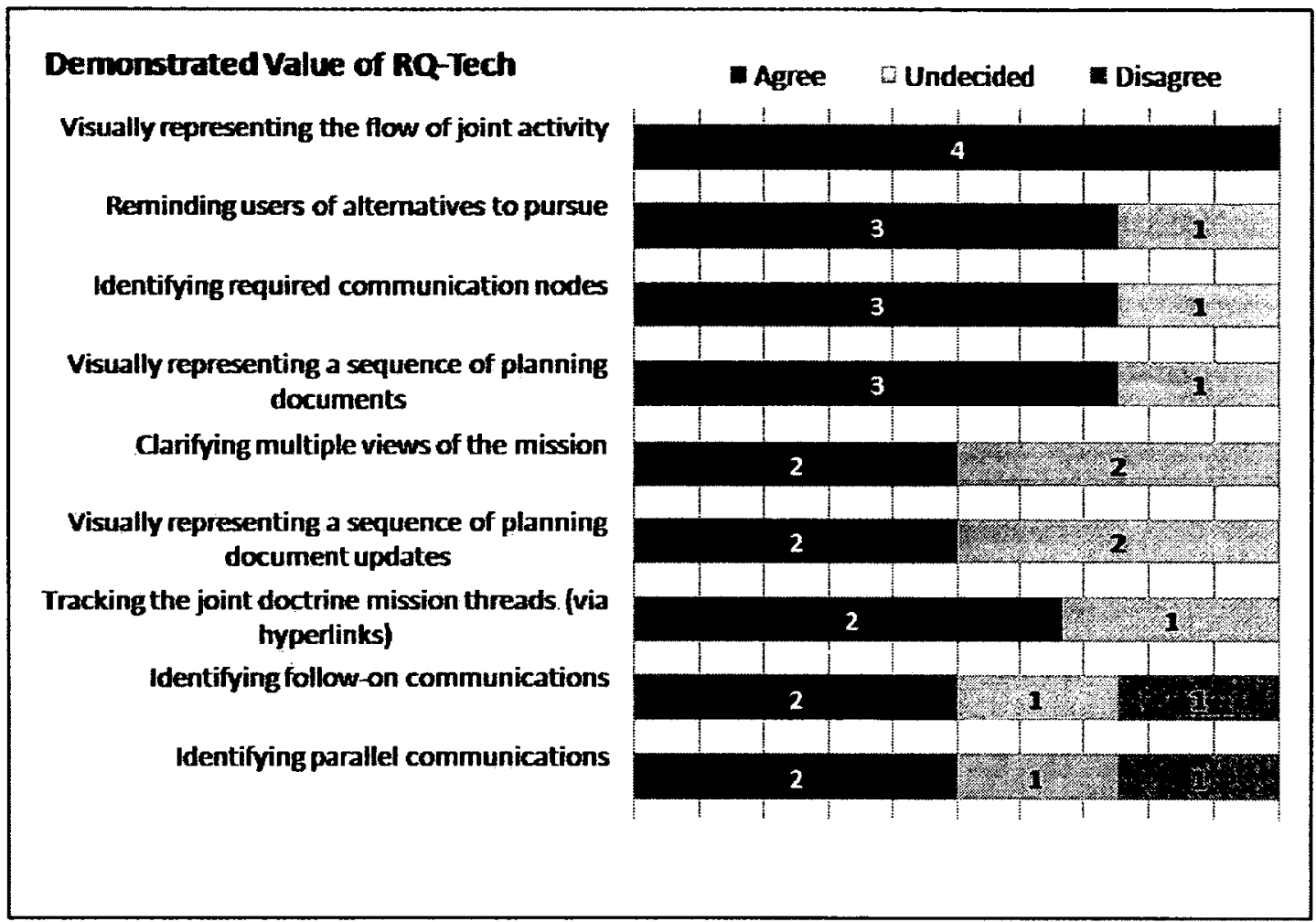

\section{Figure 20: Value of RQ-Tech Survey Results}

The participants appeared to be divided about the value of RQ-Tech versus the Defense Technical Information Center (DTIC) website for searches that they normally use to find information from Joint doctrine, as shown in Figure 21. The reference to DTIC was included to allow the SMEs to compare the most technologically advance doctrine web search tool they use to the RQ-Tech prototype. One SME found RQ-Tech better for the following reasons: more focused query $w / R Q$. DTIC returns too many options. Because $R Q$ only modeled one pub, DTIC is more holistic, but that is based on current fielding. Another SME wrote: this has the potential to provide a one source "go-to" tool for planners and decision makers. It just needs to have operator input as far as what does the end user need to be able to access.

One of the survey participants acknowledged on the survey form that he had not used DTIC enough to comment on the comparison. This explains at least one undecided response to 
the statements in this section.

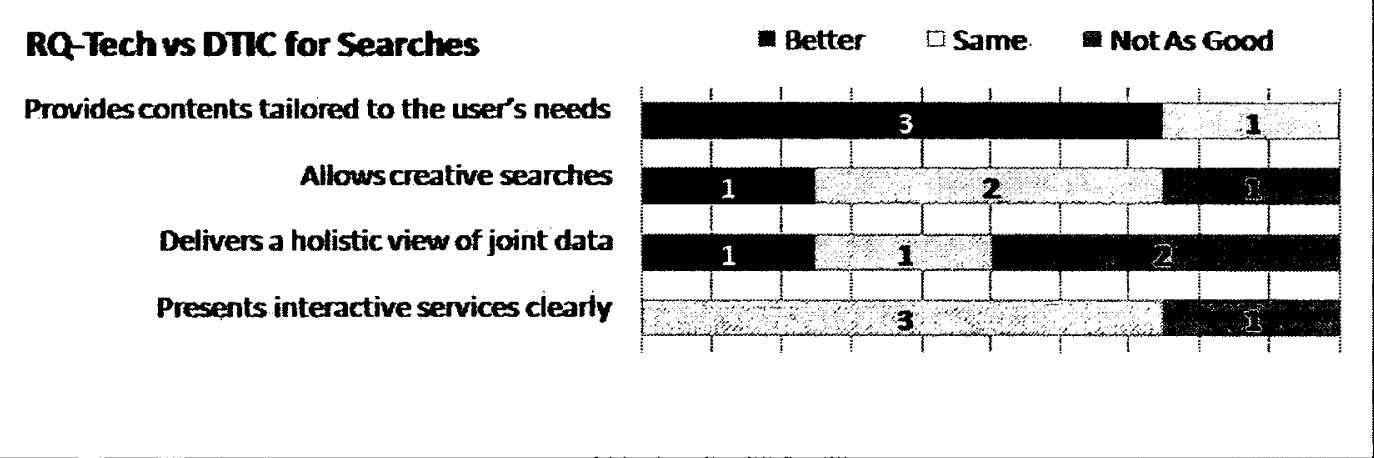

Figure 21: RQ-Tech vs. DTIC Survey Results

The participants were asked if they would be willing to recommend the RQ-Tech prototype for various processes having to do with communicating Joint doctrine. The results were overwhelmingly positive that RQ-Tech would be recommended (Figure 22).

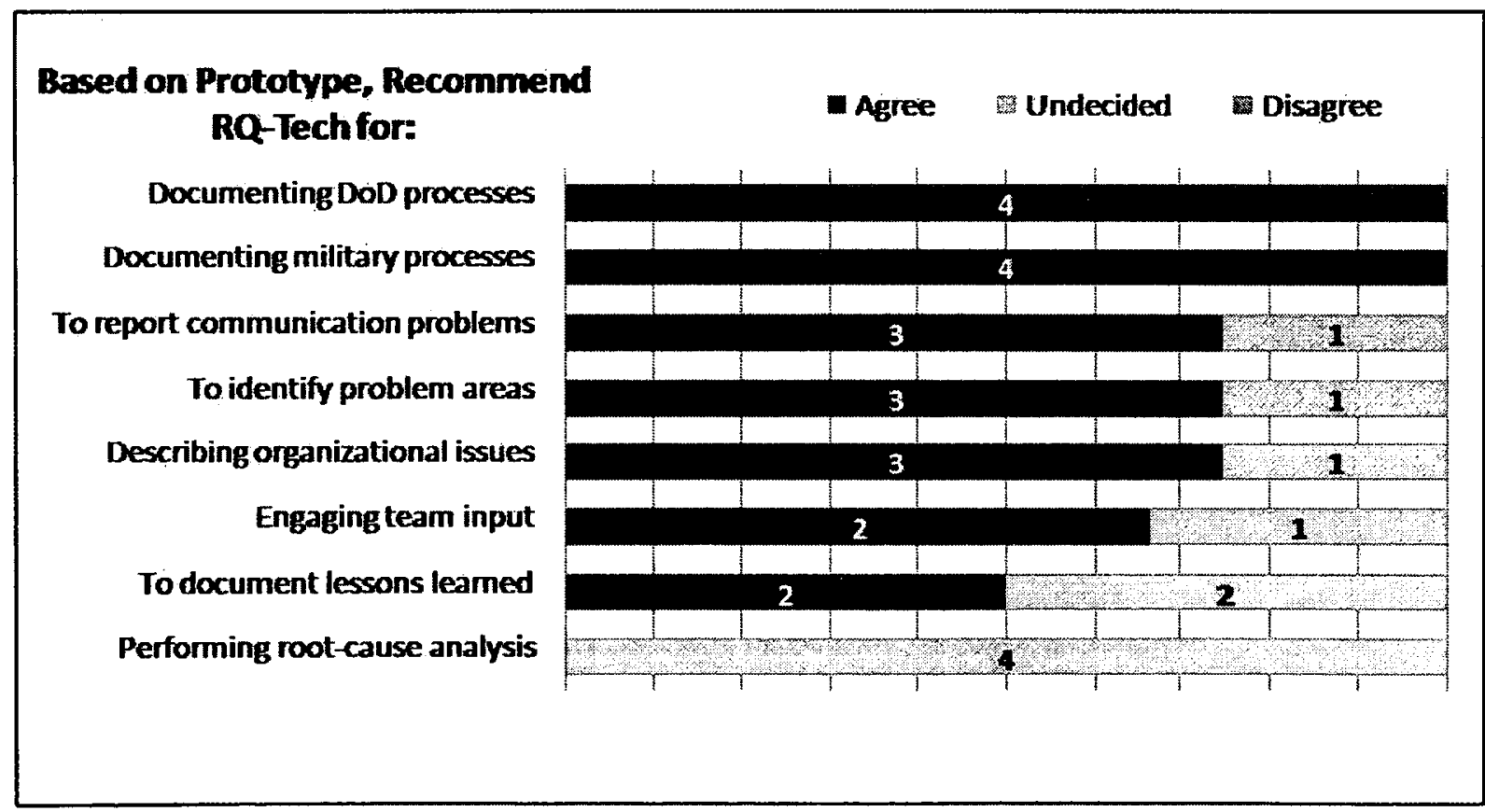

Figure 22: RQ-Tech Prototype Recommedation Survey Results

The entire set of survey results, including all user comments are contained in Appendix $\mathrm{H}$ - User 
Feedback Survey Results.

\subsection{Research Question Two - Conclusions}

The results of research question one indicated that the most significant factors to consider when translating authoritative text and rich pictures into semantic models have been identified in the RQ-Tech Methodology schema. Approximately $75 \%$ of the data in a Joint doctrine publication sample could be represented using the RQ-Tech modeling technique. Qualitative and quantitative data point to the conclusion that construct validity had been demonstrated. In addition, the RQ-Tech Methodology schema supports auditability by maintaining links to the original block of data for each modeled statement, demonstrating provenance.

The results of research question two show that the extent to which enterprise models aligned to joint doctrine are useful in representing operational scenarios was also successfully demonstrated. Responses from SMEs in the field of Joint doctrine strongly indicated the RQTech Methodology prototype and scenario builder were not only capable of representing Joint doctrine as written, the prototype and scenario builder embodied the potential to surpass current methods for locating key pieces of data required for describing Joint doctrine communication events.

- Specifically, the RQ-Tech prototype was successful in graphically conveying strategic planning events while keeping track of what specific event in Joint doctrine these events were describing.

- Because the data from the sample of doctrine was organized into triples, queries into the parsed data brought back responses that included comprehensive lists of information. Some of that information could have easily been forgotten using less intelligent modeling methods.

Users are often required to document problems encountered in the field. Usually part of the reporting process requires a description of the conditions at the time the problem occurred. 
Users must also identify the standards they were using, that is, what were they trying to accomplish when they encountered the problem. Standards and conditions are considered the context surrounding the problem. Problem report repositories are often use as evidence of what type of new capabilities are required to avert having these problems occur in the future because they convey the context that surrounded their attempt to carry out Joint doctrine. By implementing the RQ-Tech Methodology scenario builder as an approach to documenting these problem events, users are able to not only give a vivid description of the type of event that would reproduce the problem, they would effectively identify the associated Joint doctrine planning documents and events as well. By framing scenario analysis within the tenets of Joint doctrine, there is a greater opportunity to more holistically represent the complex world of Joint doctrine compared to previous EA methods. Instead of stovepipes of systems and functionality, strategic leaders could instead evolve a holistic view of capabilities they want to include in their portfolios of acquisition projects.

\section{Research Findings Summary}

Various validity and reliability types were demonstrated throughout the research design and implementation phases of the RQ-Tech Methodology. Specifically, the following activities delivered a rigorous research project in concert with the naturalistic worldview of the canons of science (Cresswell \& Plano Clark, 2011; Crowther \& Lancaster, 2008; Hannes et al., 2010; Leedy \& Ormrod, 2005):

- The research questions prompted development of a schema that used identified classes and properties to form the structure for a data collection instrument demonstrating internal consistency reliability

- A parsing process was developed and performed as a pilot to demonstrate that Joint doctrine could be parsed using the data collection schema-demonstrating 
descriptive validity

- A sampling plan was constructed that indicated which volumes of Joint doctrine would be parsed to satisfy requirements for answering research question two demonstrating content validity

- A set of graphics that could visually show how the qualitative data would form clusters and linkages between related classes was constructed - demonstrating qualitative validation

- Groomed qualitative data could be arranged graphically to show resultant patterns - demonstrating evaluative validity

- The results of the qualitative data was quantified as statistics and percentages, for example, the portion of text that was modeled using the schema, the fraction of figures that were modeled, the portion of the Joint document that was not modeled because it did not fit the schema, the type of data that was not modeled, and why it was determined it did not have to be included in the model - all demonstrating theoretical validity

- The qualitative and quantitative data was triangulated to show how the two types of methods supported each other - demonstrating construct validity

DoD's CTO expressed the need for reforming wasteful and unproductive methods currently used to satisfy the letter of the Clinger Cohen Act that requires EAs for DoD acquisition projects (Wisnosky \& Vogel, 2006). From his position as head of the organization that implements EAs, he is vocal in admitting that the current EA methodology used by the DoD is flawed. His recognition of the usefulness of the Semantic Web technology and its epic-wave movement may prove a good first step in cutting ties to the old factory-floor root metaphor that no longer represents modern organizations. However, the holistic, overarching structure between the real, complex world of human organizations and the world as seen through the eyes of computer technologists is a gap that must be addressed before real advancement in comprehensive, cost effective EAs for major DoD projects can be realized. The RQ-Tech methodology research is a study that has successfully shown how this gap can be cost-effectively bridged. 


\section{CHAPTER 5 - THEORETICAL CONTRIBUTIONS, IMPLICATIONS, AND FUTURE}

\section{INITIATIVES}

Systems Theory offers ways to frame complex SoSE problems. As discussed in previous chapters, this research exploits systems principles as a frame of reference for addressing complex problems, and in doing so advances the paradigm for EA development. This chapter discusses the theoretic contributions and implications found through research designed to investigate the RQ-Tech Methodology proposition. Also, contributions regarding methodology, methods and practical applications are presented along with the implications regarding each contribution. A summary of the entire research effort is presented, including an outline of future research initiatives.

\section{Introduction}

Solving complex systems issues effectively requires an approach capable of addressing uncertain dynamic behavior inherent in complex problems (Keating, Peterson, et al., 2003). Fundamental systems principles, including holism, emergence, complementarity, framing, hierarchy, self-organization, requisite parsimony, satisficing, sub-optimization and minimum critical specification were used to inform an advanced approach designed to address deficiencies in EAs for complex organizations. An investigation of literature confirmed that aspects of disciplined Systems Engineering methodologies would benefit from including aspects of Soft Systems Methodology, Socio-technical Systems Theory and Unbounded Systems Thinking because they add concern for human organizations and their need for flexibility and adaptability. The outcome of this informed approach is RQ-Tech, the methodology that enables increased understanding of complex systems through use of Semantic Web standards. The RQ-Tech 
approach was successful in modeling the essence of a sample of the strategic doctrinal level of the complex DoD organization. The model revealed a comprehensive array of required communications in a manner easily understood by organizational planners. When scrutinized using the naturalistic canons of science, the RQ-Tech methodology exhibited rigorous research tenets, including dependability and auditability because it preserved links from every model object back to its provenance in doctrine.

\section{Theoretical Contributions and Implications}

Value-added contributions to theory development are derived mainly from developing new and compelling why's, that is by pointing out new understanding relative to what has been understood before (Whetten, 1989). Whetten writes that theoretical insights can be discovered by borrowing perspectives from other fields. This encouragesaltering metaphors and gestalts in ways that challenge the underlying rationales supporting accepted theories (p. 493)

The main contribution of this research to the EA body of knowledge is to clearly demonstrate that a SoS organizational enterprise exhibits the principle of holism when viewed from the planner's strategic point of view. When this scope-level view is developed by enterprise planners in the form of a model designed to be read and understood by managers within the enterprise, in addition to technology architects, it shifts emphasis from the desire for new technology to the strategic concerns of the enterprise as a whole. This paradigm shift came from viewing the practice of EA through a Systems Theory lens. This changed perspective suggests how inappropriate the old way of aggregating activities to form systems descriptions had become. Now the analogy of social networking can replace the post-WW II industrialassembly-line metaphors, allowing enterprise managers the freedom to describe their 
organizational needs using interactive Semantic Web application modeling practices that are as flexible and adaptable as their enterprise needs to be.

There are several implications that can be drawn from this contribution regarding the holistic SoS enterprise. First, the strategic vantage point of the enterprise can now be defined as the scope-level enterprise model perspective. Similar to looking down from the observation tower of a sky-scraper, the scope-level has the broadest view of the whole enterprise. This unique panorama is especially enlightening if the enterprise is composed of various systems that have been designed separately, such as the various military Services of the DoD, but must operate together as one Joint Force. A second implication is that this scope-level model arches over all the business entities and multiple perspectives of each system of systems. Because it makes use of the language (text) and graphics (rich pictures) of the system's strategic-level managers, this perspective is structurally oriented to communicate meaningful ideas about how the enterprise could change to become more productive, when enterprise experts express the wants and needs for improving the enterprise. Lack of this scope-level view is a gap that has long hampered efforts to quickly and precisely identify complex enterprise technology requirements and acquisition project constraints. Filling this gap now allows the complex enterprise to be viewed not as a collection of stovepipes, but as an interdependent community.

As a second theoretical contribution, this research proposes that the holistic essence of the $E A$ can be represented by its whole documented body of corporate knowledge (i.e., the documented corporate business plan, referenced policies and high-level procedures that are important enough to require documentation in writing and rich pictures) usingtheW3C XMLstandard digital library format. The results of this research clearly show the unique connection between two important concepts; i.e., computer science surrounding Semantic Web standards, 
and the concept of the whole organization. This realization significantly moves the EA body of knowledge forward to a point where it may be considered more economically feasible to critically document complex technology projects in preparation for effective organizational change. As this RQ-Tech methodology scope-level view is communicated by the planners to the enterprise architects in the same XML language used by the enterprise architects, it blends the strategic organizational viewpoint holistically with the organization's technological viewpoint.

An important implication from this contribution is the realization that all enterprise scope-level documents as a whole represent everything significant about the complex SoS enterprise. Assuming that everything about the enterprise considered significant and authorized by the strategic level managers of the organization has been documented, this whole documented view can represent the entire scope-level model of what the SoS should-be. Hysom (2003) used the term should-be to describe a phase in the life cycle of EAs. It is a view that, when documented, can be compared to the organization as it currently is, that is, the as-is view. The should-be model minus the as-is model comparison yields the needs-are view of the organization that is ready for change. This event prompts other enterprise life-cycle phases, such as the could$b e$ and to-be views, eventually informing the requirements process for describing needed capabilities.

The RQ-Tech methodology starts with the should-be model, drawn from accepted and well-thought out descriptions of the entire organization. Just as every new company is advised to develop a business plan to show investors how they plan to produce a return on investments, the only acceptable way to communicate that business plan is in writing. Oral descriptions alone won't suffice for an enterprise that is composed of a multitude of separately defined systems. In addition, enterprise strategic planners are more likely to point to the documented descriptions of 
the enterprise that have been authorized with the signature of one or more high-level enterprise managers as a symbol that they are accepted statements that govern all enterprise decisions. For example, while a board of representatives of each military Service may never be able to agree on a definitive as-is model of how all the military Services function together, they all have agreed to uphold the written words of Joint doctrine.

Even if strategic planners have talked about needed updates to strategic documents, until these updates have been through the enterprise's configuration management process for change notification, the vision for that update is not considered official. There is no doubt that there are undocumented aspects of any SoS, and these are a powerful source of what is considered either good or bad about how the enterprise implements its business plans and policies. These valid, but undocumented aspects of the organization, when compared to what the SoS enterprise should $b e$, may represent an as-is view of organization. It is up to the enterprise to endorse or correct those that self-organize and act without regard for documented boundaries. By accepting the difference between what has been documented and what is done ad hoc is another aspect of the complex enterprise that may be of interest. For example, SSM asks organizational managers if they want to encourage free-thinking or restrain the decisions of their personnel. In any event, distinctly identifying what is within the documented boundary and what is outside is part of the unique profile of the organization. What can be constructed from organizational documents using RQ-Tech is a thoughtful application of a mature Semantic Web ontology applied to the DoD's corporate body of knowledge defined as authorized, accepted and published.

When this core doctrine is parsed into the Semantic Web format, the written words and pictures take on the role of scope-level authority for the enterprise. The marriage of authorized enterprise documentation and the Semantic Web produces a model of the essence of the 
enterprise that had only been experienced in all its complexity, power and potential by those exceptionally well-trained in the depth and breadth of Joint doctrine, and the associated libraries of references to supporting laws, policies and related publications.

Systems Theory and related systems frameworks explain the logic behind the theoretical contribution of the RQ-Tech Methodology to the EA body of knowledge. The practice of EA as we know it presently had its roots in the software crisis of the nineteen-nineties and was found lacking in philosophical grounding, as shown in Chapter 2. Soft systems principles, that is, those applicable to purposeful action taken by humans in order to make decisions or achieve organizational goals, utilize a view of the enterprise that now includes both flexibility and adaptability, as evidenced in the RQ-Tech Methodology research findings.

It may be implied that changing the analogy for constructing EAs from the quest for mechanized, repeatable fragments of activities to that of an active, communicative social network will invite discussion surrounding associated communication and collaboration impediments. These issues could be anything from training gaps, fragmented planning, or the need for seamless technology integration. This analogy-shift creates new horizons for using the common language of the Semantic Web to capture an understanding of the many interactive systems of the enterprise so that the technical challenges to the organization as a whole can be identified and solved using one common, open-standard semantic language as the required scaffolding.

Changing the approach to EAs from activity-focused to collaboration and communication unleashes powerful parallels to social network metaphors. Joint doctrine that has been coded using the FOAF-based RDF/XML standard and content analysis rules of the RQ-Tech methodology can be reused because it establishes the link to the need for new capabilities at the 
strategic and planning levels. The current EA practice begins by describing business rules at the technology level, as described by practitioners, not planners. Stove-piped solutions that produce islands of technology can be avoided by employing better enterprise change planning. When ad hoc changes are introduced, organizations tend to self-organize in response. Ad hoc new technology implementation may be just as likely to have a negative effect or no effect at all, if not thoughtfully planned and executed, as evidenced by high failure rates for complex technology projects. Thus, the introduction of change within the larger strategic picture afforded by EAs built according to this new paradigm can be enhanced through the purposeful situating of the change within the larger strategic perspective. The result might possibly provide for more intuitive transition of strategic viewpoints to the tactical orientations of architectures.

Prior to RQ-Tech's recommendations for using organizational classes and properties to illustrate the complex military decision-making processes, enterprise planners had to express their organizational challenges using the language of the technology they wanted to acquire. Systems Theory concerning minimum critical specification clearly supports models that illustrate what the organization needs, not how to construct and use it. Leaving out the technology details allows the planners the opportunity to describe needed capability in terms they can support throughout the enterprise while leaving the onus of constructing the technology models that support their enterprise models to technology experts. When this scope view is communicated by the planners in the same modeling language used by the enterprise architects, it blends the strategic organizational viewpoint holistically with the organization's technological viewpoint. When there is no need to translate languages between those communicating, it is reasonable to expect understanding between entities to substantially improve.

An additional theoretical contribution of this research is grounded in Aristotle's argument 
that the whole is more than the sum of its parts. Current EA practice recommends decomposition of major activities into their primitive components, so they can be housed in a library of functions; then later assembled to form larger functions. This practice is also true for computer code, where large sets of code usually cannot be considered reusable in a wide variety of standards and conditions. In contrast, the RQ-Tech methodology recommends that the whole set of Joint doctrine can be used over and over again, once it has been parsed into its Semantic Web constituents. When innovative solutions are sought in answer to complex conditions and an array of standards, Joint doctrine has proven its value as guidance to its users, and promises no less when used to form the adaptable and flexible model of the entire Joint organization, and the many DoD organizations that make up this large military enterprise.

The theoretical implications of having an up-to-date model of the essence of a large, complex organization won't be known until this concept gains acceptance for implementation. Those organizational enterprises that rely on creative and innovative solutions resist efforts to characterize their activities as typical or repetitive. Until now, the adaptability and flexibility traits of a Joint Force organization could not be modeled in sum total. Branching activities with many possible configurations become too complex to comprehend. However, a model that allows infinite variation is a challenge as well. It remains to be seen what an organization would do with the capability to instantly construct scenarios of doctrine-driven activities to handle a crisis or portray a problem situation. RQ-Tech research findings illustrate how users of this methodology could potentially access their doctrine in the form of social graphics. These profiles would present a multitude of possible contacts that when tapped for assistance, could collaborate on plans, and add their expertise. In the manner of a check-list, arrays of listed communication subjects and possible planning events would display what should be considered 
at any point in the planning process. These are only a few of the possible implications this dynamic model holds for further evolving the EA field and its prevailing paradigm.

In summary, value-added theoretical insights regarding EAs were derived mainly by pointing out new understanding relative to the historical and current state of knowledge. The primary theoretical contribution of the RQ-Tech methodology is a demonstration of how a system of systems organization can be modeled holistically. This theoretical realization is based on the notion that organizations document what is important. By identifying the body of documentation the enterprise accepts as its most important strategic guidelines, policies and procedures, the essence of the organization can be modeled using Semantic Web standards. When this core doctrine is parsed into the Semantic Web format, the written words and rich pictures take on the role of the scope-level model of the enterprise. Arranging the organizational classes and properties according to the Semantic Web standards allows a model to emerge that is flexible and adaptable, and can be arranged in an infinite number of configurations as appropriate to the nature of the inquiry posed for the enterprise. For an organization that is required to creatively address a large array of complicated global issues, its model must reflect both critical guidance as well as creative decision-making. The RQ-Tech Methodology delivers both.

There are a variety of practical implications that stem from these theoretical contributions. The most obvious implication is that EAs required for acquisition projects could be quickly constructed by Joint military Combatant Commanders who know what capabilities they need to handle the most pressing and critical situations their organization will encounter. A rapid EA construction methodology would allow for equally rapid technology requirements development. Technology developers almost universally use XML for cloud computing, and 
would be able to use the scope-level models constructed in the XML language without further translation. Both the enterprise planners and the enterprise technology architects would be able to better understand each other's needs.

But many important implications concerning these theoretical contributions cannot be anticipated in advance and their realization lies beyond the scope of this research endeavor. When a major shift in thinking is required, there are those that will be uncomfortable with new ideas and methods, regardless of the sound foundational logic and research that might support the necessity and path for that shift.

\section{Methodological Contributions and Implications}

A methodology provides a framework more specific than philosophy, but more general than a detailed method or tool. If the methodology is systems-based, the framework is also expected to effectively guide action (Adams \& Keating, 2011a). The RQ-Tech framework supports more effective outcomes because it incorporates the scope-level view of an enterprise as a formal EA model. The framework succeeds as a more effective guide to action because it accurately represents all aspects of the planner's enterprise from the strategic level.

It has long been assumed that a scope-level model of a complex enterprise might not be possible, given that strategic visions, missions, and procedures are documented in non-specific natural language (text) and diagrams (rich pictures) that enterprise planners use to communicate their plans. In the past, this important gap between the scope and the business rules has been glossed over. To satisfy the linkage to the scope level, simple lists of strategic goals or the highlevel enterprise mission statement of the organization have used as surrogates for the planner's holistic view. This new scope-level framework now provides the possibility to establish links to 
every organizational area that has been described in doctrine, via the logically presented digital library of the whole enterprise organization.

As a further methodological contribution, this research provides a generalizable and transportable EA framework designed to allow the users to create and update their own EAs. As a result, strategic leaders can access a framework that acts as a systems lens for use in assessing and evaluating their portfolio of projects against ever-changing strategic priorities. This portfolio management is in addition to the usual progress reporting information required from technology managers. More traditional approaches to organizational change involved Systems Engineering techniques for developing models and requirements documents. Engineers trained in systems methods and project management would have the responsibility for facilitating documentation of users' needs and recording them in a manner that would form a baseline requirements document. Once under configuration management, this requirements document would form a database for follow-on project tasks intended to design, develop, integrate, test and implement the technology solution. As previously described in the literature review, this hard systems approach became more difficult to deploy as project funds ran low while quality controlling tasks, such as testing and training, would be slashed or cut entirely. Because the RQTech methodology is more oriented toward better communications between enterprise planners and technology builders, systems engineers may find better ways to manage acquisition projects and achieve user expectations using the new RQ-Tech methodology.

It is possible that complex organizations that provide services, other than the $\mathrm{DoD}$, could benefit as well from the RQ-Tech methodology. For example, the protocol-rich healthcare communities would benefit from viewing scope-level options available across a number of departments and business units. Healthcare providers could use their knowledge of how they 
manage to work within the rules and regulations required to be assessed as quality care providers, including models that show critical communications they must maintain in order to share information regarding patient care.

Local governments using the RQ-Tech methodology would be better able to offer seamless, integrated services to citizens using the RQ-Tech approach. Requests from citizens for government assistance are difficult to handle when the request appears to be unique. Lists of options and descriptions of the types of communication various departments handle would fill information gaps.

RQ-Tech contributes the concept of the should-be model of the enterprise for every documented facet of the enterprise. When enterprise personnel can access their organization's digital library organized to respond to compound queries, it is likely that customer relations will improve. Soft systems methodologies suggest that personnel given the flexibility to perform their jobs will implement their own organizational improvements. Having a model that provides guidance as well as flexibility allows personnel to collaborate with others effectively.

The importance of documented aspects of any organization compared to those conveyed informally is not trivial. What is not important enough to document as doctrine cannot be reflected in the scope-level model. Because doctrine is vague about how events are managed, but specific on what is important, the should-be model is the one that conveys the minimum critical specifications for describing enterprise capability projects. It is the generality of doctrine that makes the scope-level view flexible and adaptable enough to suit a wide variety of specific events. Organizational personnel add the context, i.e., conditions and standards, to the minimum critical specification to describe a wide variety of situations, within the more stable and constant framework of the scope-level EA. When personnel find situations that are difficult to handle, 
they can use the should-be model as a guide for reporting the context of problem, including what made it an issue that could not be resolved without extraordinary measures. In this sense, the veracity of scope-level doctrine and supporting documents can be examined as the enterprise evolves through identification of novel situations. These situations may or may not be guided by existing doctrine. The result will either be that existing doctrine establishes the boundary parameters within which the issue must be addressed, the existing doctrine may be judged deficient in providing sufficient direction, or the situation has not been identified as requiring specific guidance when handled by trained personnel.

In summary, the RQ-Tech methodology provides methodological contributions to theories and practices regarding EAs. Specifically it puts to use the scope-level view of the enterprise that can be derived from the organization's essential documentation. Just as important enterprise documents are regularly consulted as a reference for performing work, an intelligent Semantic Web model of guidance documents provides even more comprehensive alternatives for performing the same work. RQ-Tech is a methodology that is both generalizable and transportable, that is, other complex organizations that provide services; such as healthcare providers and local governments, would be able to incorporate an enterprise model that provides guidance as well as flexibility and adaptability to their personnel. An important consideration to note about these methodological contributions is the realization that when policies and procedures are important, an organization will prudently put them in writing. Elevating written documentation to electronic library status contributes a sense of openness about the organization as well as an acknowledgment that when personnel have access to an intelligent, responsive electronic document library, they are more likely to make better decisions. 


\section{Contributions in the Form of New Methods and Practical Applications}

This research makes the the approach to EAs more easily available, dynamic, and customizable. The RQ-Tech methodology offers an open-standard for developing EAs. Open standards are available without cost or license fees. Those with programming skills can use these standards with any common XML editors they feel comfortable using. RQ-Tech was developed using Altova XMLSpy ${ }^{\mathrm{TM}}$ because the Altova ${ }^{\mathrm{TM}}$ products are designed to be used by programmers and non-programmers alike. As long as the XML documents are well-formed, they can be read and used by others who build XML/RDF documents according to W3C standards. These documents can be displayed in a variety of ways on the internet or intranet. In addition, some organizations may want to allow users to add data into XML documents, if the organization chooses to enable a dynamic environment driven by enterprise guidance. Like other EA modeling tools, it is the stored data that allows users to customize the view they think will provide the best presentation. Database query methods are also an important part of this new type of EA modeling dynamic. And methods for adding context to core doctrine elements is an important aspect of the RQ-Tech Methodology that brodens the utility of the digital library to reveal operational views of the EA. For example, the scenario building exercise (Appendix F Logistics Planning Scenario) using the RQ-Tech Methodology is only one way an organization'sfunctions could be documented. There are many other methods that users could apply, based on the reason for the scenario they would like their audience to understand.

A major implication of this new approach to EAs is the need for a core set of rules to ensure interoperability with other EAs. For example, the rule stating that: for each action, the precise block of doctrine should continue to link back to its provenance in doctrine is one that 
should always be followed. Then various types of models, and organizational uses for models, can grow according to the requirements and desires of those using the models. Perhaps in this way, organizations can realize a living $E A$ that not only accurately reflects how each organizational member is linked to the organization, but performs the actual linkagewhen the model is accepted.

There are a variety of methods and tools that could be derived from the RQ-Tech Methodology, once users allow the social network analogy to guide creative brainstorming regarding their unique enterprise. The following is a digest of some of these contributions and visions for the future.

\section{a. RQ-Tech contributes the EA Semantic Web ontology that serves as guidance to} convert current, authoritative documentation into a searchable digital library. This ontology could serve to unify disparate documents into one linked organic structure while providing a cross-check of authoritative documentation to ensure linkage across all phases of the military decision making life cycle. In this way, RQ-Tech provides a consistency check to identify areas of potential conflict within doctrine and other related enterprise guidance.

\section{b. Scope-level EAs allow system planners to become champions for needed changes} and new capabilities. To understand this new EA paradigm, users and facilitators must accept the notion that the models derived from Joint doctrine dictate communications that are mandated by the authors of Joint doctrine. This necessitates new definitions of what is required to be known about new technology. For example, under what conditions could they use the new technology; how would it be chosen as the best capability to reference within planning documents; how would planners find information about the logistics of using the new capability, such as who is qualified on the new capability, and how long will it take to get the capability into 
a state of readiness. All these issues must be present in the EAs models or the total cost of owning the capability cannot be estimated. A champion within the organization that understands the more holistic ramifications of the change can be better prepared to make the change a reality.

c. As decision-makers for what is included in their funded portfolios for change, enterprise planners reevaluate their priorities at each budget cycle and whenever the realworld military environment changes. Using the language of Joint doctrine together with the RQ-Tech Scenario-Builder provides a better potential for decision-support. The time spent in communicating what-if scenarios of how priorities have changed, including the weight of both tangible and non-tangible costs can be significant, while accuracy of this analysis is a factor. These scenarios and decisions are outside the realm of technology project managers, but are clearly within the planner's area. Therefore EAs constructed in the planner's language will enable better and more rapid decisions regarding enterprise portfolio management. This strategic-level orientation and method of inquiry can add an important dimension to understanding the consequences of shifts in context (e.g., funding priorities) beyond the tactical level. Therefore, the interconnectedness of changes can be understood at the strategic level and propagated across the organizational level with deference to the tactical level. Understanding and appreciating the broad ramifications of change supports effective decision-making.

d. The RQ-Tech methodology provides formalized, but non-proprietary ways for the user to describe capability requirements, and defines a universal EA ontology applicable to all strategic, operational, and tactical levels of EAs. It is a Semantic Web ontology that conveys important aspects of an enterprise, as defined by the organization's unique doctrine, to provide a universal description that is interoperable with any DoDAF XML model that is valid, according to W3C standards. The Semantic Web uses open standards that serve to 
unite all XML models. This RQ-Tech methodology umbrella function is a step toward unification of all enterprise model data. It is possible that existing archived enterprise models in DoDAF repositories that have followed W3C standards can be mapped to the RQ-Tech Organization, Agent and Document classes using standard namespace mapping techniques. Mapping class namespaces between business models would provide a way to federate existing data models. Even proprietary models could be linked to the RQ-Tech scope level in some fundamental way.

e. New versions of Joint doctrine are published on a three- to five-year cycle. Therefore the RQ-Tech should-be EA model remains current with much less upkeep than as-is models built using proprietary modeling tools. There is time to reap benefit from the effort required to parse and tag each document. The cost-benefit of implementing this new scope-level model in an enterprise is a compelling argument for adopting its use in the field. EA scenarios describing new as-is problems and to-be capability solutions can be quickly constructed by EA planners and their representatives from lessons learned-type documentation, thereby decreasing EA construction time and sponsor review time. Prior to this study, a new set of EAs was required to be built for each new project, since archived, proprietary as-is views were either considered obsolete or not suitable for reuse. Requirements generated from the RQTech scenario-builder are free from unnecessary design criteria, as they can be illustrated using minimum critical specification as defined in doctrine. This leaves designers the freedom to creatively exploit technology while still staying within doctrinal functional requirements stated by the users. Users of the RQ-Tech methodology have the ability to answer questions concerning technology linkage to organizations outside the sponsors' department, but still described by doctrine. This would be accomplished by following doctrinal threads uncovered 
during the mission analysis. The RQ-Tech methodology provides a low-cost method for expanding the EA boundary by reconstructing links to functions and systems required by doctrine. This holistic approach minimizes the potential for stove-piped solutions.

It is possible the total cost of parsing important policies, procedures and authoritative guidelines of the enterprise could be recouped by considering the hours of research time that could be saved using this Semantic Web-based electronic library methodology.The RQ-Tech methodology offers potential utility to others in the enterprise. Using the DoD as an example, having the ability to conduct intelligent searches across the entire digital library of Joint Doctrine and DoD policies and procedures would be a benefit to multiple US government communities;

- Authors of Joint and Service doctrine, as they write new and updated chapters

- Trainers developing scenarios for exercises and simulations,

- Instructors developing training aids for students of military doctrine, and

- As a reference for the civilian workforce tasked to develop various deliverables.

\section{f. RQ-Tech methodology techniques provide ways to map and link all the scope-} level authoritative doctrine of the enterprise as one organic structure. This structure can be considered the whole enterprise, not just a sub-set of use cases. Use cases may not reveal the breadth, scope, or interrelatedness of all authorized facets of the enterprise. In contrast, parsing authoritative enterprise documents defines all the cases the authors of doctrine determined were important enough to include as authoritative guidance, but without much specific context. Consulting the whole authoritative list before deciding on the specific requirements for enterprise change minimizes the risk of leaving out important facets of the enterprise. Using the combination of authoritative lists and descriptive scenarios that illustrate the context surrounding problematic examples would:

- Increase the probability project requirements represent the most important cases, 
- Are accurate, and

- Are correctly framed.

John Zachman (1987) has associated the term contextual to the scope-level of the enterprise, even though there is little context described in scope-level documentation. Perhaps it is because strategic level planners are most sensitive to the contextual factors of the environment that make this level one that is constantly used to evaluate threats, competition, stakeholders' opinions, and other factors that put the enterprise' goals at risk.

\section{g. The RQ-Tech methodology replaces obsolete mechanistic metaphors with those} that are rich in social analogy. When enterprise users are asked to participate in sessions to describe their capability needs in the form of activities, it could be difficult to describe multifaceted, branching or non-standard activities. With the focus shifted to communication and collaboration, users' needs can be more accurately described and documented using the RQ-Tech scenario modeling tool and techniques. How these activities are performed may be influenced by the technology available to the team, the Service, or the enterprise. However, the nature of what must be performed exists at a higher level. Investigating the importance of what can serve to bring a very different perspective to understanding and setting boundaries in order to constrain how capabilities should function.

In summary, this study has identified several new EA practical applications and methods. It provided a Semantic Web ontology that is useful for representing the essence of organizational guidance, policies, and major procedures. This new approach to EAs provides a reusable view of the entire organization, and presents this view in the language of the organization's managers who are also responsible for prioritizing the list of capabilities designed to benefit to the entire organization. These organizational decision-makers must reevaluate their priorities each budget 
cycle. By using RQ-Tech methods and tools, they have the potential to support these decisions using real-world what-if scenarios instead of relying on reports from their much more isolated technology managers. Because the RQ-Tech methodology is built using Semantic Web standards, the ontology is available for anyone to use without cost. Providing an open standard encourages any and all organizations to use it as a basis for exchanging ideas without exorbitant fees. While the time and effort involved in parsing the large library of organizational artifacts is significant, there are many opportunities to quickly reap significant benefits from this investment. For example, authors of Joint doctrine, Joint Force and Service trainers and instructors could easily find ways to save time by using this Joint digital library. The RQ-Tech methods and tools do required a substantial change in thinking about the organization as a Webenabled social structure. However, with this change in thinking also comes the opportunity to develop more intuitive methods for using modern technology to solve significant communication issues.

\section{Future Initiatives and Research Questions}

Considering the results of the research as well as identified contributions and implications, there appears to be two areas that warrant further research. The first area that has generated a multitude of further questions focused on contributions to the EA theoretical framework. This study suggests that the use of the should-be model would producesuperior results compared to methods currently used to generate EA models and subsequent users' requirements for enterprise change management. However, there are many unknowns that should be investigated prior to implementing an RQ-Tech approach. The following questions are ripe for further research: 
- EAs that establish should-be models are able to compare them to as-is views of the organization beset by problems and inefficiencies. The delta between the two models forms the needs-are model (Hysom, 2003). What approach should be considered when an organization has an authoritative should-be model available for use?

- Based on the needs-are approach to organizational change, what would be a corresponding way to evaluate and document requirements?

- What elements of the RQ-Tech Scenario Builder would be sufficient for generating a requirements document for necessary project lifecycle requirements?

- What Semantic Web methods are appropriate for describing new capabilities for supporting operational planning needs? For advancing strategic planning goals?

- Identify how users can use the RQ-Tech Prototype to view not only what improved capability the proposed technology would provide, but how the technology would interoperate with what they already have.

- What are Semantic Web methods for identifying a holistic plan for seamlessly integrating new technology into the enterprise?

- What are the significant elements to consider when analyzing enterprise portfolio projects and comparing them to strategic goals?

The second area considered fruitful for further research includes questions generated

from the results of this research effort, including specific participant comments concerning RQ-

Tech practical applications and methods for use.

- How can complex semantic issues, such as message topics, be further indexed for easier use and better understanding?

- Connections between the strategic/operational level of the organization and the system and tactical levels should be investigated.

- Determine how to represent and link the communication tools that have been built for DoD use to appropriate EA views.

- Identify how XML schema definitions match to those in UML in order to understand how to extend the RQ-Tech Semantic Web model to the system level?

- Identify users of Joint doctrine and DoD policies and procedures who would benefit from a DoD digital library.

- There is much more to learn about enterprise organizations by understanding how they are the same and how they differ from each other. Comparing the various patterns revealed after parsing organizational documentation into classes and properties could reveal new ontological groupings. This appears to be a worthwhile follow-on activity. 
From a practical standpoint, there are many issues involved with taking the prototype of a concept and bringing it up to full capability. Potential beneficiaries of this new methodology would expect answers to these research questions prior to attempting to use RQ-Tech for their organizational EAs.

\section{Conclusions}

The objective of this research wasto develop and apply a system-theoretic based methodology and corresponding model for EA development. The current situation regarding EA development and use has been described as both costly and ineffective. Yet complex, system of systems organizations cannot afford the alternative which is to manage their acquisition programs ad hoc.

A review of literature carefully examined several key systems principles that supported the assertion that current methods for understanding how complex service organizations should approach change are deficient. A review of the Zachman framework proved useful for providing a semantic structure for considering organizations using the familiar analogy of building architecture to enable system designers a way to find the information they needed to develop and implement new capabilities. However, by design, this framework neither recommended nor espoused any specific enterprise modeling techniques.

Frameworks that advocated a mechanistic focus, such as the Systems Engineering methods for managing projects, and UML were explored. However, it was shown that these methodologies did not include elements for addressing the human elements that would eventually be encountered during the project lifecycle. There were other frameworks that were keen on investigating the softer side of engineering applied to organizations, including Soft 
Systems Methodology, and Socio-technical Systems Theory. While offering a refreshing view of organizations and despite grounding in systems principles, these frameworks were vague on the details regarding how to employ the results of creative thinking sessions to the organizational change management projects in conjunction with producing new, state-of-the-art technological capabilities required for improved complex organizations. The use of the Unified Modeling Language (UML) recommends specific modeling techniques, yet is heavily focused on the needs of the technology provider. UML is not focused on supporting enterprise planners and their need to articulate enterprise problems and their corresponding capability needs.

The Semantic Web, and specifically, the use of triples as implemented in RDF were frameworks that have been proven capable of handling flexibility and dynamic modeling tasks. However, the methodology for visualizing an enterprise organization in a repeatable, reusable way has not yet been recommended and/or accepted as a standard.

System of Systems Engineering is the only methodology studied that would be capable of framing a complex enterprise of various enterprise systems holistically, while recognizing sciotechnological aspects of the organization. However, there are few tools and methods that are grounded in Systems Theory available for use on SoSE projects. Figure 23 summarizes the attributes required for EAs. As shown, Reusable, Quality Technical Architectures (RQ-Tech) is the only methodology that has the potential to satisfy this set of Systems Theory grounded requirements. 


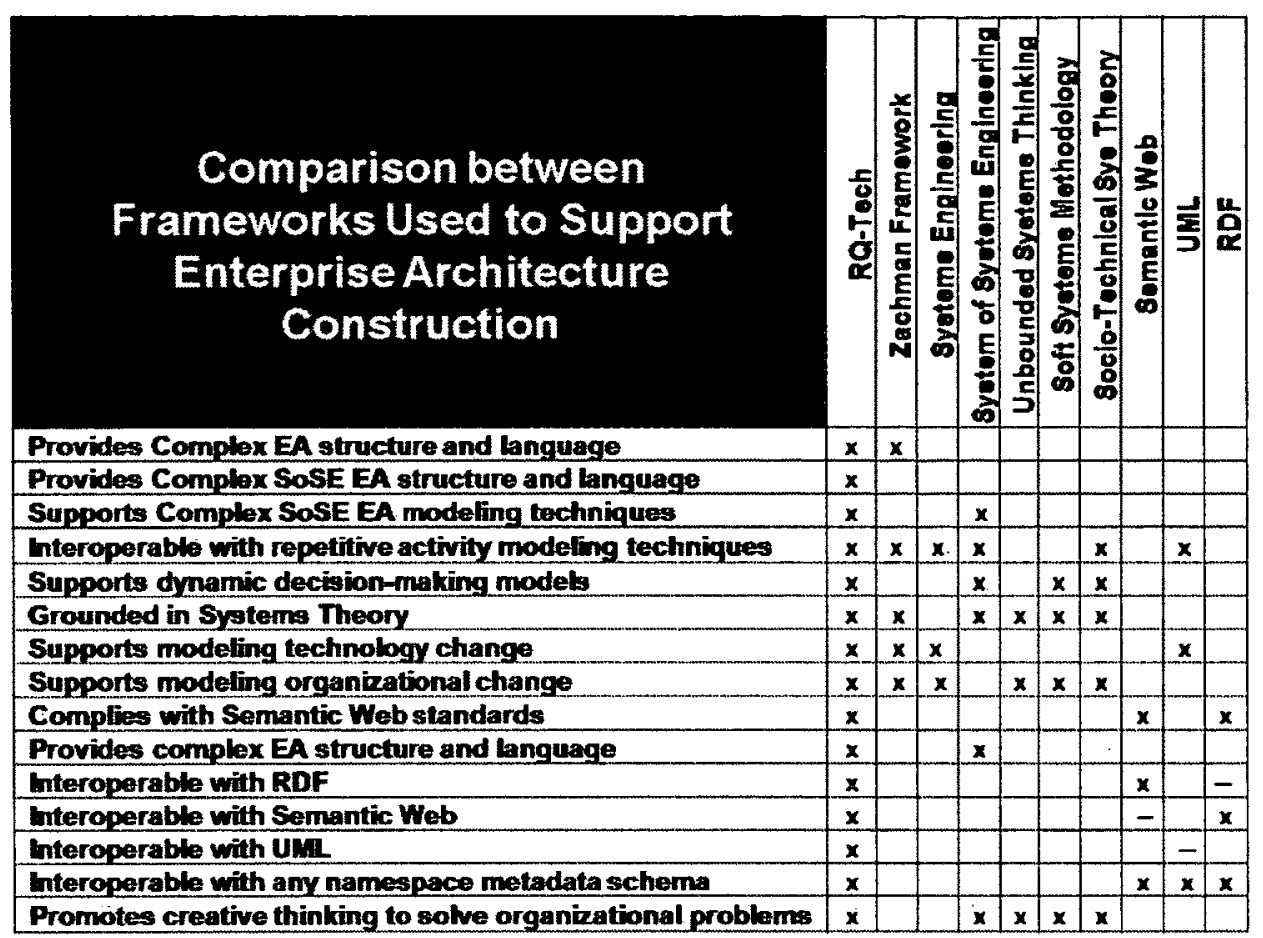

Figure 23: Enterprise Architecture Capability Comparisons

RQ-Tech provides an intuitive top-down approach for understanding complex human organizations and the context of their problems. It offers both a methodology and new Semantic Web tool set that has demonstrated the potential to contribute to the conceptual understanding of critical information exchanges and a strategic understanding of business objects involved. This research has shown it to be a successful approach to EAs that fills critical gaps found in the literature regarding EAs. 
APPENDIX A -JOINT PUBLICATION STATUS

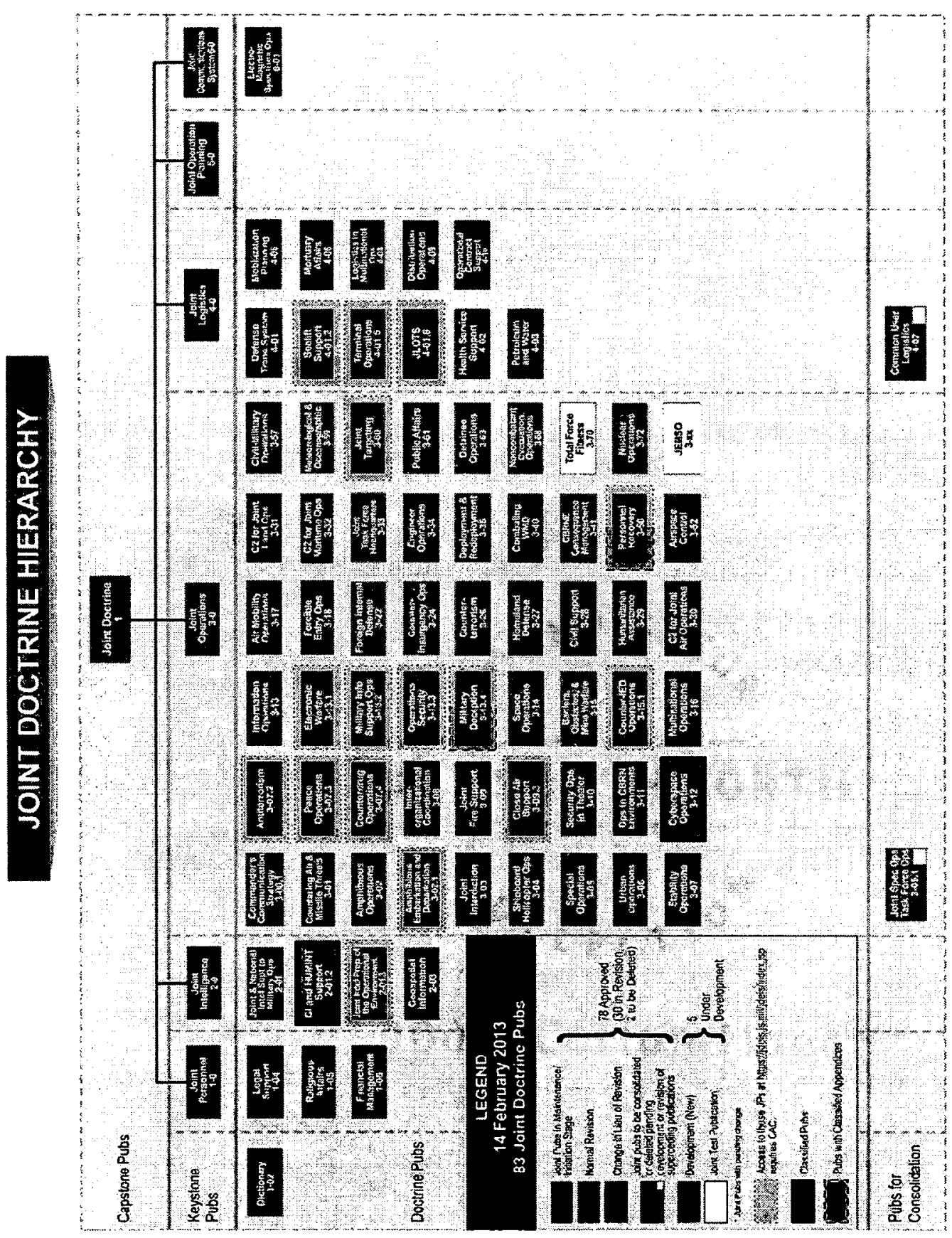

This diagram represents the entire body of Joint doctrine. An up-to-date status chart is available online at http://www.dtic.mil/doctrine/doctrine/status.pdf 


\section{APPENDIX B - RQ-TECH XML SCHEMA}

The schema can be thought of as a definition of the column headers of a table or spreadsheet.According to the $\mathrm{W} 3 \mathrm{C}$, the purpose of an XML Schema is to define the legal building blocks of an XML document.

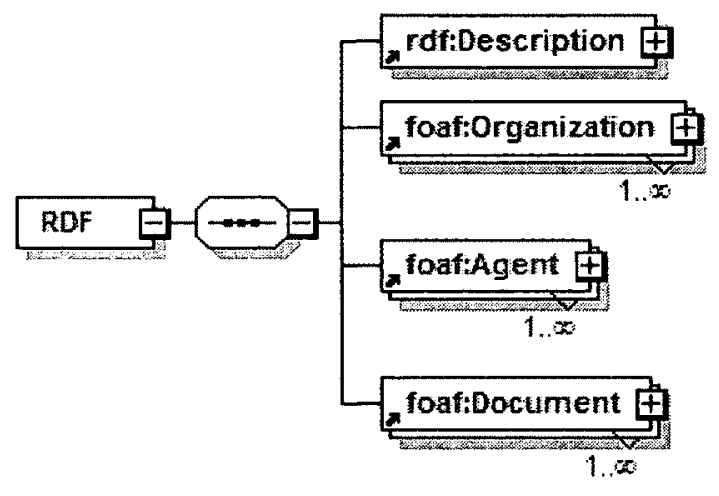

Generated by XMLSpy

www .altova.com

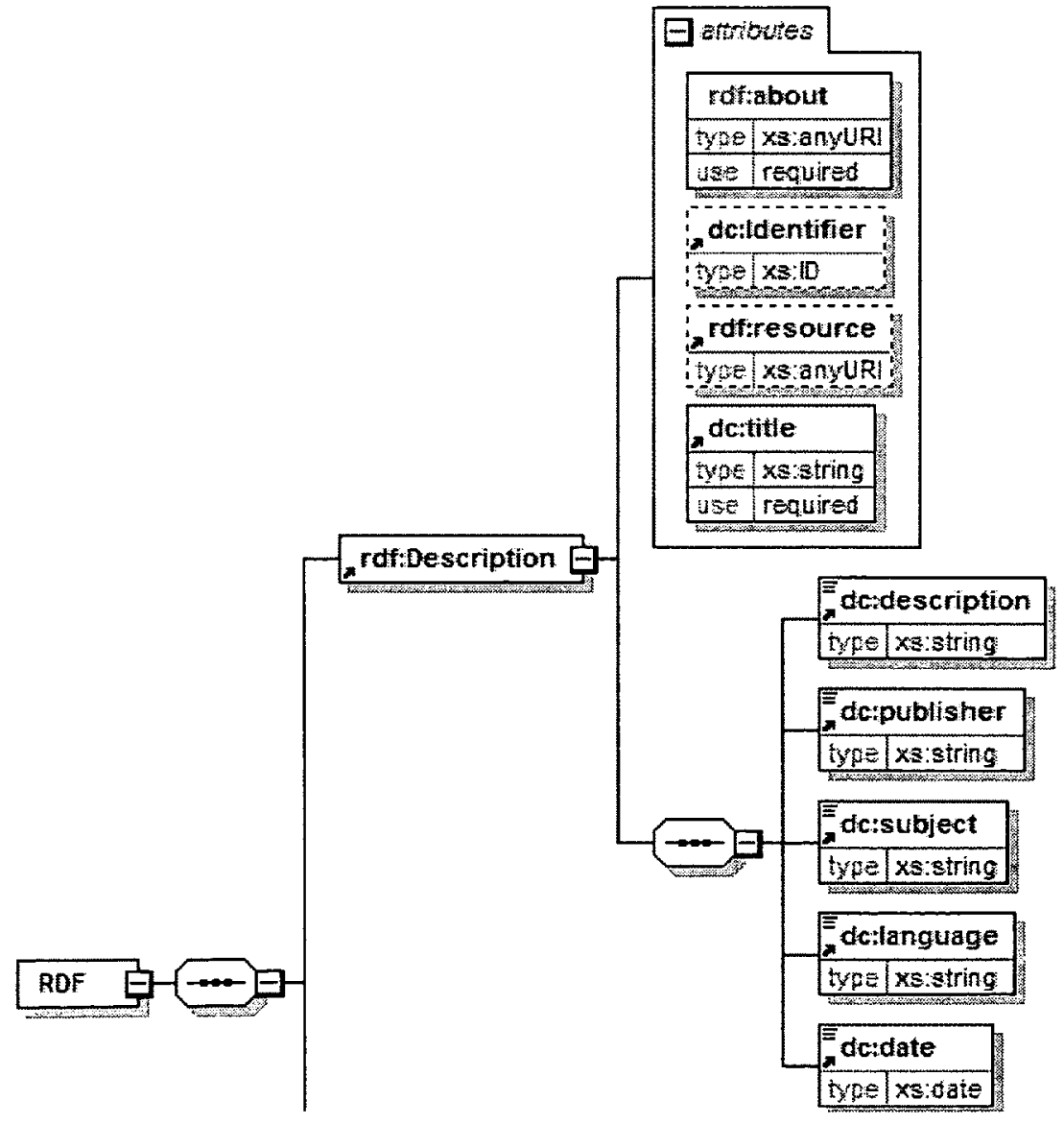




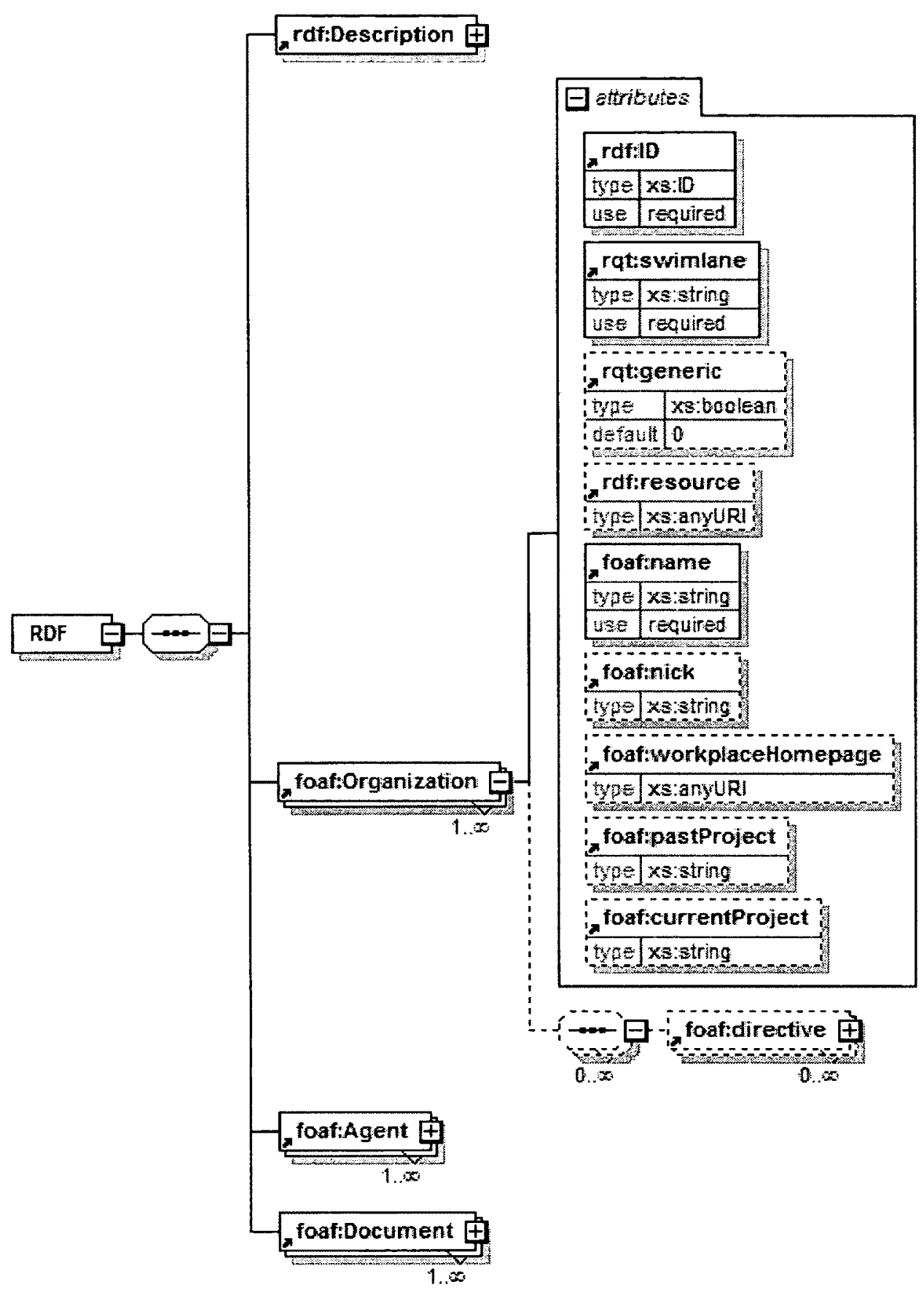

Generated by XMLSpy

www.altova.com 


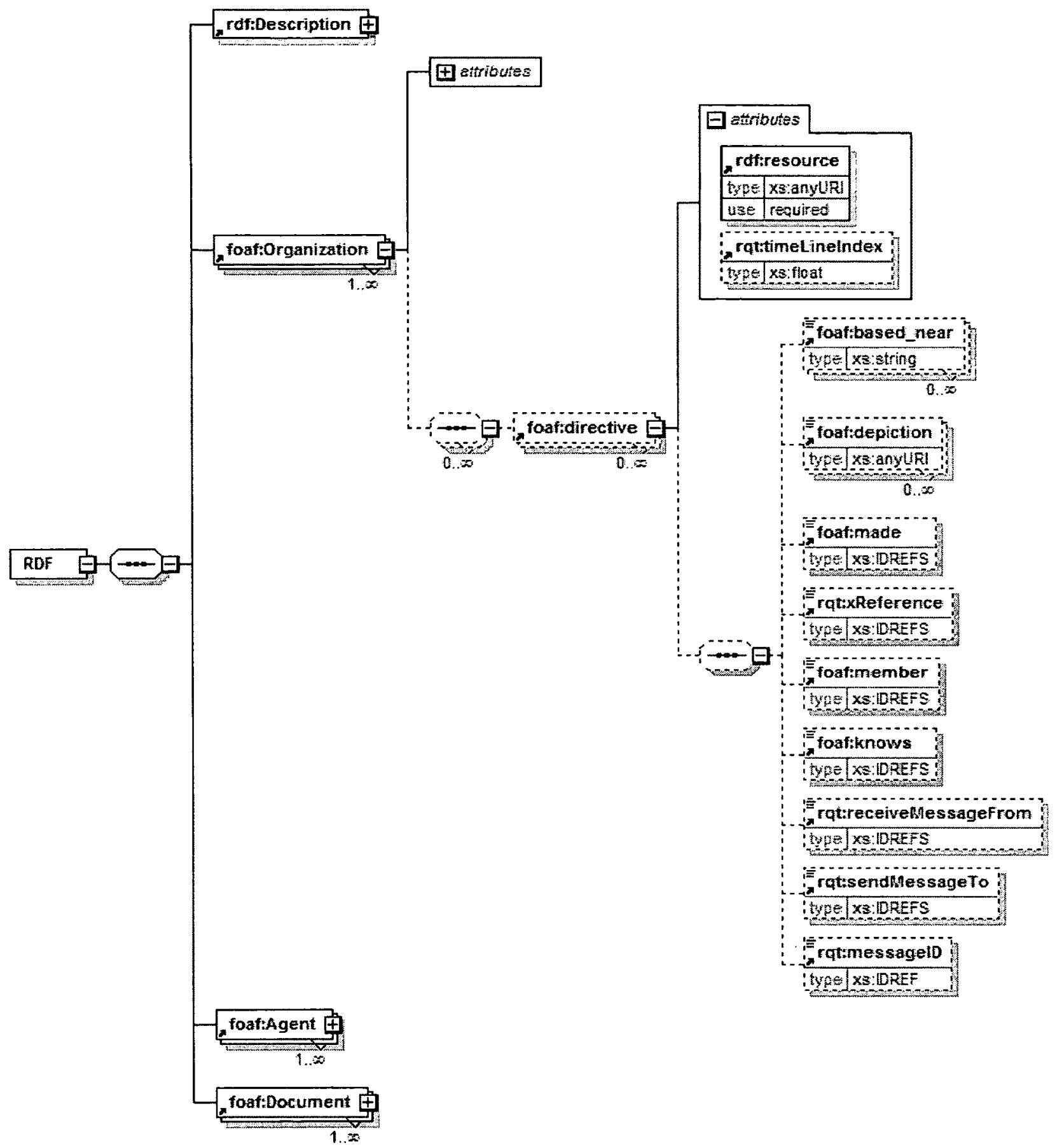




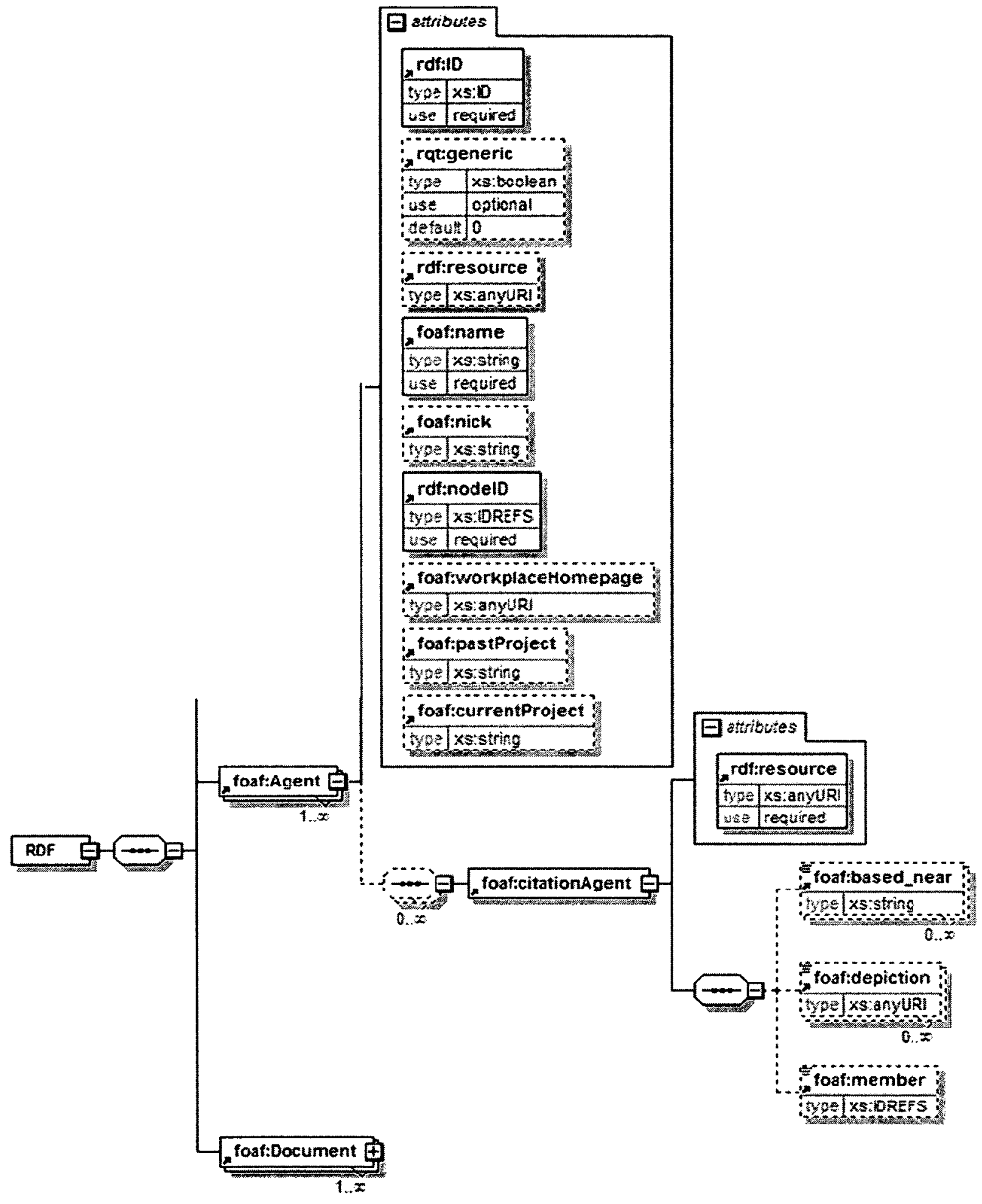




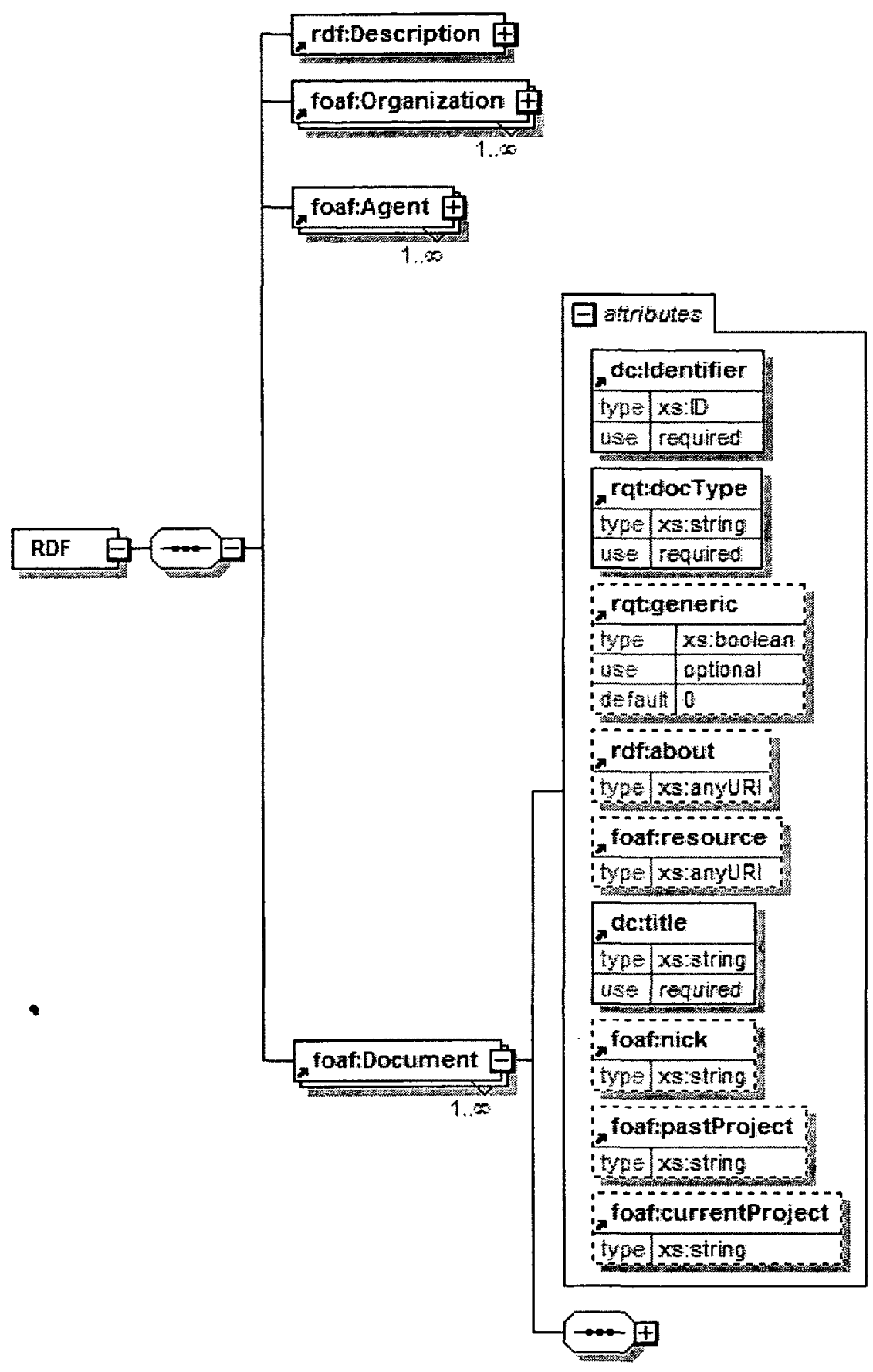




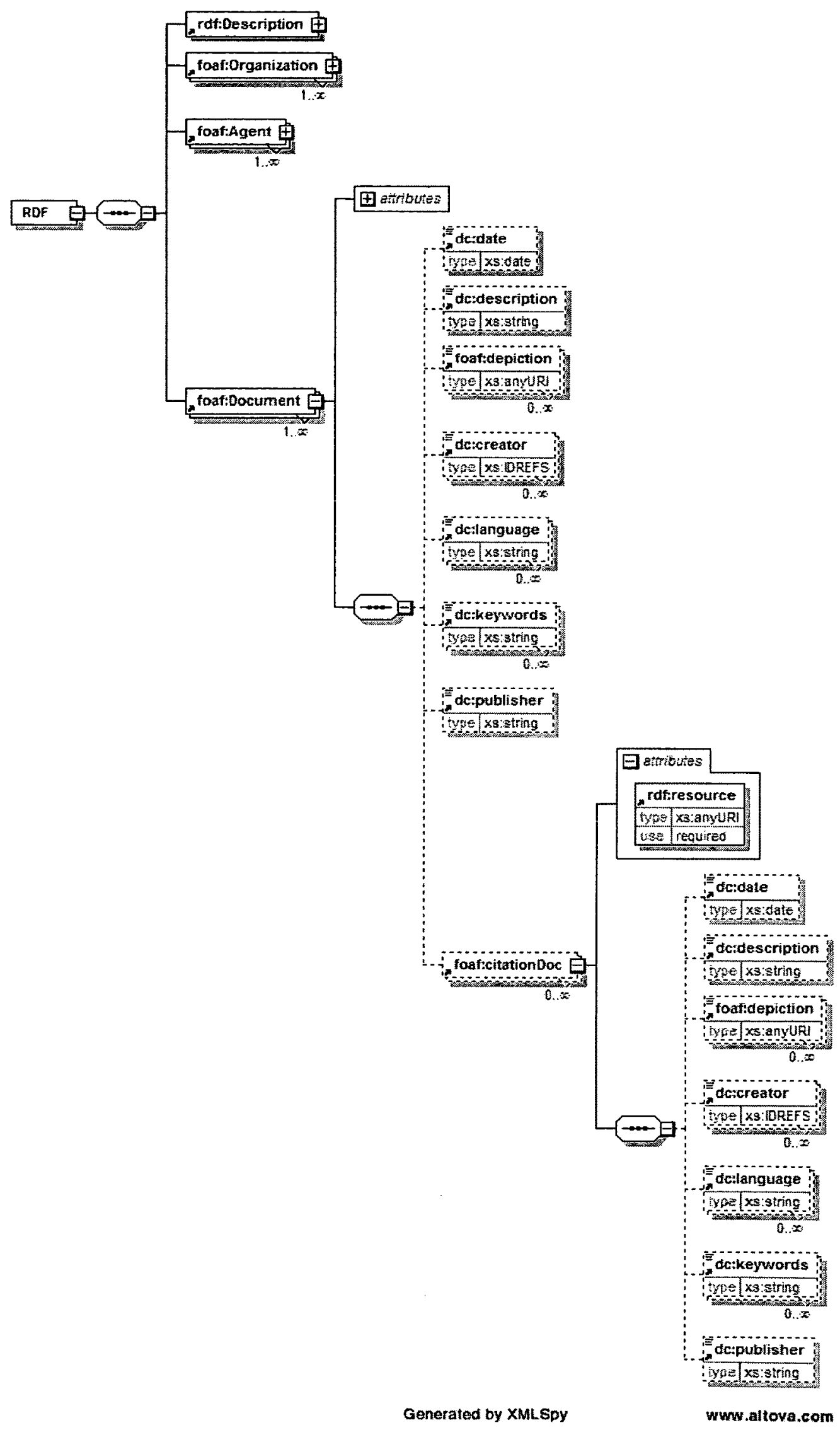




\section{APPENDIX C - METHOD FOR DOCUMENT-PARSING}

The method for selecting the most appropriate XML tag(s) for each parsed document-block of text or picture is described below.

\section{Using the Jt. Pub Glossary, identify which acronyms apply to Organizations}

(departments, boards, bureaus, centers, cells, working groups, etc.):

- Input each organization, populating the following columns:

- Mandatory - rdf:ID - (name with “_" instead of spaces, “““" instead of "“”)

- Mandatory - rdf:generic - (default is " 0 ", meaning "false") A good clue is that if the org is outside of joint force and/or DoD, then it is likely that a common org can be considered generic

- Mandatory - rtq:swimlane - (choose from list - InterGovOrg, USGov, DoD, JtForce, NonGovOrg) note: An internet search can help in determining which swimlane to select.

- Mandatory - rdf:resource - ("\#" plus chapter identifier plus page number plus "_" and then the block number) In the case of the glossary (GL) the block number is not required.

- Mandatory - foaf:pastProject - (JPX.xx) This is the joint pub identifier that is being parsed.

- Mandatory - foaf:name - This is the rdf:ID with "spaces" instead of "_". Can also include special characters like " $/$ " or ","

- Optional - foaf:nick - The acronym listed in the glossary. This should not be made up without sighting the acronym as officially shown in the joint publication.

- Optional - foaf:workplaceHomepage - This will almost always need to be looked up. If the main webpage for the organization is obvious, include the url. Otherwise, leave blank for organizations that are less well-known.

Note: This is all that should be filled in from the glossary pages for an Organization.

The remaining columns are all optional and should only be filled in while parsing the body of the document.

2. Using the Jt. Pub Glossary, identify which acronyms apply to Agents (director, commander, officer, etc.):

- Fill out all the same fields as Organization above, with the exception of 


\section{rqt:swimlane.}

- Mandatory - rdf:nodeID - Enter the rdf:ID of the Organization to which the agent belongs. This is a mandatory field and must be filled in. If the Agent is in the glossary, but its parent organization is not found anywhere within this joint publication, the organization should be found by using a web search. In this case, a new Organization needs to be constructed using the guidelines that apply to an organization, as above, however the rdf:resource should be the url of the site used to identify the Agent as belonging to that organization.

\section{Using the Organization's acronym, search the current joint publication to find all}

\section{instances of the Organization,}

Advise that after you add all the glossary orgs, agents, and plans, then go to the first chapter and just read a page or two, mark out the blocks on the page, then mark and highlight the paragraphs according to the steps below:

- Highlight the orgs in yellow, the agents in 51 reen and the documents in (Don't highlight the activities as that will be done later as the hard copy is analyzed)

- Then use a pencil and circle the verbs that describe the type of communication Now open your spreadsheet and perform the following. (These tips helped me keep my place and saved a few keystrokes once I got used to the rhythm.)

- Find org id, then insert row under and highlight it yellow

- Read to see if the org "is established by" an agent or org

If yes, then

- go to the org (or the agent's parent org - rdf:nodeID) and insert row under and highlight it yellow

- Then go back to the org id in 3. and copy it (ctrl c),

- then back to the establishing org and paste (ctrl v) it into the "member id column"; and

- then add the resource, resourceFrag, and pastProject, and pull down the "+" to copy the org id (this will un-highlight the new row).

- Then copy it (ctrl c) the resource, resourceFrag, and pastProject cells,

- Go back to the original empty, yellow row, and paste (ctrl v) in the cells.

3. Then read to see the next orgs (yellow highlighter) and/or agents (green highlighter) and find 
it in your spreadsheet list

If the org (or agendit) is not in the list, then

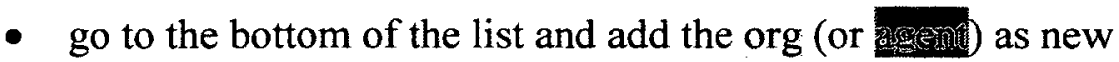

4. Copy the org (or agent) id, then go to the yellow highlighted empty row, and tab over to paste the id in the proper column according to the following guidance:

- If words like collaborate, liaison, coordinate, then paste into both the receiveMessageFrom (from ID) and sendMessageTo (to ID)

- If words like representatives from, comprised, then paste into member

- If words like receives tasking/orders from, then paste into receiveMessageFrom (from ID)

- If words like communicates with, keeps informed, then paste into sendMessageTo (to ID) 5. Then copy the resource,resourceFrag, and Past_project,

6. Then pull down to copy the org id (this will un-highlight the new row).

In summary, to populate the spreadsheet:

- Find the original Organization entry; then insert a row below.

- Mandatory for each line- Copy the rdf:ID down to the new row

- Mandatory for each line- Type in the rdf:resource: ("\#” plus chapter identifier plus page number plus "_" and then the block number)

- Mandatory - Copy the foaf:pastProject: (JPX.xx) This is the joint pub identifier that is being parsed.

- Do not fill in foaf:name and foaf:nick again, as that was done in the initial entry. foaf:workplaceHomepage is generally not populated with more than one entry, however it is possible that an additional url could apply for this entry that is different from the original entry, if any.

- Optional - foaf:based_near - a geographic location(s) of where this organization is located. This is a text field, not length delimited.

- Optional - foaf:depiction - a url of the "rich picture" that is in the joint pub. These will show a schematic of the organization and its members. The url can be the same as the rdf:resource, since it will be designed a block identifier in addition to the chapter and page number. Note: Only the figures that represent the organizational view should be included in the spreadsheet.

- Optional -foaf:made - Enter the dc:Identifier of the document the Organization has created. dc:Identifier is the document version of rdf:ID and follows the 
same rules. Then add the notation to "made the document" in the "to-do list", as this is a 2-step process. Note: Use only if the words state the document is a product of that Organization. If the passage states use of the document vice creation of the document, then use the rqt:sendMessageTo or rqt:receiveMessageFrom functions along with the rqt:messageID, as described below.

- Optional -foaf:member - If the doctrine passage suggest that this organization has either Agents or representatives from another organization as a member, then list 


\section{APPENDIX D - RQ-TECH SPREADSHEET WORKBOOK SAMPLE}

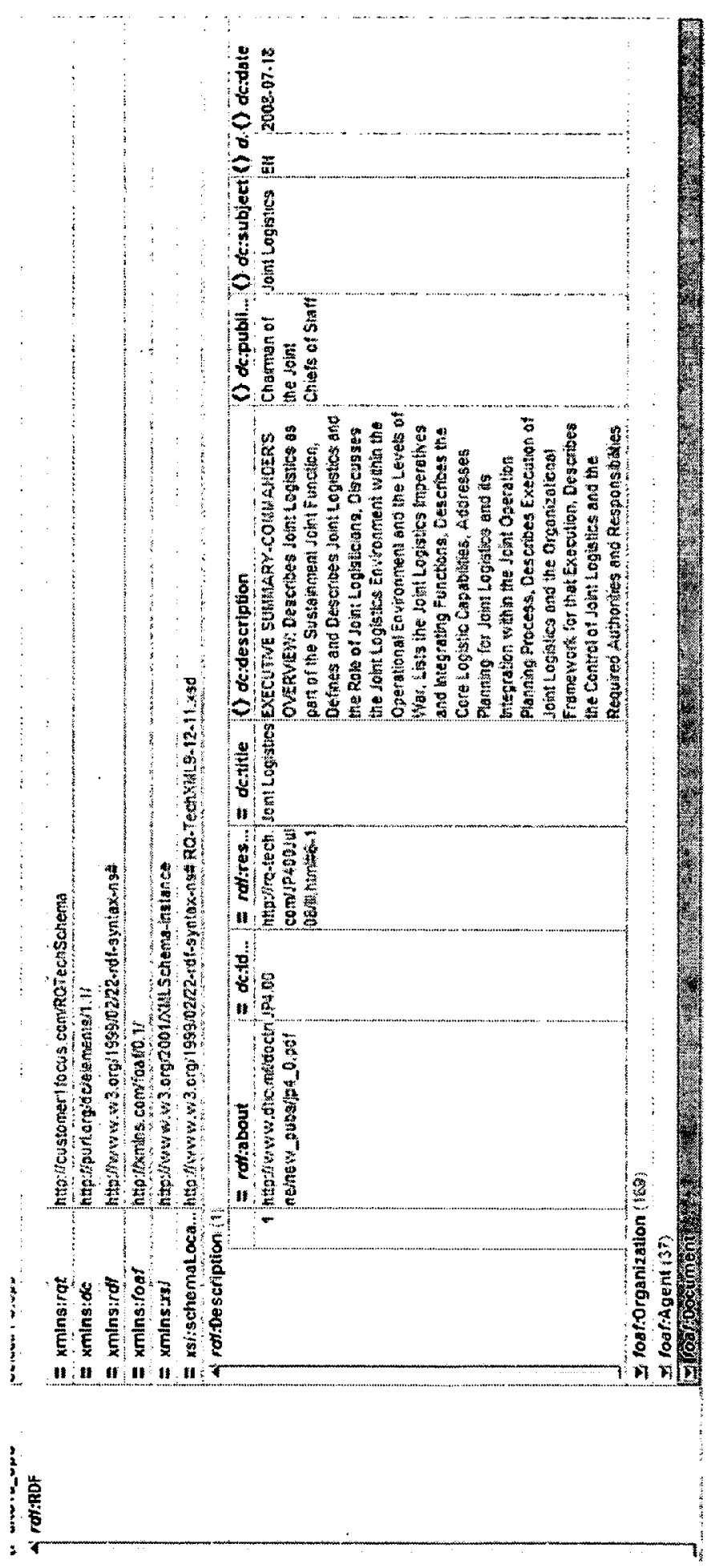




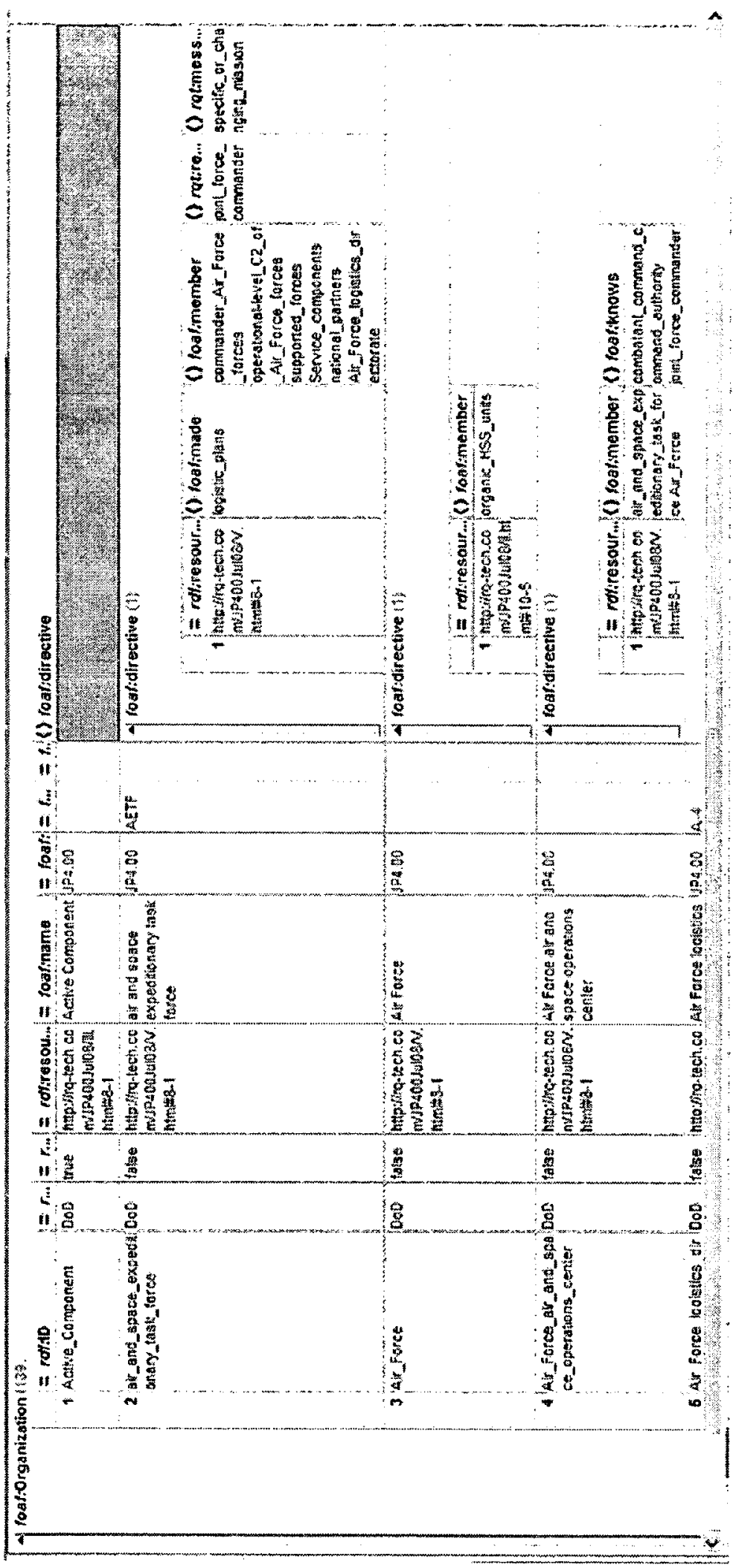




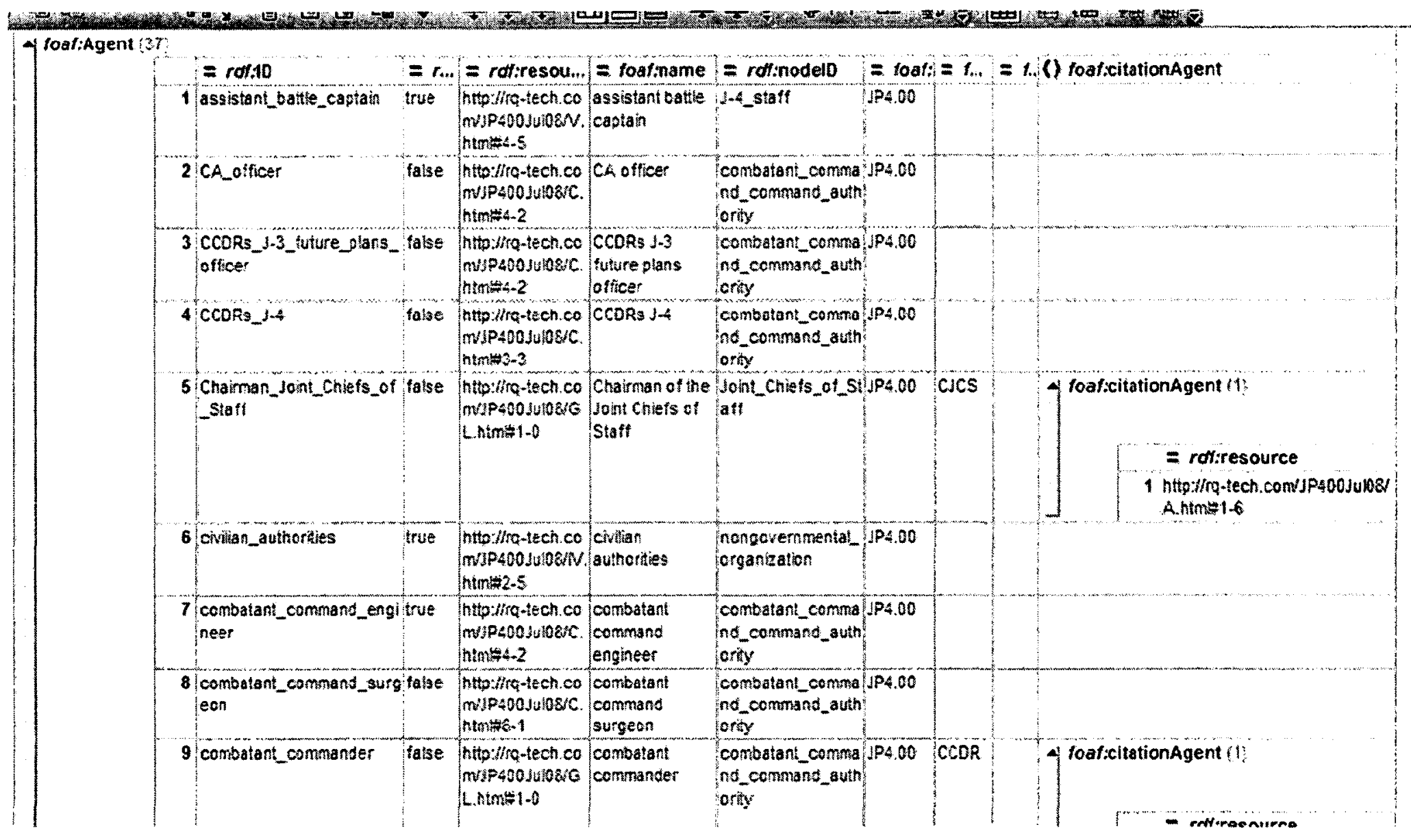




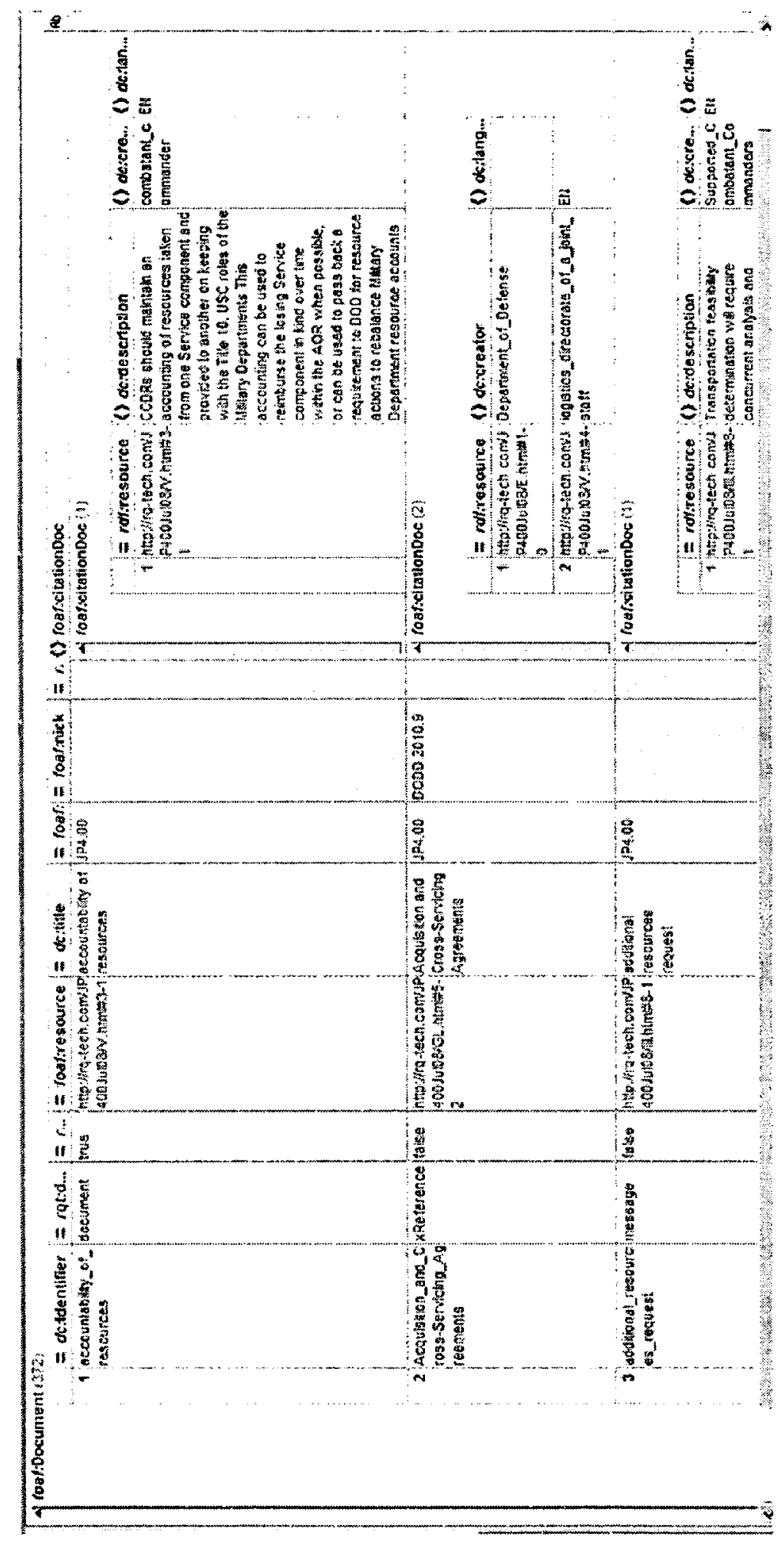



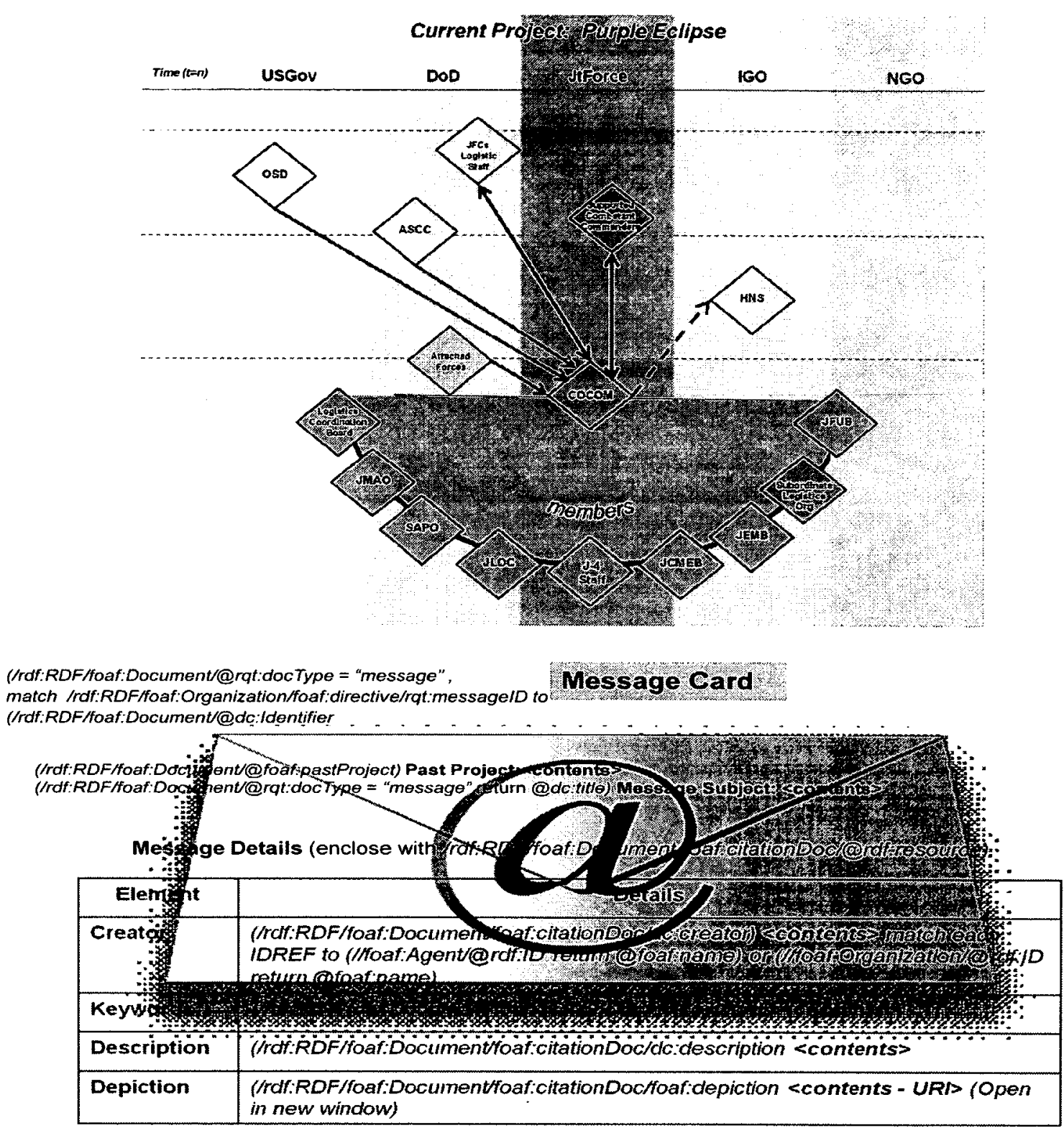

Current Project Message Details:

\begin{tabular}{|c|c|c|c|}
\hline Time (t) & Creator & Current Message Subject & Description \\
\hline $\begin{array}{c}\text { Enter } \\
\text { float } \\
\text { number }\end{array}$ & $\begin{array}{c}\text { Select Agent Or Organization or } \\
\text { Enter New Agent or } \\
\text { New Organization }\end{array}$ & $\begin{array}{c}\text { Select from list of all } \\
\text { Document@orqtidocType } \\
\text { "message" or } \\
\text { EnterNewMessage }\end{array}$ & Enter text \\
\hline
\end{tabular}




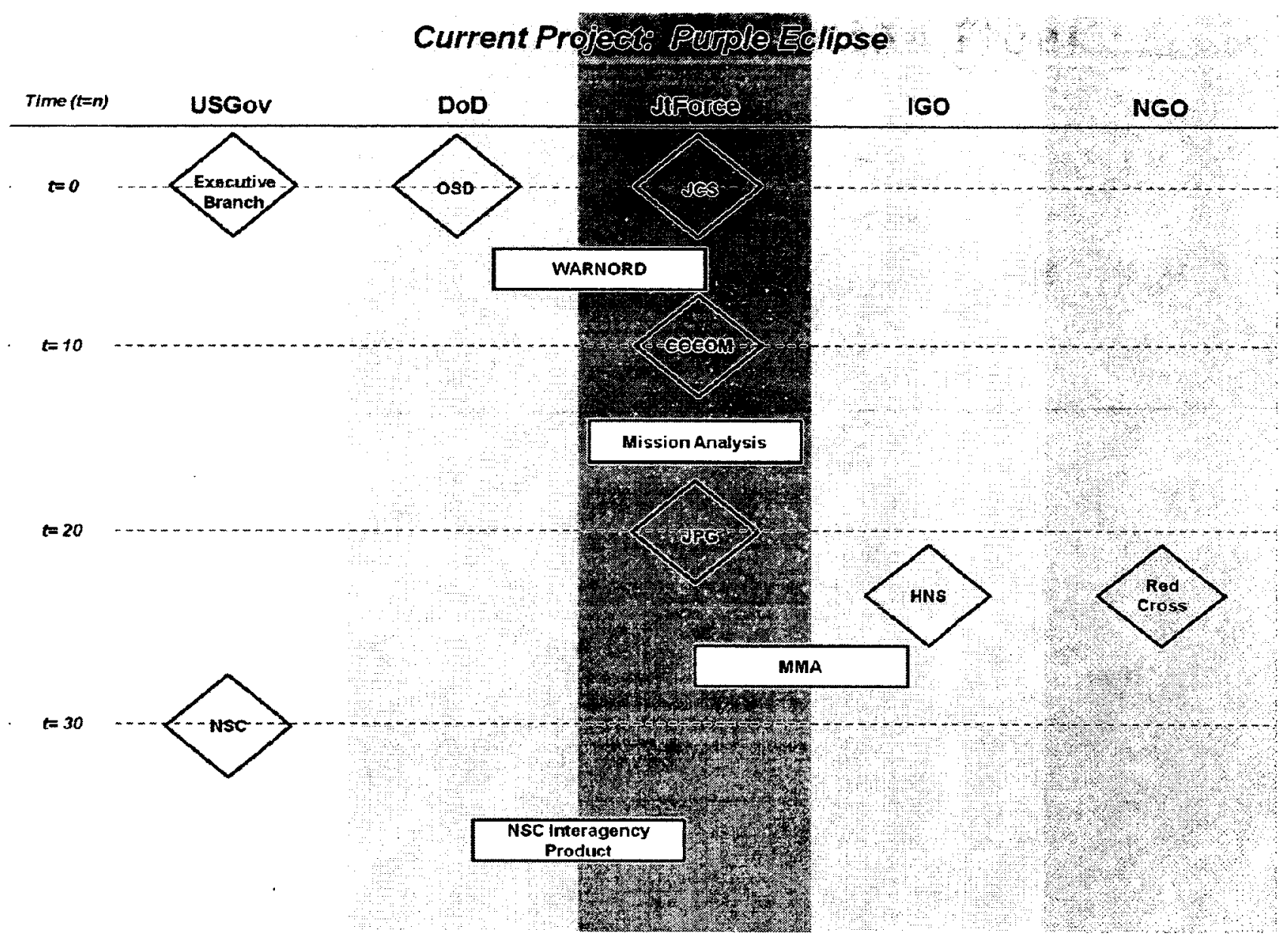


Nick name $=$

Document. pdf $=$

Generic $=$

Past Project $=$

Keywords:

Document Title:

Document Template:
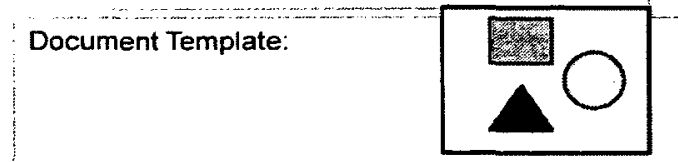

Document Details

\begin{tabular}{|l|l|l|l|l|}
\hline Date & & & \\
\hline
\end{tabular}

Current Project Bocumban Deetilsis

\begin{tabular}{|c|c|c|c|}
\hline Time (t) & Creator & 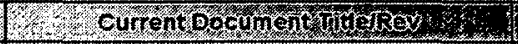 & Description \\
\hline $\begin{array}{c}\text { Enter } \\
\text { float } \\
\text { number }\end{array}$ & $\begin{array}{l}\text { Select from list of all } \\
\text { Agents or Orgs: of } \\
\text { Enter New }\end{array}$ & 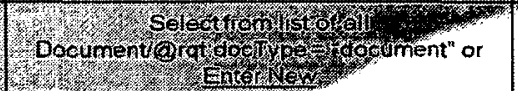 & Enter text \\
\hline
\end{tabular}




\section{APPENDIX F - LOGISTICS PLANNING SCENARIO}

The following is the scene-setter used to provide context surround the problematic event. It is a simplified scenario concerning logistics planning similar to what their students work through during planned exercises at the JFSC.

\section{Scenario for Joint Force Staff College Participants}

You have accepted an invitation to participate in a requirements gathering session for Capability \# One (CO\#1) as subject matter experts in military planning and decision making. The DoD acquisition community developing the capability definition document (CDD) for CO\#1 would like to understand what the warfighters are experiencing as they work through a fictional, but typical event that begins with a Warning Order that triggers the COCOM Level activities with the code name Purple Eclipse (PE). Some of you have first-hand knowledge of PE while others have experienced similar events and challenges to those who assembled the lessons learned from PE. All are invited to use their background in military decision making and their knowledge of Joint Doctrine while working with the CO\#1 facilitator to reconstruct the tasks and issues that faced that fictional COCOM, and in particular, the logistics teams that were organized and assigned to develop CONPLANs and OPLANs, during that event. Joint Capabilities Integration and Development System (JCIDS) requires that the CO\#1 facilitator gathers information about how Joint Doctrine is used during the scenario the facilitator builds from your inputs. This is important because capability developers need to understand the business rules (in this case, the military doctrine) that must either be followed or changed in order to deliver improved and/or new capabilities. Please note that this event gathers background information about how the PE planning and communications advance, as well as issues encountered. However you will not be asked to brainstorm about new or improved features that will later be designed into $\mathrm{CO} \# 1$ 
specifically.

During the facilitated session, you will have computer access to non-classified links to Joint Doctrine and other government publications, instructions or policy. Because of the JCIDS requirement, it may be necessary to specifically identify references to documentation that you know support your statements during the session. However, classified or proprietary information is neither required nor implied as necessary.

Thank you in advance for approaching this session with an open mind as to the facilitator's techniques. You will have opportunities to anonymously express your impressions of how well these techniques addressed the task at hand as well as how you personally felt as you worked through the event. 
APPENDIX G - USER FEEDBACK SURVEY

The following is the survey instrument given to the JFSC participants at the end of the demonstration and prototyping session.

\section{Using the RQ-Tech Doctrine Methodology - Survey}

\section{Survey Subject Demographic Profile} (circle or write in most appropriate answer(s) and/or "all/any that apply")

\section{Education - Undergraduate Major}

Bachelor of Arts Bachelor of Science Technology Military Academy None

\section{Education - Graduate Level}

Masters - ongoing or complete $\quad \mathrm{PhD}$ - ongoing or complete None

Background (please do not "double count" years with shared duties)

Years active duty.

Years reservist

Years civil service on military project(s)

Years contractor service on military project(s)

Years with other projects linked to military and/or doctrine 
Using the RQ-Tech Doctrine Methodology - Survey

Please select the number below that best represents your personal value judgment

\begin{tabular}{|c|c|c|c|c|c|c|}
\hline \# & Statement & $\begin{array}{c}\text { Strongly } \\
\text { Agree }\end{array}$ & Agree & Undecided & Disagree & $\begin{array}{l}\text { Strongly } \\
\text { Disagree }\end{array}$ \\
\hline 1 & \multicolumn{6}{|c|}{ The Alphabetical List of Organizations } \\
\hline $\mathbf{a}$ & $\begin{array}{l}\text { The method for selecting an organization } \\
\text { (to find out more about it) was simple to use. }\end{array}$ & 5 & 4 & 3 & 2 & 1 \\
\hline b & $\begin{array}{l}\text { The list of organizations was useful because } \\
\text { it presented specific organization names for } \\
\text { a choice. }\end{array}$ & 5 & 4 & 3 & 2 & 1 \\
\hline c & $\begin{array}{l}\text { The list of organizations was useful because } \\
\text { it presented generic organization names for } \\
\text { a choice. }\end{array}$ & 5 & 4 & 3 & 2 & 1 \\
\hline 2 & \multicolumn{6}{|c|}{\begin{tabular}{|c|c|} 
& The Organization Card \\
\end{tabular}} \\
\hline $\mathbf{a}$ & $\begin{array}{l}\text { The list of members of an organization was } \\
\text { valuable in understanding the parent } \\
\text { organization. }\end{array}$ & 5 & 4 & 3 & 2 & 1 \\
\hline b & $\begin{array}{l}\text { The list of documents the organization } \\
\text { made was valuable in understanding the } \\
\text { holistic role of the organization. }\end{array}$ & 5 & 4 & 3 & 2 & 1 \\
\hline c & $\begin{array}{l}\text { The link to the organization's homepage } \\
\text { provided a valuable perspective for } \\
\text { understanding the organization. }\end{array}$ & 5 & 4 & 3 & 2 & 1 \\
\hline d & $\begin{array}{l}\text { The cross-reference links provided } \\
\text { potentially valuable access to details about } \\
\text { organizational elements of interest. }\end{array}$ & 5 & 4 & 3 & 2 & 1 \\
\hline $\mathbf{e}$ & $\begin{array}{l}\text { The organizational communications table } \\
\text { was valuable for understanding the } \\
\text { responsibilities of the parent organization. }\end{array}$ & 5 & 4 & 3 & 2 & 1 \\
\hline 3 & \multicolumn{6}{|c|}{ Links to the Joint Doctrine Publication } \\
\hline $\mathbf{a}$ & $\begin{array}{l}\text { The hyperlinks to blocks of Joint Doctrine } \\
\text { are valuable for validating elements of the } \\
\text { Organization Card }\end{array}$ & 5 & 4 & 3 & 2 & 1 \\
\hline b & $\begin{array}{l}\text { The hyperlinks for each element accurately } \\
\text { referenced blocks of Joint Doctrine. }\end{array}$ & 5 & 4 & 3 & 2 & 1 \\
\hline
\end{tabular}

Please comment on items above, especially those marked Strongly Agree and/or Strongly Disagree

1. List of Organizations

2. The Org Card

3. Links to Jt. Doctrine Pub 


\begin{tabular}{|c|c|c|c|c|c|c|}
\hline & \multicolumn{6}{|c|}{ RQ-Tech Process for Scenario-Building } \\
\hline 4 & \multicolumn{6}{|c|}{ Using the RQ-Tech prototype demonstrated value as an enabler for: } \\
\hline $\mathbf{a}$ & $\begin{array}{l}\text { Visually representing the flow of joint } \\
\text { activity }\end{array}$ & 5 & 4 & 3 & 2 & 1 \\
\hline b & $\begin{array}{l}\text { Visually representing a sequence of planning } \\
\text { documents }\end{array}$ & 5 & 4 & 3 & 2 & 1 \\
\hline c & $\begin{array}{l}\text { Visually representing a sequence of planning } \\
\text { document updates }\end{array}$ & 5 & 4 & 3 & 2 & 1 \\
\hline d & Identifying required communication nodes & 5 & 4 & 3 & 2 & 1 \\
\hline e & Identifying parallel communications & 5 & 4 & 3 & 2 & 1 \\
\hline $\mathbf{f}$ & Identifying follow-on communications & 5 & 4 & 3 & 2 & 1 \\
\hline g & Clarifying multiple views of the mission & 5 & 4 & 3 & 2 & 1 \\
\hline h & Reminding users of alternatives to pursue & 5 & 4 & 3 & 2 & 1 \\
\hline $\mathbf{i}$ & $\begin{array}{l}\text { Tracking the joint doctrine mission threads } \\
\text { (via hyperlinks) }\end{array}$ & 5 & 4 & 3 & 2 & 1 \\
\hline 5 & \multicolumn{6}{|c|}{ The RQ-Tech prototype demonstrated the potential for use: } \\
\hline $\mathbf{a}$ & To identify problem areas & 5 & 4 & 3 & 2 & 1 \\
\hline b & To document lessons learned & 5 & 4 & 3 & 2 & 1 \\
\hline c & To report communication problems & 5 & 4 & 3 & 2 & 1 \\
\hline d & Other (write in blank space below) & 5 & 4 & 3 & 2 & 1 \\
\hline
\end{tabular}

Please comment on items above, especially those marked Strongly Agree and/or Strongly Disagree

4. RQ-Tech as a value-enabler

5. Potential Uses for RQ-Tech 


\begin{tabular}{|c|c|c|c|c|c|c|}
\hline \multirow[t]{2}{*}{6} & \multicolumn{6}{|c|}{$\begin{array}{l}\text { Compare the potential of the RQ-Tech library of joint publications to } \\
\text { http://www.dtic.mil/doctrine/mobile/app/index.html }\end{array}$} \\
\hline & & $\begin{array}{l}\text { RQ- } \\
\text { Tech } \\
\text { Best }\end{array}$ & $\begin{array}{c}\text { RQ- } \\
\text { Tech } \\
\text { Better }\end{array}$ & Same & $\begin{array}{l}\text { DTIC } \\
\text { Better }\end{array}$ & $\begin{array}{c}\text { DTIC } \\
\text { Best }\end{array}$ \\
\hline $\mathbf{a}$ & Provides contents tailored to the user's needs & 5 & 4 & 3 & 2 & 1 \\
\hline b & Allows creative searches & 5 & 4 & 3 & 2 & 1 \\
\hline c & Delivers a holistic view of joint data & 5 & 4 & 3 & 2 & 1 \\
\hline $\bar{d}$ & Presents interactive services clearly & 5 & 4 & 3 & 2 & 1 \\
\hline 7 & \multicolumn{6}{|c|}{$\begin{array}{l}\text { Based on use of the RQ-Tech prototype, I would recommend that the RQ-Tech analogy of social } \\
\text { networks can be extended to: }\end{array}$} \\
\hline & 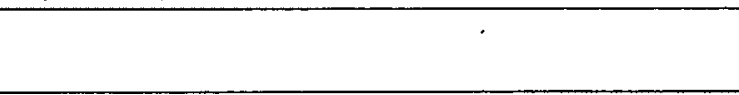 & $\begin{array}{c}\text { Strongly } \\
\text { Agree }\end{array}$ & Agree & Undecided & Disagree & $\begin{array}{l}\text { Strongly } \\
\text { Disagree }\end{array}$ \\
\hline $\mathbf{a}$ & Documenting military processes & 5 & 4 & 3 & 2 & 1 \\
\hline b & Documenting DoD processes & 5 & 4 & 3 & 2 & 1 \\
\hline c & Performing root-cause analysis & 5 & 4 & 3 & 2 & 1 \\
\hline$\overline{\mathbf{d}}$ & Describing organizational issues & 5 & 4 & 3 & 2 & 1 \\
\hline e & Engaging team input & 5 & 4 & 3 & 2 & 1 \\
\hline f & Other (write in blank space below) & 5 & 4 & 3 & 2 & 1 \\
\hline
\end{tabular}

Please comment on items above, especially those marked Strongly Agree and/or Strongly Disagree

6. RQ-Tech query methods vs DTIC searches

7. RQ-Tech Social Network analogy

\section{Additional Comments and Perceptions}




\section{APPENDIX H - USER FEEDBACK SURVEY RESULTS}

The following is the survey results received from the JFSC participants at the end of the demonstration and prototyping session. The feedback from each participant is color-coded.

\section{Using the RQ-Tech Doctrine Methodology - Survey}

\section{Survey Subject Demographic Profile}

(circle or write in most appropriate answer(s) and/or "all/any that apply")

\section{Education - Undergraduate Major}

Bachelor of Arts; Bachelor of Arts; Bachelor of Science; Technology (A.S. in business);

\section{Education - Graduate Level}

Masters - ongoing; $\mathrm{PhD}$ - ongoing; $\mathrm{PhD}$ - ongoing

Background (please do not "double count" years with shared duties)

_14_21_30_4_Years active duty (worked in Doctrine development for 2 years)

Years reservist

_9_4_6_34_Years civil service on military project(s)

_ 1 ___ Years contractor service on military project(s)

Years with other projects linked to military and/or doctrine 


\section{Using the RQ-Tech Doctrine Methodology - Survey}

Please select the number below that best represents your personal value judgment

\begin{tabular}{|c|c|c|c|c|c|c|}
\hline$\#$ & Statement & $\begin{array}{c}\text { Strongly } \\
\text { Agree }\end{array}$ & Agree & Undecided & Disagree & $\begin{array}{l}\text { Strongly } \\
\text { Disagree }\end{array}$ \\
\hline 1 & \multicolumn{6}{|c|}{ The Alphabetical List of Organizations } \\
\hline a & $\begin{array}{l}\text { The method for selecting an organization } \\
\text { (to find out more about it) was simple to } \\
\text { use. }\end{array}$ & $5-2$ & $4-2$ & & & \\
\hline b & $\begin{array}{l}\text { The list of organizations was useful } \\
\text { because it presented specific organization } \\
\text { names for a choice. }\end{array}$ & & $4-2$ & $3-2$ & & \\
\hline c & $\begin{array}{l}\text { The list of organizations was useful } \\
\text { because it presented generic organization } \\
\text { names for a choice. }\end{array}$ & & $4-2$ & $3-2$ & & \\
\hline 2 & \multicolumn{6}{|c|}{ The Organization Card } \\
\hline a & $\begin{array}{l}\text { The list of members of an organization } \\
\text { was valuable in understanding the parent } \\
\text { organization. }\end{array}$ & & $4-2$ & $3-1$ & $2-1$ & \\
\hline $\mathrm{b}$ & $\begin{array}{l}\text { The list of documents the organization } \\
\text { made was valuable in understanding the } \\
\text { holistic role of the organization. }\end{array}$ & $5-1$ & $4-2$ & & & \\
\hline $\mathrm{c}$ & $\begin{array}{l}\text { The link to the organization's homepage } \\
\text { provided a valuable perspective for } \\
\text { understanding the organization. }\end{array}$ & & $4-1$ & $3-3$ & & \\
\hline d & $\begin{array}{l}\text { The cross-reference links provided } \\
\text { potentially valuable access to details } \\
\text { about organizational elements of interest. }\end{array}$ & & $4-2$ & $3-1$ & $2-1$ & \\
\hline $\mathrm{e}$ & $\begin{array}{l}\text { The organizational communications table } \\
\text { was valuable for understanding the } \\
\text { responsibilities of the parent } \\
\text { organization. }\end{array}$ & & & $3-3$ & & \\
\hline 3 & \multicolumn{6}{|c|}{ Links to the Joint Doctrine Publication } \\
\hline a & $\begin{array}{l}\text { The hyperlinks to blocks of Joint } \\
\text { Doctrine are valuable for validating } \\
\text { elements of the Organization Card }\end{array}$ & $5-1$ & $4-2$ & $3-1$ & & \\
\hline b & $\begin{array}{l}\text { The hyperlinks for each element } \\
\text { accurately referenced blocks of Joint } \\
\text { Doctrine. }\end{array}$ & & $4-3$ & $3-1$ & & \\
\hline
\end{tabular}

Please comment on items above, especially those marked Strongly Agree and/or Strongly Disagree

\section{List of Organizations}

a. Possibly create two pull downs (1) with specific org names e.g., Jt. Staff J4 and (2) generic 
names

b. It would have been helpful to have them organized by parent organizations e.g., combatant command, J-1, J-2, J-3

- Also, break into a separate pull down menu - the processes

c. The list of organizations was easy to select from. It would be better if functions could be specified and placed into a different list.

d. Good but also confusion when listed with functions. Need to separate.

\section{The Org Card}

a. multiple document references give additional drill downs based on reason for query. A user may look up a topic for varying reasons

b. Hierarchical start point would be JP 5.0, put in links to sections that refer generically to log functions \& transportation/deployment - those could be sublinked to data in JP 4.0. Maybe more of a "I need to convey this info, where do I look for guidance.

c. It was hard to follow. I think we had insufficient time to develop a comfort level with the format., Compounding the issue is the problem of mismatch between problem (planning) \& pub (logistics). As we discussed, the JP 5-0 would probably have been a better pub to illustrate your concepts.

d. Message from and Messages to not very insightful. "Communications" or "coordinationwith" might be better labels.

\section{Links to Jt. Doctrine Pub}

a. Link to doctrine was very important for accuracy, credibility and specificity

b. (see above)

d. Good idea, this will help with understanding roles. 


\begin{tabular}{|l|l|l|l|l|l|l|}
\hline & \multicolumn{6}{|c|}{ RQ-Tech Process for Scenario-Building } \\
\hline 4 & Using the RQ-Tech prototype demonstrated value as an enabler for: & & \\
\hline a & $\begin{array}{l}\text { Visually representing the flow of joint } \\
\text { activity }\end{array}$ & $5-1$ & $4-3$ & & & \\
\hline b & $\begin{array}{l}\text { Visually representing a sequence of } \\
\text { planning documents }\end{array}$ & $5-1$ & $4-2$ & $3-1$ & & \\
\hline c & $\begin{array}{l}\text { Visually representing a sequence of } \\
\text { planning document updates }\end{array}$ & $5-1$ & $4-1$ & $3-2$ & & \\
\hline d & $\begin{array}{l}\text { Identifying required communication } \\
\text { nodes }\end{array}$ & $5-1$ & $4-2$ & $3-1$ & & \\
\hline e & Identifying parallel communications & & $4-2$ & $3-1$ & $2-1$ & \\
\hline f & Identifying follow-on communications & & $4-2$ & $3-1$ & $2-1$ & \\
\hline g & Clarifying multiple views of the mission & & $4-2$ & $3-2$ & & \\
\hline h & Reminding users of alternatives to pursue & $5-1$ & $4-2$ & $3-1$ & & \\
\hline i & $\begin{array}{l}\text { Tracking the joint doctrine mission } \\
\text { threads (via hyperlinks) }\end{array}$ & & $4-2$ & $3-1$ & & \\
\hline $\mathbf{5}$ & \multicolumn{7}{|l|}{ The RQ-Tech prototype demonstrated the potential for use: } & & \\
\hline a & To identify problem areas & $5-2$ & $4-1$ & $3-1$ & & \\
\hline b & To document lessons learned & & $4-2$ & $3-2$ & & \\
\hline c & To report communication problems & $5-2$ & $4-1$ & $3-1$ & & \\
\hline d & Other (write in blank space below) & & & & & \\
\hline
\end{tabular}

Please comment on items above, especially those marked Strongly Agree and/or Strongly Disagree

\section{RQ-Tech as a value-enabler}

a. The RQ-Tech tool was very valuable to decompose the process. Excel may not have been the best $\mathrm{s} / \mathrm{w}$ tool. A colleague of ours uses visio to create swimlanes. Constructing the swimlanes is a very valuable exercise to identify major actors, activities and sequences.

b. This has a good potential for mapping processes, but there are a lot of subprocesses (these will tak you down rabbit holes). For example, under USGov, this could have multiple swimlanes that are interrelated with the DoD processes, so it correctly focuses on the intra-DoD processs. There needs to be some sort of linkage, however between DoD and other organizations as these do affect DoD decision making.

c. I felt that the number of swim lanes was too restrictive. You end up grouping things together 
that are difficult to visualize. Wonder if mapping first on a white board \& then transcribing onto the prototype later would have been better. I felt constrained by prototype structure rather than putting all of the pieces together and then fitting.

- I see the potential for the doctrinal threads but current scenario/set-up didn't support.

- We failed to develop the diagram to sufficient detail to allow multiple views.

- I see a lot of the potential items addressed in your survey but we really did not develop the scenario to be sufficient detail to illustrate. If the original flow that had been fairly complete to start with and then we validated/verified it the level of detail would have been sufficient to illustrate your concepts. I see a lot of work and thought but we didn't go far enough to show the true value of your ideas.

- At this point you're probably not interested but we could probably get 4-5 faculty members together to build the map (process) that could then backfill with the doctrinal references and fit into your swimlane chart. The other down-side is that you probably have to map JP 5.0 (a not insignificant amount of work). It would allow for a focus from the Joint Planning Group (JPG) effort which fits the scenario as well as providing a good doctrinal fit.

\section{Potential Uses for RQ-Tech}

a. ID players, activities, communications

- get group to see larger picture beyond individual responsibilities

- ID precursor activities \& follow-on activities

- mitigate frustration of "why I don't know a certain piece of info yet." Because its precursor has not occurred.

b. If you were to break out the pull-down menus into one for orgs and one for processes - the process one could have links to doctring - how is this decision made and how is it 
communicated.

d. Based on our AAR (after action report) with the group this needs to have other Pubs linked.

This will greatly enhance the capability and usefulness of this prototype. The idea is solid, the knowledge base needs expanding.

\begin{tabular}{|c|c|c|c|c|c|c|}
\hline \multirow[t]{2}{*}{6} & \multicolumn{6}{|c|}{$\begin{array}{l}\text { Compare the potential of the RQ-Tech library of joint publications to } \\
\text { http://www.dtic.mil/doctrine/mobile/app/index.html }\end{array}$} \\
\hline & & \begin{tabular}{l|} 
RQ- \\
Tech \\
Best
\end{tabular} & $\begin{array}{l}\text { RQ- } \\
\text { Tech } \\
\text { Better }\end{array}$ & Same & $\begin{array}{l}\text { DTIC } \\
\text { Better }\end{array}$ & $\begin{array}{l}\text { DTIC } \\
\text { Best }\end{array}$ \\
\hline a & $\begin{array}{l}\text { Provides contents tailored to the user's } \\
\text { needs }\end{array}$ & $5-1$ & $4-2$ & $3-1$ & & \\
\hline $\mathrm{b}$ & Allows creative searches & $5-1$ & & $3-2$ & $2-1$ & \\
\hline $\mathrm{c}$ & Delivers a holistic view of joint data & & $4-1$ & $3-1$ & $2-2$ & \\
\hline $\mathrm{d}$ & Presents interactive services clearly & & & $3-3$ & $2-1$ & \\
\hline \multirow[t]{2}{*}{7} & \multicolumn{6}{|c|}{$\begin{array}{l}\text { Based on use of the RQ-Tech prototype, I would recommend that the } R Q-T e c h \text { analogy } \\
\text { of social networks can be extended to: }\end{array}$} \\
\hline & & \begin{tabular}{|l|} 
Strongly \\
Agree
\end{tabular} & Agree & Undecided & Disagree & $\begin{array}{l}\text { Strongly } \\
\text { Disagree }\end{array}$ \\
\hline $\mathrm{a}$ & Documenting military processes & $5-1$ & $4-3$ & & & \\
\hline $\mathrm{b}$ & Documenting DoD processes & $5-1$ & $4-3$ & & & \\
\hline $\mathrm{c}$ & Performing root-cause analysis & & & $3-4$ & & \\
\hline $\mathrm{d}$ & Describing organizational issues & $5-1$ & $4-2$ & $3-1$ & & \\
\hline $\mathrm{e}$ & Engaging team input & & $4-2$ & $3-1$ & & \\
\hline $\mathrm{f}$ & Other (write in blank space below) & & & & & \\
\hline
\end{tabular}

Please comment on items above, especially those marked Strongly Agree and/or Strongly Disagree

\section{RQ-Tech query methods vs DTIC searches}

a. more focused query $w / R Q$, DTIC search returns too many options

- Because RQ only modeled one pub, DTIC is more holistic but that is based on current fielding

b. This has the potential to provide a one service "go-to" tool for planners and decision makers.

It just needs to have operator input as far as whet does the end user need to be able to access.

c. Pretty limited views. Potential looks good but hard to tell if significantly better than DTIC.

d. Have not used DTIC enough to compare. 


\section{RQ-Tech Social Network analogy}

a. I liked the RQ social network analogy! It is a great portrayal of interactions \& interdependencies. Illustrates need to collaborate vs. stovepipe thinking/processes.

b. I like this as it shows linkages. The hub could be JP 5.0 and JOPES for processes

d. Good idea - could expand to show what type of social interaction generated link.

\section{Additional Comments and Perceptions}

a. Social network analogy \&swimlane diagrams were the RQ model strengths. They accurately reflect reality - interdependancies; parallel planning; multiple inject points; input/output requirements.

- The s/w is an outcome that will happen. e.g. a better tool than excel or better gui for the tech library. The models are more important (social \& flow model).

b. I don't think that it has enough data yet for creative searches. More user engagement might help here.

- Check out the "UN Cluster System" and UNJLC. This hub and spoke system reminds me of the social network analogy - the people down the hall in the civil mil fusion center can provide info.

d. Thank you for reaching out to us. I look forward to seeing 2.0 


\section{REFERENCES}

Ackoff, R. (2001). A Brief Guide to Interactive Planning and Idealized Design.

Adams, K. M. (2011). Systems principles: foundation for the SoSE methodology. International Journal for System of Systems Engineering, 2(2/3), 120-155.

Adams, K. M. (2012). Systems Theory: A Formal Construct for Understanding Systems. International Journal of System of Systems Engineering, 3(3/4), 209-224.

Adams, K. M., Hester, P. T., Bradley, J. M., Meyers, T. J., \& Keating, C. B. (2014). Systems Theory: The Foundation for Understanding Systems. Systems Engineering, 17(1), 1-12.

Adams, K. M., \& Keating, C. (2011a). Overview of the systems of systems engineering methodology. Int. J. System of Systems Engineeing, 2(2/3), 112-119.

Adams, K. M., \& Keating, C. (2011b). System of Systems Engineering. Norfolk: National Centers for System of Systems Engineering.

Anderson, P.W. (1972). More is Different: Broken Symmetry and the Nature of the Hierarchical Structure of Science. Science 177, 393-396.

Bailey, Ian. (2011). Enterprise Ontologies - Better Models of Business. In A. Tolk \& L. C. Jain (Eds.), Intelligence-Based Systems Engineering (pp. 327-342). Berlin: Springer-Verlag.

Bergman, Mike, \& Giasson, Fred. (2009). When Linked Data Rules Fail. Adaptive Information, Adaptive Innovation, Adaptive Infrastructure $\left(A I^{3}\right)$. http://www.mkbergman.com/category/linked-data/

Berners-Lee, Tim. (1997). World-Wide Computer. Communications of the ACM, 40(2), 57-58.

Berners-Lee, Tim, Hall, Wendy, Hendler, James A., O'Hara, Kieron, Shadbolt, Nigel, \& Weitzner, Daniel J. (2006). A framework for web science. Found. Trends Web Sci., I(1), 1-130. doi: $10.1561 / 1800000001$

Brewer, Van, \& Sousa-Poza, A. (2009). Generalized Research Canons for JTB(+) Knowledge. Paper presented at the The 13th World Multi-Conference on Systemics, Cybernetics and Informatics: WMSCI 2009 Orlando, Florida, USA.

Brickley, D., \& Miller, L. (Producer). (2000). Introducing FOAF. FOAF Project. Retrieved from http://www.foaf-project.org/ 
Broekstra, J., Klein, M., Fensel, D., \& Horrocks, I. (2000). Adding formal semantics to the Web: Building on top of RDF Schema. Paper presented at the ECDL 2000 Workshop on the Semantic Web.

Buede, Dennis M. (2009). Engineering Design of Systems - Models and Methods: John Wiley \& Sons.

Checkland, P. (1983). O.R. and the Systems Movement: Mappings and Conflicts. The Journal of the Operational Research Society, 34(8), 661-675.

Checkland, P. (1992). Systems and Scholarship: The Need to Do Better. The Journal of the Operational Research Society, 43(11), 1023-1030.

Checkland, P. (2000). Soft Systems Methodology: A Thirty Year Retrospective. Systems Research and Behavioral Science, 17, 11-58.

Cherns, Albert. (1976). Principles of Socio-Technical Design. Human Relations 29(8), 783-792.

CJCS. (1996). Interagency Coordination During Joint Operations. Washington, DC.

Clemons, Eric K., \& Gu, Bin. (2003). Justifying Contingent Information Technology Investments: Balancing the Need for Speed of Action with Certainty before Action. Journal of Management Information Systems, 20(2), 11-48.

Corning, P. A. (2002). The Re-emergence of "Emergence": A venerable concept in search of a theory. Complexity, 7(6), 18-30.

Cresswell, John W. (2003). Research Design (2nd ed.). Thousand Oaks: Sage Publications.

Cresswell, John W., \& Plano Clark, Vicki L. (2011). Designing and conducting mixed methods research--2nd ed. Los Angeles: Sage.

Crowther, David, \& Lancaster, Geoff. (2008). An Overview of Data Collection: Approaches, Methods and Techniques Research Methods, --2nd ed. (pp. 64 - 78). Boston: Elsevier.

DoD. (2007). DoD Architecture Framework Version 1.5. Washington DC.

DoD. (2009). DoD Architecture Framework Version 2.0. WashingtonDC.

DoD. (2013). DoD Website. Retrieved Mar. 18, 2013, 2013, from http://www.defense.gov/about/

Emery, F. E., \& Trist. (1978). Analytical model for sociotechnical systems. In W. A. Pasmore \& J. J. Sherwood (Eds.), Sociotechnical systems: A Sourcebook (pp. 120-133): University Associates, Inc. 
Emmeche, Claus, Køppe, Simo, \& Stjernfelt, Frederik. (1997). Explaining Emergence: Towards an Ontology of Levels. Journal for General Philosophy of Science / Zeitschrift für allgemeine Wissenschaftstheorie, 28(1), 83-119.

Engelsman, Wilco, Quartel, Dick, Jonkers, Henk, \& van Sinderenb, Marten. (2010). Extending enterprise architecture modelling with business goals and requirements. Enterprise Information Systems, 5(1), 9-36.

Fairhurst, Gail T., \& Sarr, Robert A. (1996). The Art of Framing: Managing the Language of Leadership. San Francisco: Jossey-Bass.

Felhi, Faîçal, \& Akaichi, Jalel. (2012). Adaptation of web services to the context based on workflow: Approach for self-adaptation of Service Oriented Architectures to the context. International Journal of Web \& Semantic Technology, 3(4), 1-13. doi: $10.5121 /$ ijwest.2012.3401

Flake, G. W., Pennock, D. M., \& Fain, D. C. (2003). The self-organized Web: The yin to the Semantic Web's yang. IEEE Intelligent Systems, 18(4), 3.

Forsberg, K., \& Mooz, H. (1991). The Relationship of Systems Engineering to the Project Cycle. Paper presented at the First Annual Symposium of the National Council On Systems Engineering (NCOSE).

GAO. (2009). DEFENSE ACQUISITIONS: DOD Must Balance Its Needs with Available Resources and Follow an Incremental Approach to Acquiring Weapon Systems (GAO-09431T). Washington, D.C: Retrieved from http://www.gao.gov

Gibbs, W. W. . (1994). Software's Chronic Crisis. Scientific American, 27l(3), 86-95.

Goethals, Frank G., Snoeck, Monique, Lemahieu, Wilfried, \& Vandenbulcke, Jacques. (2006). Management and enterprise architecture click: The FAD(E)E framework Information Systems Frontiers, 8(2), 67-79. doi: DOI: 10.1007/s10796-006-7971-1

Graves, Mike, Constabaris, Adam, \& Brickley, Dan. (2007). FOAF: Connecting People on the Semantic Web. Cataloging \& Classification Quarterly, 43(3-4), 191-202. doi: 10.1300/J104v43n03_10

Gruber, T. (2008). Ontology. In L. Liu \& M. T. Özsu (Eds.), Encyclopedia of Database Systems.

Gruninger, Michael. (2003). Enterprise Modelling. In P. N. Bernus, L.; Schmidt, G. (Ed.), Handbook on Enterprise Architecture (pp. 515-541). New York: Springer.

Hannes, Karin, Lockwood, Craig , \& Pearson, Alan. (2010). A Comparative Analysis of Three Online Appraisal Instruments' Ability to Assess Validity in Qualitative Research. Qualitative Health Research, 20(12), 1736-1743. 
Heylighen, F. (2001). The Science of Self-Organization and Adaptivity. Oxford: The Encyclopedia of Life Support Systems.

Heylighen, F. (2008). Complexity and Self-organization. Oxford.

Heyman, Karen. (2008). The Move to Make Social Data Portable. Computer, 41(4), 13-15.

Hitch, C. (1953). Sub-optimizations in Operations Problems. Journal of the Operational Research Society of America, 1((3)), 87-99.

Hoyland, C. A. (2011). An Analysis of Enterprise Architectures Using General Systems Theory. Paper presented at the IEEE International Conference on Systems, Man, and Cybernetics (SMC), Anchorage, AK, USA. retrieved from

Hoyland, C. A., \& Adams, K. M. (2009, 14-17 Sept. 2009). RQ-Tech method for user-involved software development. Paper presented at the Software Architecture, 2009 \& European Conference on Software Architecture. WICSA/ECSA 2009. Joint Working IEEE/IFIP Conference on.

Hysom, R. (2003). Enterprise Modelling - The Readiness of the Organization. In P. N. Bernus, L.; Schmidt, G. (Ed.), Handbook on Enterprise Architecture (pp. 373-415). New York: Springer.

IFIP-ITAC. (2003). The Generalized Enterprise Reference Architecture and Methodology (GERAM) Ver 1.6.3 Final. In P. Bernus, K. Mertins \& G. Schmidt (Eds.), Handbook on Enterprise Architecture. Heidelberg: Springer-Verlag.

Jackson, Michael C. (2000). Systems approaches to management. New York: Kluwer Academic/Plenum Publishers.

Jackson, Michael C. (2003). Systems Thinking: Creative Holism for Managers. University of Hull, UK: John Wiley \& Sons, Ltd.

Jauch, Lawrence R., Osborn, Richard N., \& Martin, Thomas N. (1980). Structured Content Analysis of Cases: A Complementary Method for Organizational Research. The Academy of Management Review, 5(4), 517-525.

Jepsen, Thomas C. (2009). Just What Is an Ontology, Anyway? IT Pro(September/October), 2227.

Jick, Todd D. (1979). Mixing Qualitative and Quantitative Methods: Triangulation in Action. Administrative Science Quarterly, 24(4), 602-611. doi: 10.2307/2392366

Joint Staff-J7. (2013). Joint Electronic Library (JEL), Joint Publications. Retrieved 18 Mar 2013, from http://www.dtic.mil/doctrine/new pubs/jointpub.htm 
Keating, C. (2000). Limitations for Deployment of Systems-based Initiatives in Non-traditional Settings. Paper presented at the American Society for Egineering Management, National Conference, Washington, DC.

Keating, C., Peterson, W., \& Rabadi, G. (2003). Framing of Complex System of Systems Engineering Problems. Paper presented at the American Society for Engineering Management, St. Louis, MO.

Keating, C., Rogers, R., Unal, R., Dryer, D., Sousa-Poza, A., Safford, R., . . Rabadi, G. (2003). System of Systems Engineering. Engineering Management Journal: Special Issue on Systems Engineering, 15(3), 36-45.

Koestler, Arthur. (1967). The Ghost in the Machine. New York.

Kovacic, S., Sousa-Poza, A., \& Keating, C. (2008, 2-4 June 2008). Complex situations: An alternative approach for viewing a System of Systems. Paper presented at the System of Systems Engineering, 2008. SoSE '08. IEEE International Conference on.

Krippendorff, Klaus. (2004). Content analysis: An introduction to its methodology --2nd ed. Thousand Oaks: Sage Publications.

Kroes, Peter, Franssen, Maarten, van de Poel, Ibo, \& Ottens, Maarten. (2006). Treating Sociotechnical Systems as Engineering Systems: Some Conceptual Problems. Systems Research and Behavioral Science, 23, 803-814.

Lapkin, Allega, Burke, Burton, \& Bittler, Handler. (2008). Gartner Clarifies the Definition of the Term 'Enterprise Architecture'. Gartner, Inc.

Leedy, P. D., \& Ormrod, J. E. (2001). Practical Research Planning and Design (7th ed.). Upper Saddle River, NJ: Merrill Prentice Hall.

Leedy, P. D., \& Ormrod, J. E. (2005). Practical research: Planning and design--8th ed. Upper Saddle River, NJ: Pearson Merrill Prentice Hall.

Levin, Sen. Carl. (2009). Levin, McCain Introduce Legislation to Reform Weapon Systems Acquisition Process. Senator Carl Levin: News Release. http://levin.senate.gov/newsroom/release.cfm?id=308529

Levins, Richard. (1974). The Limits of Complexity. In H. Pattee (Ed.), Hierarchy Theory; The Challenge of Complex Systemsy (pp. 109-127). New York: George Braziller.

Lewis, Clarence Irving. (1918). A survey of symbolic logic. Berkeley University of California Press. 
Likert, R. A. (1932). A Technique for the Measurement of Attitudes. Archives of Psychology, 23(140), 1-55.

Maier, M. W. (1998). Architecting principles for systems-of-systems. Systems Engineering, I, 267-284. doi: 10.1002/(SICI)1520-6858(1998)1:4<267::AID-SYS3>3.0.CO;2-D

Maxwell, J. A. (2010). Using Numbers in Qualitative Research. Qualitative Inquiry, 16(6), 475482.

Mesjasz, Czesław. (1988). Applications of Systems Modelling in Peace Research. Journal of Peace Research, 25(3), 291-334. doi: 10.1177/002234338802500319

Miller, George A. (1956). The Magical Number Seven, Plus or Minus Two: Some Limits on Our Capacity for Processing Information. The Psychological Review, 63(2), 81-97.

Mitroff, Ian I., \& Linstone, Harold A. (1993). The Unbounded Mind: Breaking the Chains of Traditional Business Thinking. New York: Oxford Press.

Morgan, Gareth, \& Smircich, Linda. (1980). The Case for Qualitative Research. The Academy of Management Review, 5(4), 491-500.

NIST. (1993). Integration Definition for Function Modeling (IDEF0).

Noran, O. (2003). A Mapping of Individual Architecture Frameworks (GRAI, PERA, C4ISR, CIMOSA, ZACHMAN, ARIS) onto GERAM. In P. N. Bernus, L.; Schmidt, G. (Ed.), Handbook on Enterprise Architecture (1 ed., pp. 66-210). New York: Springer.

Nowotny, Helga. (2005). The Increase of Complexity and its Reduction. Theory, Culture \& Society, 22(5), 15-31.

OASD. (2007). Global Information Grid (GIG) Architecture Federation Strategy. Washington, DC: Office of the Assistant Secretary of Defense.

OED. (Ed.) (2013) Oxford English Dictionary. Oxford University Press.

OMB. (2000). Circular No. A-130 Revised Transmittal No. 4, Management of Federal Information Resources.

OMB. (2009). Improving Agency Performance Using Information and Information Technology $1-56$.

Opdahl, Andreas L., Berio, Giuseppe, Harzallah, Mounira, \& Matulevičius, Raimundas. (2012). An ontology for enterprise and information systems modelling. Applied Ontology, 7(1), 49-92. 
Paolillo, John C. , Mercure, Sarah, \& Wright, Elijah. (2005). The social semantics of LiveJournal FOAF: Structure and change from 2004 to 2005. Paper presented at the 1st Workshop on Semantic Network Analysis at the ISWC 2005 Conference

Pasmore, William A., \& Khalsa, Gurudev S. (1993). The Contributions of Eric Trist to the Social Engagement of Social Science. Academy of Management Review, 18(3), 546-569.

Pattee, H. H. . (1974). Postscript - Unsolved Problems and Potential Applications of Hierarchy Theory. In H. Pattee (Ed.), Hierarchy Theory; The Challenge of Complex Systems (pp. 129-155). New York: George Braziller.

Patton, Michael Quinn. (2002). Qualitative Research \& Evaluation Methods (3 ed.). Thousand Oaks: Sage Publications.

Piaszczyk, Chris. (2011). Model Based Systems Engineering with Department of Defense Architectural Framework. Systems Engineering, 14(3), 305-326. doi: 10.1002/sys.20180

PL104-106. (1996). Information Technology Management Reform Act, 40 U.S.C. 1401 et seq. Washington, DC: Government Printing Office.

Pollock, Jeffrey T. (2009). Semantic Web for Dummies. Hoboken, NJ: Wiley Publishing, Inc.

Pomerol, Jean-Charles, Brézillon, Patrick, \& Pasquier, Laurent. (2002). Operational Knowledge Representation for Practical Decision-Making. Journal of Management Information Systems, 18(4), 101-115.

Prater, Jean, Mueller, Ralf, \& Beauregard, Bill. (2012). An ontological approach to oracle BPM. The Semantic Web, 402-410.

Quatrani, T. (2003). Introduction to the Unified modeling language. A technical discussion of UML: Rational Software-IBM Corp.

Ropohl, Günter. (1999). Philosophy of Socio-Technical Systems. Society for Philosophy and Technology, 4(3).

Ross, D. T. (1985). Applications and Extensions of SADT. Computer, 18(4), 25-34.

Schlager, J. (1956). Systems engineering: key to modern development. IRE Transactions(July), 64-66.

Shen, Hui, Wall, Brian, Zaremba, Michal, Chen, Yuliu, \& Browne, Jim. (2004). Integration of business modelling methods for enterprise information system analysis and user requirements gathering. Computers in Industry, 54(3), 307-323. doi: http://dx.doi.org/10.1016/j.compind.2003.07.009 
Simon, H. A. (1956). Rational Choice and the Structure of the Environment. Psychological Review, 63(2), 129-138.

Simon, H. A. (1974a). How Big is a Chunk? Science, 183(February 8), 482 - 488.

Simon, H. A. (1974b). The Organization of Complex Systems. In H. Pattee (Ed.), Hierarchy Theory; The Challenge of Complex Systemsy (pp. 156). New York: George Braziller.

Skyttner, L. (1996). General Systems Theory: An Introduction Basic Ideas of Systems (pp. 3068): Macmillan Press, Ltd.

Sowa, J. F. (2011). Future Directions for Semantic Systems. In A. Tolk \& L. C. Jain (Eds.), Intelligence-Based Systems Engineering (Vol. 10). Berlin Springer-Verlag.

Taylor, J. C., \& Felten, D. F. (1993). Performance by Design: Sociotechnical Systems in North America. Englewood Cliffs: Prentice-Hall, Inc.

Tolk, A. (2006). Composable M\&S Web Services for Net-Centric Applications. Journal of defense modeling and simulation, 3(1).

Tolk, A., Litwin, T. G., \& Kewley, R. H. (2008). A systems engineering process supporting the development of operational requirements driven federations. Paper presented at the Simulation Conference, 2008. WSC 2008. Winter.

Uppington, G., \& Bernus, P. (2003). Analysing the Present Situation and Refining Strategy. In P. N. Bernus, L.; Schmidt, G. (Ed.), Handbook on Enterprise Architecture (pp. 309-332). New York: Springer.

Uschold, Michael, \& Gruninger, M. (2004). Ontologies and semantics for seamless connectivity. SIGMOD Rec., 33(4), 58-64. doi: http://doi.acm.org/10.1145/1041410.1041420

van Ruijven, Ing L. C. (2012). Ontology and Model-based Systems Engineering. Procedia Computer Science, 8(0), 194-200. doi: http://dx.doi.org/10.1016/j.procs.2012.01.042

Vernadat, F. (2002). Enterprise modelling and integration. Paper presented at the IFIP TC5/WG5.

von Bertalanffy, L. (1995). General System theory. New York: Braziller.

W3C. (2000). Resource Description Framework Schema Specification 1.0.

W3C. (2004a). Architecture of the World Wide Web, Volume One: W3C Recommendation.

W3C. (2004b). RDF Primer W3C Recommendation. 
W3C. (2004c). XML Schema Part 1: Structures Second Edition.

Walmsley, Priscilla. (2002). Definitive XML Schema. Upper Saddle River, NJ: Prentice Hall PTR.

Warfield, John N. (1988). The Magical Number Three - Plus or Minus Zero. Cybernetics and Systems: An International Journal, 19, 339-358.

Watson, A. (2008). Visual Modelling: past, present and future. http://www. uml. org

Western Electric Company. (1929). Research studies in employee effectiveness and industrial relations. Paper presented at the The annual autumn conference of the Personnel Research Federation, New York.

Whetten, D. A. (1989). What constitutes a theoretical contribution? Academy of Management Review, 14(4), 490-495.

Williams, Theodore J., Rathwell, Gary A., \& Li, Hong. (2001). A Handbook on Master Planning and Implementation for Enterprise Integration Programs Based On The Purdue Enterprise Reference Architecture and the Purdue Methodology. Purdue Laboratory for Applied Industrial Control, 342.

Wisnosky, Dennis E. (2011). Engineering Enterprise Architecture: Call to Action. Common Defense Quarterly(9), 9-14.

Wisnosky, Dennis E., \& Vogel, Joseph. (2006). DoDAF Wizdom. Naperville, IL: Wizdom Systems, Inc.

Wood, William G., Barbacci, Mario, Clements, Paul, Palmquist, Steve, Ang, Huei-Wan, Bernhardt, Loring, ... Krummenoehl, Art. (2003). DoD Architecture Framework and Software Architecture Workshop Report. In SEI (Ed.).

Yourdon, Edward. (1989). Modern Structured Analysis. Englewood Cliffs, NJ: Prentice-Hall, Inc.

Zachman, J. A. (1987). A Framework for Information Systems Architecture. IBM Systems Journal, VOL 26(NO 3), 276-292.

Zachman, J. A. (1996). Enterprise Architecture and Legacy Systems - Getting Beyond the "Legacy". Information Engineering Services Pty Ltd.

Zachman, J. A. (2011). Enterprise Architecture: Managing Enterprise Complexity and Change. Paper presented at the IEEE International Conference on Systems, Man, and Cybernetics, Anchorage, AK USA. 
Zelm, Martin. (1997). Summary of Proceedings. Paper presented at the International Conference on Enterprise Integration and Modelling Technology (ICEIMT'97), Turin, Italy.

Zhang, Y., \& Wildemuth, B. M. (2009). Qualitative analysis of content. In B. Wildemuth (Ed.), Applications of social research methods to questions in information and library science (pp. 308 - 319). Westport, CT: Libraries Unlimited. 


\title{
VITA
}

\author{
Christine A. Hoyland
}

Old Dominion University - NCSoSE

607 Mowbray Arch; Norfolk, VA 23507 - chris.hoyland@customerl focus.com

\section{Education}

- California State University at Fresno - BS Mechanical Engineering, 1983

- Virginia Polytechnic Institute in Blacksburg - MS Systems Engineering, 1999

- Old Dominion University, Norfolk, VA - Ph.D. Engineering Management \& Systems Engineering, 2013

\section{Grad Research Assistant - NCSoSE}

\section{Work History}

$2010-2013$

- Graduate Training Assistant, Developer for System of Systems Engineering Certificate (SoSEC) training, Facilitator for NCSoSE Special Projects

\section{NAVSEA Computer Engineer}

- Defense Acquisition System project manager. Involved in Net-Enabled Command and Control Capability (NECC), a DISA-lead project. Deputy requirements manager and Lead government training and implementation manager for Service Oriented Architecture (SOA) for JFCOM warfighters.

- CCB Secretariat - Nimitz Battle Group combat system integration, underway, and live-fire testing

- Joint National Training Capability - Lead Technical Standards Systems Engineer and Architect, JFCOM Standing Joint Force Headquarters - Special Projects manager

\section{Independent Consultant}

$1996-2001$

- Requirements analysis, project planning, IS interface documentation, course development and delivery for various clients including IBM, Geo Washington University Business School, Joint Logistics Center

- Prototyped automated Sys Eng requirements traceability system for Newport News CVN-76 new construction

- Nuclear test and quality assurance engineer at Pearl Harbor Naval Shipyard, TQM lead for Nuclear Engineering Dept, member of Advanced Industrial Management (AIM) project for naval ship repair projects government team member 
